\title{
Recent Advances in Functional Carbon Quantum Dots for Antitumour
}

\author{
Rong Cai $\mathbb{D}^{\prime}$ \\ Long Xiao (i) \\ Meixiu Liu' \\ Fengyi Du $\mathbb{D}^{2}$ \\ Zhirong Wang' \\ 'Central Laboratory, Zhangjiagang TCM \\ Hospital Affiliated to Nanjing University \\ of Chinese Medicine, Suzhou, Jiangsu, \\ 215600, People's Republic of China; \\ ${ }^{2}$ School of Medicine, Zhenjiang, Jiangsu, \\ 2I20I3, People's Republic of China
}

Correspondence: Zhirong Wang; Fengyi Du Tel +86 I38 6222 4593; +86 I59 529005 I3 Email zjgfy_spine_wzr@njucm.edu.cn; biodfy@ujs.edu.cn

\begin{abstract}
Carbon quantum dots (CQDs) are an emerging class of quasi-zero-dimensional photoluminescent nanomaterials with particle sizes less than $10 \mathrm{~nm}$. Owing to their favourable water dispersion, strong chemical inertia, stable optical performance, and good biocompatibility, CQDs have become prominent in biomedical fields. CQDs can be fabricated by "top-down" and "bottom-up" methods, both of which involve oxidation, carbonization, pyrolysis and polymerization. The functions of CQDs include biological imaging, biosensing, drug delivery, gene carrying, antimicrobial performance, photothermal ablation and so on, which enable them to be utilized in antitumour applications. The purpose of this review is to summarize the research progress of CQDs in antitumour applications from preparation and characterization to application prospects. Furthermore, the challenges and opportunities of CQDs are discussed along with future perspectives for precise individual therapy of tumours
\end{abstract}

Keywords: CQDs, antitumour, drug delivery, phototherapy

\section{Introduction}

At present, tumours are still one of the main culprits threatening human health. Due to the heterogeneity and metastatic nature of tumours, their diagnosis, treatment and control are not easy. Depending on the different sites and nature of the tumour, a comprehensive analysis of the clinical manifestations and signs of the patient, combined with laboratory examination and imaging and cytopathological examination, usually leads to a definitive diagnosis. ${ }^{1}$ However, there is still a lack of ideal and specific methods for early diagnosis, especially for deep tumours. There are many kinds of malignant tumours, which have different properties, involve different tissues and organs, occur during different stages of diseases, and have different responses to various treatments, so most patients need comprehensive treatment. ${ }^{2}$ Surgery is a good way to remove tumours, but it can only eradicate early or earlier solid tumours. ${ }^{3}$ Drug therapy is chemotherapy that can kill tumours. Since tumour cells differ most from normal cells in their rapid cell division and growth, antitumour drugs usually work by disrupting the mechanisms of cell division, such as DNA replication or chromosomal separation. ${ }^{4,5}$ Nevertheless, most chemotherapeutic drugs are not specific, so they simultaneously kill normal tissue cells that divide, often harming healthy tissues that need to divide to function properly. Radiotherapy uses radiation to kill tumour cells, thereby shrinking the tumours. ${ }^{6-8}$ Radiation can control the growth of tumour cells by damaging their genetic material, thus preventing them from growing or dividing. ${ }^{9,10}$ The disadvantage of radiotherapy is that it is limited to areas of radiation exposure, and it kills tumour cells while affecting normal cells. ${ }^{11}$ Therefore, the 
early detection and diagnosis of tumours and the specific elimination of tumour cells have become the direction of antitumour research.

Located in the second period of the IVA group on the periodic table, carbon is a simple, stable and common element that is widely present in nature. ${ }^{12}$ Since the last century, carbon has played an important role in the development of nanomaterials. ${ }^{13}$ Although these nanomaterials are mainly composed of the same element, carbon, they have different functions and sizes due to their different structures, which ensures that they have different but extraordinary properties. Carbon nanomaterials have been widely reported and include carbon nanotubes (CNTs), ${ }^{14}$ carbon fibres $(\mathrm{CFs})^{15}$ and carbon quantum dots (CQDs). ${ }^{16} \mathrm{CNTs}$, also known as bucky tubes, are one-dimensional quantum materials with a unique structure of coaxial circular tubes. ${ }^{17}$ Research on the nucleation thermodynamics of CNTs is ongoing and has made great progress. ${ }^{18} \mathrm{CF}$ is a unique fibre with more than $90 \%$ carbon content, and it has great application potential in the development of advanced technology. ${ }^{19}$ CQDs are carbon-based zerodimensional nanoparticles with particle sizes less than $10 \mathrm{~nm}$ that are composed of dispersed spherical carbon particles. ${ }^{20}$ Their nuclei are generally formed by $\mathrm{sp}^{2}$ hybridization, and they have two kinds of structures: lattices and nonlattices. ${ }^{21}$ In 2004, Professor Xiaoyou Xu of the University of South Carolina et al reported for the first time that during the electrophoretic purification of single-walled carbon nanotubes, CQDs that can emit bright fluorescence were found in the products, ${ }^{22}$ thus introducing CQDs and opening the door for scientific researchers to further explore them. In 2007, Cao et al reported that the two-photon absorption cross sections of prepared CQDs were comparable to the two-photon absorption cross sections of the best semiconductor quantum dots or core shell nanoparticles reported in previous literature and demonstrated that the CQDs could enter breast cancer cells. $^{23}$ In 2012, Lin et al mixed CQDs with oxidants such as $\mathrm{KMnO}_{4}$ and $\mathrm{Ce}^{4+}$ to stimulate their chemiluminescence, which is the production of light through a chemical reaction. $^{24}$ In 2017, Yuan et al first fabricated CQDs that had the ability to emit fluorescence from red to blue light species by controlling the fusion and carbonization of citric acid and diaminonaphthalene, which provided a new clue for the development of light-emitting diodes. ${ }^{25}$ In 2019 , Guo et al embedded CQDs into alginate gel beads to form composite materials that could absorb rare earth elements, which could be applied as a rare earth element adsorbent for environmental protection. $^{26}$ In 2021, Tao et al developed CQDs that emitted blue light in water and redshifted in the solid state and reported that these CQDs could be utilized as fluorescent ink for anticounterfeiting and for printing high-quality fluorescent images. ${ }^{27}$ Figure 1 shows the development history of CQDs since their discovery.

With the in-depth exploration of CQDs, researchers have gradually obtained a thorough understanding of them. Generally, the following commonalities can be listed. Due to the influence of precursors, the surface of CQDs is covered with hydrophilic functional groups such as $-\mathrm{COOH}$ and $-\mathrm{OH}$, and the particle sizes are small, which endows them with the potential for good biocompatibility. ${ }^{33-35}$ Besides, the hydrophilic groups on the surface of CQDs promote the interaction with proteins in vivo, resulting in the formation of protein corona, which changes the original properties of CQDs. ${ }^{36,37}$ Therefore, how to change the surface properties of CQDs to realize the controllable load of proteins and how to regulate the interaction between the two has become one of the hot topics that many scientists compete to study. CQDs also have excellent fluorescence properties, which gives them considerable application prospects in the field of bioluminescence imaging and sensors. ${ }^{38}$ Due to their small structure, CQDs can be trapped in tumour sites by an enhanced permeability and retention effect (EPR). ${ }^{39,40}$ In normal tissues, the microvascular endothelial space is dense and intact, and CQDs are difficult to penetrate the vascular wall, while in solid tumor tissues, blood vessels are abundant, and the wide vascular wall space, poor structural integrity and missing lymphatic return result in high selective permeability and retention of large CQDs. ${ }^{41,42}$ Therefore, EPR effect promotes the selective distribution of CQDs in tumor tissues, which can increase antitumour efficacy and reduce systemic side effects. Moreover, the additional functions of CQDs can be added by modification and doping. We can utilize the abovementioned characteristics of CQDs to develop and expand their antitumour applications and provide new ideas for the discovery, diagnosis, treatment and monitoring of tumours in the future. This review outlines the features and characterizations of CQDs, introduces the preparation of CQDs, elaborates the application of CQDs in antitumour applications, including drug delivery, phototherapy, monitoring and auto-antitumour applications, and discusses the design of related topics.

\section{Features and Characteristics of CQDs}

\section{Preparation of CQDs}

The synthesis methods of CQDs include the "top-down" method and the "bottom-up" method. ${ }^{43-45}$ The "top-down" 


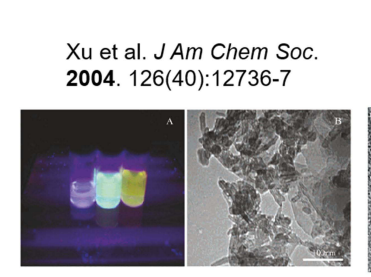

First discovery of CQDs

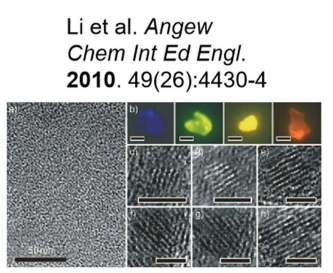

Photocatalysts

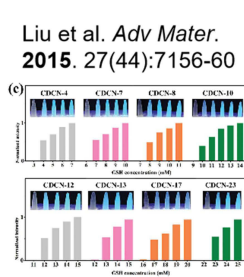

Detect intracellular Redox State
Cao et al. J Am Chem Soc 2007. 129(37):11318-9

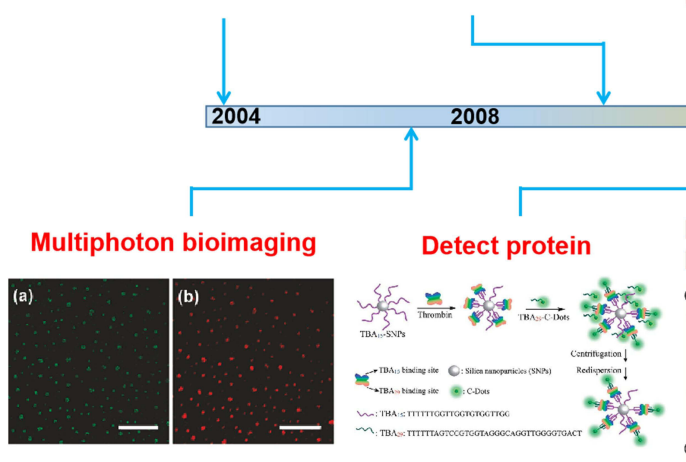

Xu et al. Analyst. 2012. 137(23):5483-6.

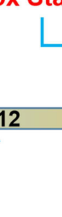

Bright Multicolor Bandgap Fluorescent

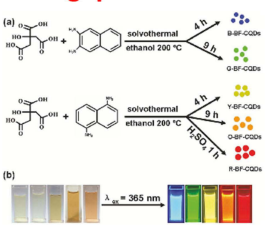

Yuan et al. Adv Mater. 2017. 29(3)

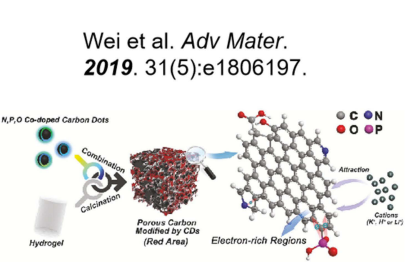

Negative electrode materials
Guo et al. J Colloid Interface Sci. 2020. 562:224-234

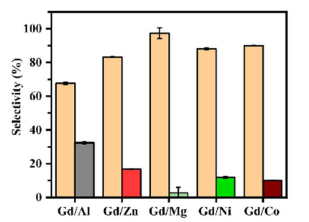

Absorb rare earth elements

Figure I The development history of CQDs.

Notes: Images reprinted with permission from Xu X, Ray R, Gu Y, et al. Electrophoretic analysis and purification of fluorescent single-walled carbon nanotube fragments. J Am Chem Soc. 2004;126(40):I2736-12737, Copyright (2004) American Chemical Society ${ }^{22}$;reprinted with permission from Cao L, Wang X, Meziani MJ, et al. Carbon dots for multiphoton bioimaging. J Am Chem Soc. 2007; I29(37): I I318-1 I319, Copyright (2007) American Chemical Society ${ }^{23}$; reprinted with permission from Yuan F, Wang Z, Li X, et al. Bright Multicolor Bandgap Fluorescent Carbon Quantum Dots for Electroluminescent Light-Emitting Diodes. Adv Mater. 20I7;29(3). (C 20I6 WILEY-VCH Verlag $\mathrm{GmbH} \&$ Co. KGaA, Weinheim ${ }^{25}$; reprinted with permission from J Colloid Interface Sci. 562, Guo Z, Li Q, Li Z, et al. Fabrication of efficient alginate composite beads embedded with $\mathrm{N}$-doped carbon dots and their application for enhanced rare earth elements adsorption from aqueous solutions. 224-234, Copyright 2020, with permission from Elsevier ${ }^{26}$; reprinted with permission from J Colloid Interface Sci. 588, Tao Y, Lin J, Wang D, Wang Y. Na+-functionalized carbon dots with aggregation-induced and enhanced cyan emission. 469-475, Copyright (202I), with permission from Elsevier ${ }^{27}$; reprinted with permission from Li H, He X, Kang Z, et al. Water-soluble fluorescent carbon quantum dots and photocatalyst design. Angew Chem Int Ed Engl. 2010;49(26):4430-4434. Copyright @ 20I0 WILEY-VCH Verlag GmbH \& Co. KGaA, Weinheim ${ }^{28}$; reprinted with permission from Liu Y, Tian Y, Tian Y, et al. Carbon-Dot-Based Nanosensors for the Detection of Intracellular Redox State. Adv Mater. 20I5;27(44):7I567I60. () 2015 WILEY-VCH Verlag GmbH \& Co. KGaA, Weinheim ${ }^{29}$; reprinted with permission from Xue X, Fang T, Yin L. Multistage delivery of CDs-DOX/ICG-loaded liposome for highly penetration and effective chemo-photothermal combination therapy. Drug Deliv. 2018;25(I): 1826-I83930; republished with permission of Xu B, Zhao C, Wei W, et al. Aptamer carbon nanodot sandwich used for fluorescent detection of protein. Analyst. 2012;137(23):5483-5486, permission conveyed through Copyright Clearance Center, Inc ${ }^{31}$; reprinted with permission from Wei JS, Ding C, Zhang P, et al. Robust Negative Electrode Materials Derived from Carbon Dots and Porous Hydrogels for High-Performance Hybrid Supercapacitors. Adv Mater. 2019;3I(5):el806I97. @ 20I8 WILEY-VCH Verlag GmbH \& Co. KGaA, Weinheim. ${ }^{32}$

method refers to the separation of CQDs with small particle sizes from carbon-based materials (such as CNTs, CF, graphite) by chemical or physical methods, including arc discharge, $^{22}$ electrochemical methods, ${ }^{46}$ chemical oxidation, ${ }^{47}$ laser ablation ${ }^{48}$ and combustion. ${ }^{49}$ Contrary to the "top-down" method, the "bottom-up" method mainly refers to the formation of CQDs by carbonization and polymerization of a series of small molecules through chemical reactions, including hydrothermal methods, ${ }^{50}$ microwave methods $^{55}$ and template methods. ${ }^{60}$ Table 1 summarizes the advantages and disadvantages of various methods for preparing CQDs.

\section{"Top-Down" Method}

Arc discharge is a self-sustaining discharge method that uses gas plasma generated in a sealed reactor to drive anodic electrodes to decompose CQDs from bulk carbon precursors. To generate high-energy plasma, the heat of the reactor can be as high as tens of thousands of degrees Celsius under the action of the electric current, so arc discharge is the most intense method of gas discharge. The most obvious visual characteristics of arc discharge are bright arc columns and electrode spots, while energy balance is another important law that describes the arc discharge phenomenon. The generation of energy is the JHEAT of the arc, and the divergence of energy occurs through radiation, convection and conduction. $\mathrm{Xu}$ et al accidentally harvested three kinds of CQDs with different fluorescence characteristics when purifying single-walled carbon nanotubes by the arc discharge method. These three CQDs can emit blue-green, yellow and orange 
Table I Various Methods of Preparing CQDs as Well as Their Advantages and Disadvantages

\begin{tabular}{|l|l|l|l|l|}
\hline Method & Classification & Advantages & Disadvantages & Reference \\
\hline Arc discharge & $\begin{array}{l}\text { "Top-down" } \\
\text { method }\end{array}$ & Excellent water dispersibility & Particle size with large difference & [22] \\
\hline $\begin{array}{l}\text { Electrochemical } \\
\text { method }\end{array}$ & $\begin{array}{l}\text { "Top-down" } \\
\text { method }\end{array}$ & $\begin{array}{l}\text { Easy to adjust the particle size and } \\
\text { fluorescence properties, high yield }\end{array}$ & Special equipment required & [46,6I] \\
\hline $\begin{array}{l}\text { Chemical } \\
\text { oxidation }\end{array}$ & $\begin{array}{l}\text { "Top-down" } \\
\text { method }\end{array}$ & $\begin{array}{l}\text { Excellent water dispersion and fluorescence } \\
\text { characteristics }\end{array}$ & Special equipment required & [47,62] \\
\hline $\begin{array}{l}\text { Laser ablation } \\
\text { "Top-down" }\end{array}$ & $\begin{array}{l}\text { Excellent water dispersion and fluorescence } \\
\text { characteristics }\end{array}$ & $\begin{array}{l}\text { Low yield, inhomogeneous particle size } \\
\text { and complex operation }\end{array}$ & [48,63] \\
\hline $\begin{array}{l}\text { Combustion } \\
\text { "Top-down" } \\
\text { method }\end{array}$ & Simple operation & $\begin{array}{l}\text { Low yield and inhomogeneous particle } \\
\text { size }\end{array}$ & {$[49,64]$} \\
\hline $\begin{array}{l}\text { Hydrothermal } \\
\text { method }\end{array}$ & $\begin{array}{l}\text { "Bottom-up" } \\
\text { method }\end{array}$ & Homogeneous particle size and high yield & Long time consuming & {$[50-54]$} \\
\hline $\begin{array}{l}\text { Microwave } \\
\text { method }\end{array}$ & $\begin{array}{l}\text { "Bottom-up" } \\
\text { method }\end{array}$ & Simple, fast and environmental protection & Low yield and multiple impurities & [55-59] \\
\hline $\begin{array}{l}\text { Template } \\
\text { method }\end{array}$ & "Bottom-up" & $\begin{array}{l}\text { Homogeneous particle size and excellent } \\
\text { water dispersibility }\end{array}$ & Tedious operation & [60] \\
\hline
\end{tabular}

fluorescence at $365 \mathrm{~nm}^{22}$ Although this method can synthesize CQDs with good water dispersion, the size of the CQDs formed in the discharge process is different, and they generally have a larger particle size distribution.

Electrochemical methods are simple and convenient preparation methods that can be carried out under normal temperature and pressure. With the function of inhibiting maltose activity, chiral CQDs were fabricated from L- or D-glutamic acid through electrochemical methods to be used as a candidate drug for controlling blood sugar. ${ }^{46}$ Yen et al reported a three-electrode electrochemical method for the direct synthesis of high-quality CQDs in pure water electrolyte. ${ }^{61}$ This method provides a step for the preparation of aqueous CQD solutions without further postprocessing, such as filtration, dialysis, centrifugation, column chromatography and gel electrophoresis. The results show that the prepared CQDs have a catalytic effect on $\mathrm{H}_{2} \mathrm{O}_{2}$ and reduce the charge transfer resistance and ionic diffusion resistance. Although special equipment is needed, the particle size and fluorescence properties of CQDs synthesized by electrochemical methods can be easily adjusted, and the CQDs are formed in high yield.

Chemical oxidation has been widely used to decompose bulk carbon-based materials into CQDs and introduce hydrophilic groups such as $-\mathrm{COOH}$ or $-\mathrm{OH}$, which can significantly improve the water dispersion and fluorescence of CQDs. Qiao et al prepared CQDs by a chemical oxidation method using activated carbon as a raw material in the treatment of nitric acid, which had excellent photostability and cell avirulence and could penetrate living cells, so they had the potential to be utilized as living cell imaging agents. ${ }^{47} \mathrm{Hu}$ et al utilized coal tar pitch as a raw material to prepare CQDs-based nanosensors by chemical oxidation for the detection of $\mathrm{Cu}^{2+}, \mathrm{Fe}^{3+}$ and L-ascorbic acid. ${ }^{62}$

Laser ablation is used to irradiate the surface of carbon-based materials with large particle sizes with a highenergy laser pulse, causing the materials to reach a high temperature and high pressure, quickly heat up and evaporate into the plasma state, and finally crystallize through steam to form CQDs. Yu et al prepared triple valence CQDs in toluene by laser irradiation, which increased the fluorescence lifetime. ${ }^{48}$ Moreover, graphene was observed during production through a real-time detection system. Kang et al transformed Earth's rich resources and low-cost coal into CQDs within 5 minutes through a simple, lowcost, environmentally friendly liquid pulse laser ablation method. ${ }^{63}$ CQDs prepared by laser ablation have good water dispersibility and strong fluorescence properties, but their wide application is hindered by low yield, uneven particle size and complex operation.

Combustion is a method that involves collecting CQDs from the products of burning organic matter. Zinc oxide and 
zinc sulfide CQDs were synthesized by combustion using zinc nitrate and thioacetamide as raw materials and ethylene glycol as fuel, whose water solution exhibited three bluegreen emission peaks at $420 \mathrm{~nm}, 486 \mathrm{~nm}$ and $520 \mathrm{~nm} .{ }^{49}$ Han et al prepared single- and double-doped CQDs by a combustion method, which could skillfully adjust the doping amount of heteroatoms by changing the precursor concentration. ${ }^{64}$ Although combustion is easy to operate, the yield of CQDs is low, and the particle size is different.

\section{"Bottom-Up" Method}

The hydrothermal method is one of the most commonly used methods to synthesize CQDs. The main process is to dissolve small organic molecules and/or polymers in water or organic solvents to form reaction precursors, followed by transferring them to a stainless steel autoclave lined with Teflon and finally forming CQDs at high temperature. Ye et al first prepared two-photon CQDs by a hydrothermal method for detecting intracellular $\mathrm{pH}$, which depended on the disaggregation and aggregation of their physical states, thus contributing to future applications in living systems. ${ }^{50}$ Atchudan et al utilized $P$. acidus and aqueous ammonia as raw materials to form CQDs by a hydrothermal method. ${ }^{51}$ The prepared CQDs can be used as fluorescence inks and $\mathrm{Fe}^{3+}$ detectors, which provides a new idea for the monitoring of $\mathrm{Fe}^{3+}$ in industrial wastewater. Jiang et al prepared room temperature phosphorescence (RTP)-based CQDs from trimellitic acid (TA) by a hydrothermal method; these CQDs were designed to be applied for anti-counterfeiting and information encryption. ${ }^{52}$ Zheng et al utilized amino acids and polymers as raw materials to fabricate CQDs for blood analysis and cell imaging by hydrothermal methods. ${ }^{53}$ Our group reported a method of preparing iodine-doped CQDs as a highefficiency CT contrast agent for the first time by hydrothermal carbonization. ${ }^{54}$ Compared with traditional iodine contrast agents, the prepared CQDs not only have unique photoluminescence and X-ray attenuation characteristics but also have the characteristics of a long cycle and passive target CT imaging. The operation of the hydrothermal method is simple, the size of CQDs is almost the same, and the yield is high.

Among the bottom-up methods, the microwave method is the most rapid commercial method. The preparation process involves dissolving the precursor in the solution to form a transparent solution, followed by heating it in a microwave oven. CQDs with PEI modified on the surface were prepared by the microwave method. ${ }^{55}$ Among them, PEI played two important roles: enhanced fluorescence and gene delivery. Singh et al prepared CQDs with quinolinate phosphoribosyl transferase (QPRTase) on the surface by the microwave method, which was used to detect the endogenous neurotoxin quinolinic acid (QA), thus providing a candidate for the treatment of neurological disorders. ${ }^{56}$ In addition, to address the difference in $\mathrm{pH}$ between wounds and normal regions, CQDs with the function of monitoring $\mathrm{pH}$ were fabricated by the microwave method; these CQDs provided new clues for the identification, treatment and healing of wounds in the future. ${ }^{57}$ In addition, Pierrat et al utilized citric acid and BPEI25K as raw materials to prepare CQDs by the microwave method to transfect nucleic acids in vivo and in vitro, thus providing a new method for drug delivery to the lungs. ${ }^{58}$ Our group also reported a synthesis of nitrogen-doped CQDs that uses citric acid and ammonium acetate as precursors through a microwave method. These CQDs had strong photoluminescence, good water solubility and stable optical properties. ${ }^{59}$ It is worth noting that an inhomogeneous multilayer structure was observed for the first time in nitrogen-doped CQDs. The microwave method is a simple, rapid and environmentally friendly method for the synthesis of CQDs.

The template method is a technique of preparing CQDs with special materials as templates and then removing the template by physical or chemical methods to collect the CQDs. Yang et al synthesized organic templated TiOS under solvent-free conditions, performed heat treatment at $300{ }^{\circ} \mathrm{C}$ in vacuum to prepare N-CDs@TiOS, and finally, they transformed the organic template into N-CDs and embedded them into a titanium sulfate matrix to collect the CQDs. ${ }^{60}$ This kind of CQDs can be used as an efficient photosensitizer and has good application potential in visible light-driven photocatalysis, which provides an effective way to prepare CQDs by a template method for visible light catalysis. The CQDs prepared by the template method have good water dispersibility and uniform particle size, but the operation is cumbersome.

\section{Photoluminescence of CQDs}

Photoluminescence (PL), a basic characteristic of CQDs, has been widely researched in related fields. PL refers to the electrons of matter jump from the valence band to the conduction band and leave holes in the valence band under the excitation of light. ${ }^{65}$ In the conduction band and valence band, electrons and holes reach the lowest unoccupied excited state by relaxation and enter a quasi-equilibrium state. In this quasi-equilibrium state, electrons and holes 
emit light through recombination, forming spectra of intensity or distributing energy across different wavelengths. ${ }^{66}$ Although PL can only be used for qualitative analysis rather than quantitative analysis, it has high resolution. ${ }^{67}$ In recent years, many studies have been performed on the PL mechanism of CQDs, but there has been no unified conclusion. ${ }^{68-70}$ This lack of consensus may be because different raw materials, surface passivators or preparation methods have a great impact on the structure and PL properties of CQDs. It is widely believed that the mechanism of the PL properties of CQDs involves surface defects, ${ }^{71}$ lattice defects ${ }^{72}$ and quantum confinement effects. ${ }^{73}$ The PL analysis of CQDs has the significant advantages of high sensitivity and strong selectivity, including an excitation spectrum and emission spectrum, making it possible to choose a variety of wavelengths for molecular fluorescence analysis. ${ }^{74}$ It is noteworthy that the traditional CQDs are excited by single photon, which leads to photobleaching when they are used for tumour tissue imaging. Two-photon CQDs are excited by two-photon nearinfrared light, which can improve the tissue penetration, and thus observe in deep tissues and prolong the observation time. ${ }^{75,76}$ Therefore, their research in tumour tissue imaging is more popular. PL is an important characteristic of CQDs, and PL measurements are helpful for later research. The influence of external pressure on the fluorescence properties of CQDs can be judged by measuring the PL and UV-Vis spectra. ${ }^{77}$ As shown in Figure 2A, Ding et al utilized urea and p-phenylenediamine to fabricate CQDs by a hydrothermal method; the CQDs were filtered through silica column chromatography into eight different components, each of which emitted a different fluorescence colour. ${ }^{78}$ In addition, the cerium-doped CQDs (Ce-doped CQDs) prepared by our research group also showed excellent fluorescence properties. ${ }^{79}$ As shown in Figure 2B, with increasing excitation wavelength, the fluorescence intensity of Ce-doped CQDs increased gradually, reaching a peak at $360 \mathrm{~nm}$, and then decreased gradually.

UV visible (UV-Vis) spectrophotometry is a method for the determination of the absorbance of the substance in the range of 190-800 nm, which can be used to determine the linear optical absorption behaviour of CQDs. ${ }^{80}$ When the light passes through the solution, the absorption of the substance changes with the wavelength of the light. In the ultraviolet absorption spectrum, electrons undergo four different types of transitions, $\sigma \rightarrow \sigma^{*} n \rightarrow \sigma^{*} \pi \rightarrow \pi^{*}$ and $\mathrm{n} \rightarrow \pi^{*}$ which are arranged according to the decreasing order of energy required by various transition types. ${ }^{81}$ Among them, $\sigma \rightarrow \sigma^{*}$ transitions indicate the presence of $\mathrm{C}-\mathrm{C}$ bonds, ${ }^{82} \mathrm{n} \rightarrow \sigma^{*}$ transitions demonstrate the presence of $-\mathrm{OH}$ and $-\mathrm{NH}_{2}$ bonds, ${ }^{83} \pi \rightarrow \pi^{*}$ transitions occur due to the double bond absorption of aromatic nuclei, ${ }^{84}$ and $n \rightarrow \pi^{*}$ transitions imply the presence of $\mathrm{C}=\mathrm{O}, \mathrm{C}=\mathrm{S},-\mathrm{N}=\mathrm{O}$ and $-\mathrm{N}=\mathrm{N}-{ }^{85}$ The same concentration of the solution to be measured has different absorbance for different wavelengths of light, while for the same solution to be measured, the higher the concentration, the greater the absorbance, but the wavelength corresponding to the maximum absorption peak $(\lambda \max )$ is the same. Therefore, by measuring the

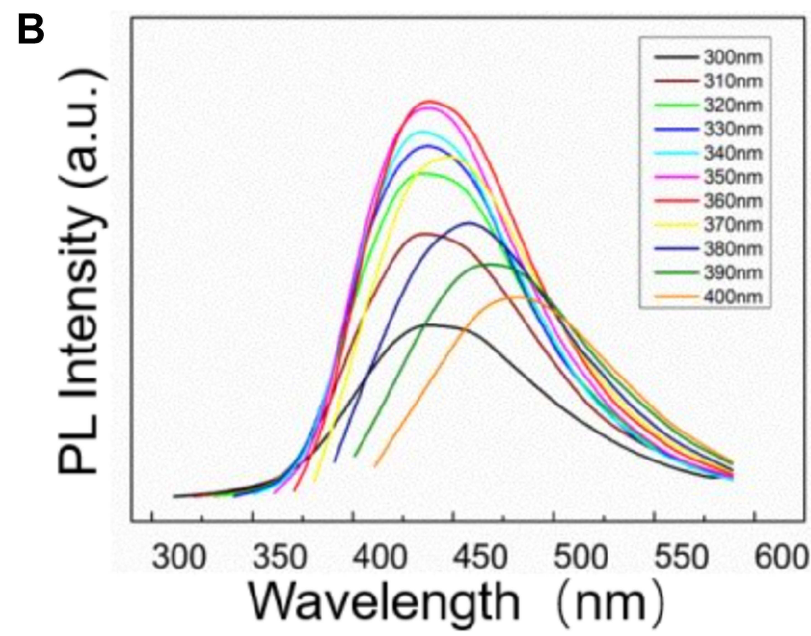

Figure 2 (A) Scheme of CQDs. Reprinted with permission from Ding H, Yu SB, Wei JS, Xiong HM. Full-color light-emitting carbon dots with a surface-state-controlled luminescence mechanism. ACS Nano. 2016;10(1):484-49I. Copyright (2016) American Chemical Society. ${ }^{78}$ and (B) PL spectra of Ce-doped CQDs. Reprinted with permission from Zhang M, Zhao L, Du F, et al. Facile synthesis of cerium-doped carbon quantum dots as a highly efficient antioxidant for free radical scavenging. Nanotechnology. 2019;30(32):32510IZ. ${ }^{79}$ 

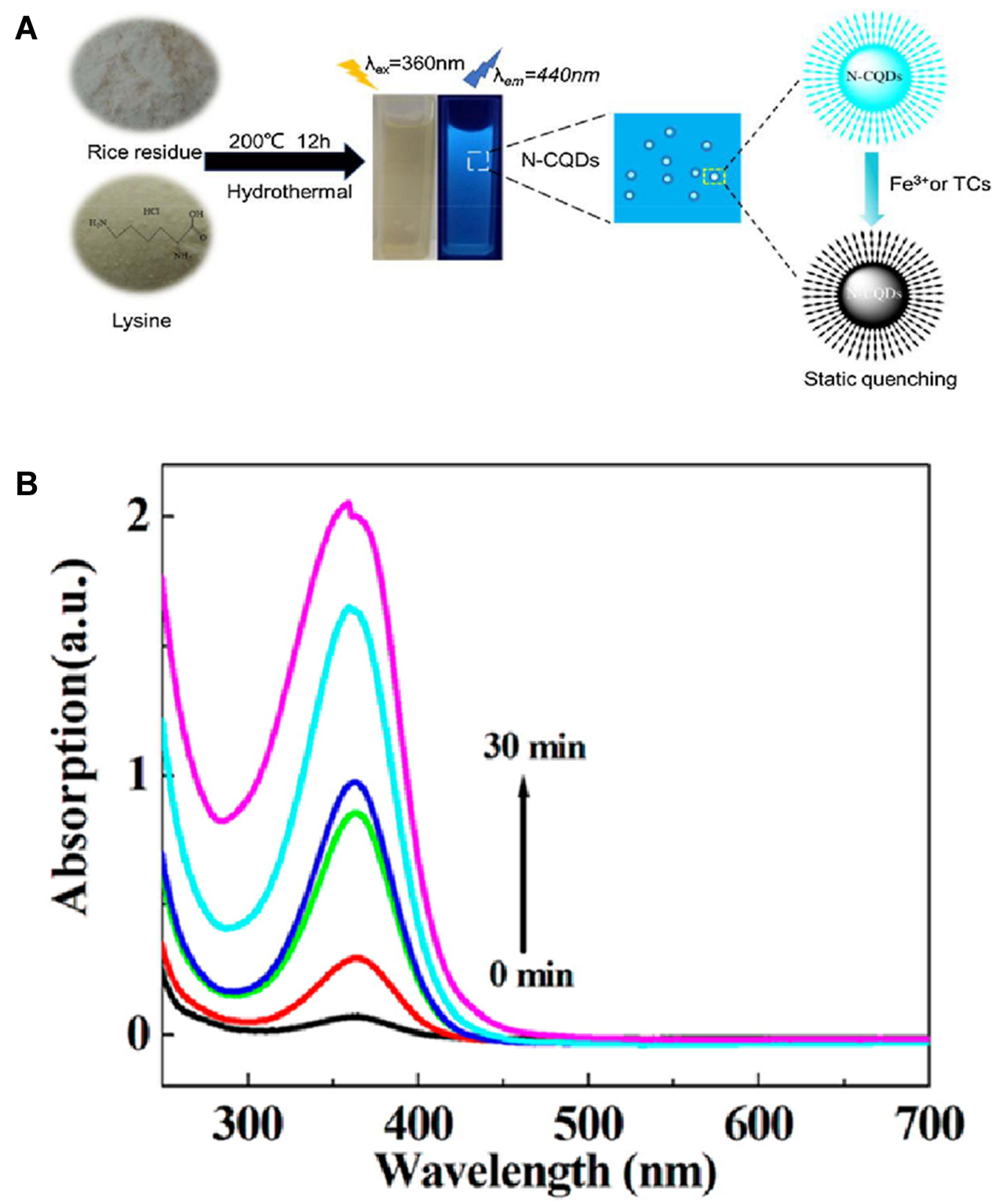

Figure 3 (A) Mechanism of N-CQDs. Reprinted from J Colloid Interface Sci, 539, Qi H, Teng M, Liu M, et al. Biomass-derived nitrogen-doped carbon quantum dots: highly selective fluorescent probe for detecting Fe3+ ions and tetracyclines. 332-34I, Copyright 2019, with permission from Elsevier. ${ }^{86}$ and (B) UV-Vis spectra of B-CDs. Reprinted with permission from Liu H, He Z, Jiang LP, Zhu JJ. Microwave-assisted synthesis ofwavelength-tunable photoluminescent carbon nanodots and theirpotential applications. ACS Appl Mater Interfaces. 2015;7(8):4913-4920. Copyright (2015) American Chemical Society. ${ }^{87}$

Abbreviations: N-CQDs, nitrogen-doped CQDs; B-CDs, blue luminescent carbon dots.

absorbance of the substance at different wavelengths and drawing the relationship between the absorbance and wavelength, the absorption spectrum of the substance can be obtained. As shown in Figure 3A, Qi et al prepared nitrogen-doped CQDs (N-CQDs), which fluoresced blue under ultraviolet light but were quenched when $\mathrm{Fe}^{3+}$ was encountered. ${ }^{86}$ In addition, the prepared aqueous B-CD solution was colourless and transparent under normal environmental conditions. ${ }^{87}$ With the extension of microwave irradiation time, the peak value of the aqueous B-CD solution at $360 \mathrm{~nm}$ gradually increased, and its colour gradually darkened, which indicated that microwave irradiation could shorten the reaction time (Figure 3B).

\section{Characterization and Biocompatibility of CQDs}

A requirement for the biological application of CQDs is that they must be harmless to the organism, so analysis of their biocompatibility is the primary task. The excellent biocompatibility of CQDs is due to their small size and surface groups, ${ }^{88}$ as well as biocompatibility of precursors, 

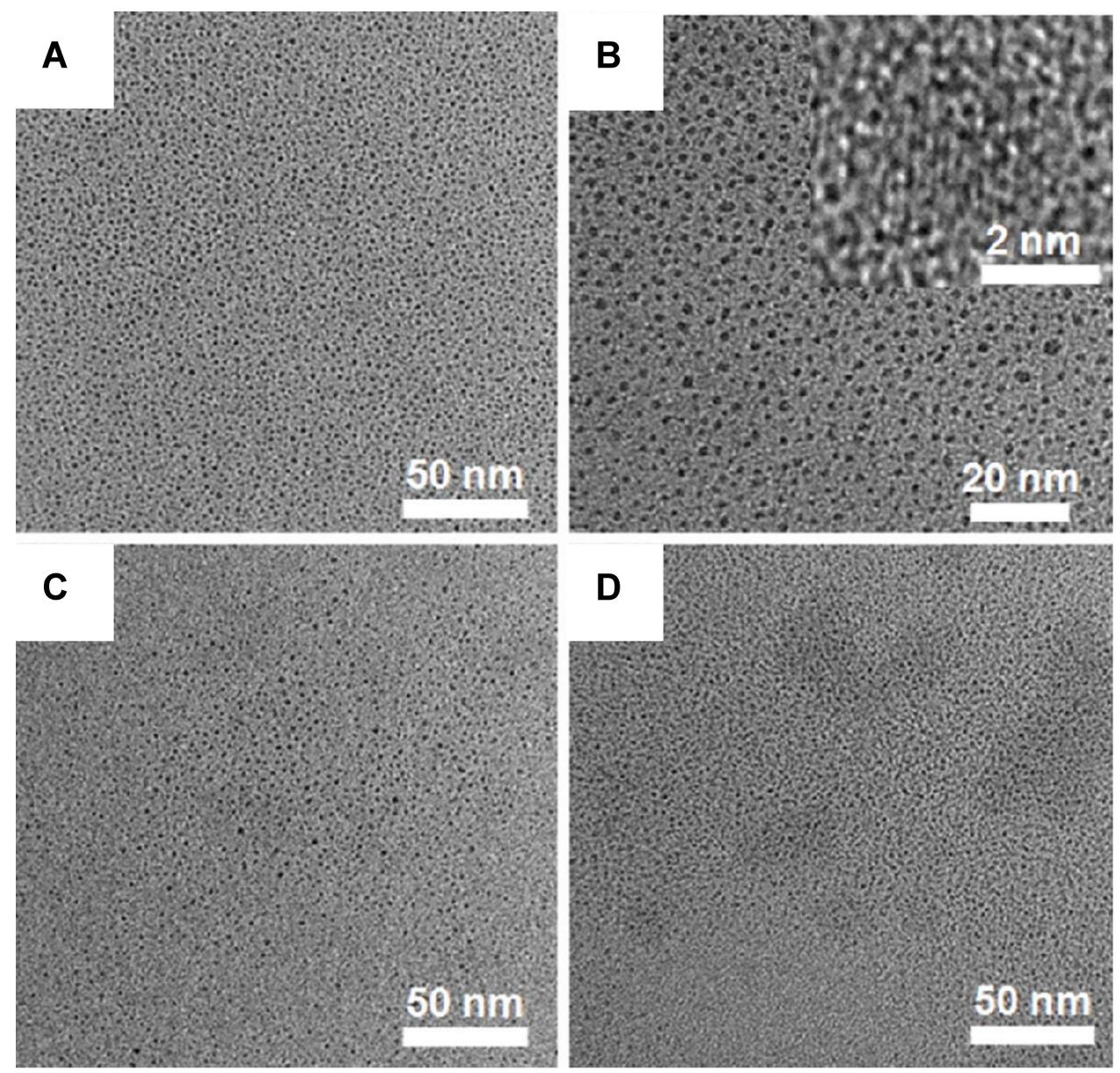

Figure 4 TEM and high-resolution TEM images of (A and B) r-CDs, (C) c-CDs, and (D) I-CDs. Reprinted with permission from Zhang J, Yuan Y, Liang G, Yu SH. Scale-up synthesis of fragrantnitrogen-doped carbon dots from bee pollens for bioimaging and catalysis. Adv Sci (Weinh). 2015;2(4):I500002. (C) 20I5 The Authors. Published by WILEY-VCH Verlag GmbH \& Co. KGaA, Weinheim. ${ }^{99}$

Abbreviations: $r-C D$ s, carbon quantum dots from rapeseed flower bee pollen; $c-C D$ s, carbon quantum dots from camellia bee pollen; I-CDs, carbon quantum dots from lotus bee pollen.

distribution of the surface charges and even the structural properties of carbon elements. ${ }^{89-91}$ The particle size of CQDs is generally less than $10 \mathrm{~nm}$, which makes it impossible to observe through ordinary optical microscopy. Moreover, the wavelength of transmission electron microscopy (TEM) is much shorter than that of visible light and ultraviolet light, which enables the resolution of TEM to reach $0.2 \mathrm{~nm} .{ }^{92-94}$ The working principle of TEM is to project the accelerated and focused electron beam onto a very thin sample. The direction of the electron beam changes due to the collision between the electron and the atom in the sample, resulting in solid angle reflection. ${ }^{95-97}$ The size of the scattering angle is related to the density and thickness of the sample, so different light and dark images are formed, which are displayed on the imaging device after the image is magnified and focused. ${ }^{98}$
The three kinds of CQDs, including r-CDs (Figure 4A), c-CDs (Figure 4C), and 1-CDs (Figure 4D), were distributed uniformly in water, and the particle size was approximately 2 nm. ${ }^{99}$ Furthermore, as shown in Figure 4B, the r-CDs were magnified again, and their crystal structure was observed by high-resolution transmission electron microscopy (HRTEM). In addition, $\mathrm{Li}$ et al prepared two CQDs, including ACDs and OCDs. ${ }^{100}$ The ACDs had a crystalline structure with a lattice spacing of $0.208 \mathrm{~nm}$, while the OCDs did not, which implied that there were lattice and nonlattice conformations in the CQDs. In addition, TEM showed that the size of the N, P-CDs varied, and the maximum size was approximately 15 $\mathrm{nm} .{ }^{101}$ In addition, the N,P-CDs were magnified again by HRTEM. Different N,P-CDs had different lattice spacings of $0.24 \mathrm{~nm}, 0.35 \mathrm{~nm}$ and $0.51 \mathrm{~nm}$, which implied that the $\mathrm{N}$, P-CDs did not have uniform lattice spacing, which may be related to the plane spacing of the N,P-CDs. Furthermore, 


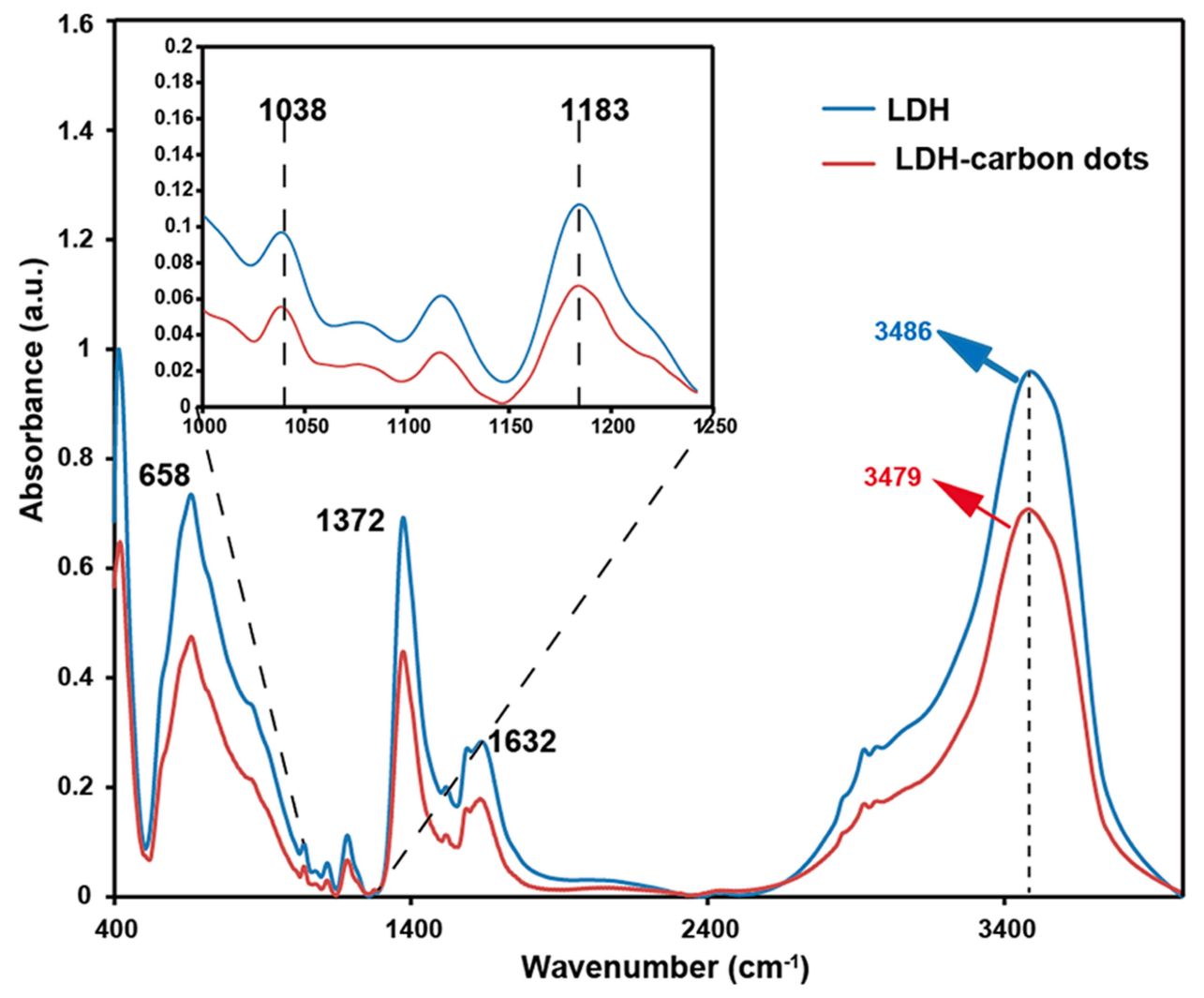

Figure 5 FTIR spectra of LDH and LDH-carbon quantum dots. Reprinted with permission from Zhang M, Yao Q, Lu C, et al. Layered double hydroxide-carbondot composite: high-performance adsorbent for removal of anionicorganic dye. ACS Appl Mater Interfaces. 20I4;6(22):20225-20233. Copyright (20I4) American Chemical Society. ${ }^{108}$

Abbreviations: FTIR, Fourier transform infrared spectroscopy; LDH, layered double hydroxide.

energy dispersive X-ray (EDX) spectroscopy is usually used in combination with TEM because it can determine the content of elements in CQDs by comparing the intensities of spectral lines of different elements.

Fourier transform infrared spectroscopy (FTIR), which is mainly composed of a Michelson interferometer and computer, can be used to analyse the chemical structure and surface groups of CQDs. ${ }^{102} \mathrm{~A}$ Michelson interferometer is a precision measuring instrument that uses the interference principle of light to precisely measure the length and tiny changes in length. ${ }^{103}$ The principle is that incident light is reflected back by the corresponding plane mirror after being divided into two beams by the spectroscope. Because the two beams have the same frequency, the same vibration direction and constant phase difference (ie, the interference conditions are satisfied), interference can occur. ${ }^{104}$ The different optical paths of the two beams can be realized by adjusting the length of the interference arm and changing the refractive index of the medium so that different interference patterns can be formed. ${ }^{105}$ The intensity distribution of the original light source can be calculated by Fourier transform of the interference function on a computer. ${ }^{106}$ Compared with traditional spectrometers, FTIR has the following advantages: fast scanning speed, high resolution, high sensitivity and wide spectral range. ${ }^{107}$ Zhang et al prepared layered double hydroxide-combined CQDs (LDH-carbon quantum dots) capable of adsorbing methyl blue. ${ }^{108}$ As shown in Figure 5, compared with the fixed hydrogen bond peak of LDH, the hydrogen bond peak of LDH-carbon quantum dots blueshifted (3490 to $3479 \mathrm{~cm}^{-1}$ ), suggesting that there was a hydrogen bond between LDH and CQDs. Moreover, the peaks at $1183 \mathrm{~cm}^{-1}$ and $1038 \mathrm{~cm}^{-1}$ were attributed to the $-\mathrm{SO}_{3^{-}}$of LDH and LDH-carbon quantum dots.

X-ray photoelectron spectroscopy (XPS), an advanced analytical technique for the microanalysis of electronic materials and components, can analyse the chemical elements in CQDs, and it is usually coordinated with auger electron spectroscopy (AES). ${ }^{109}$ The principle of XPS is to irradiate the CQDs with X-rays so that the core electrons of the atoms or molecules (also known as photoelectrons) 

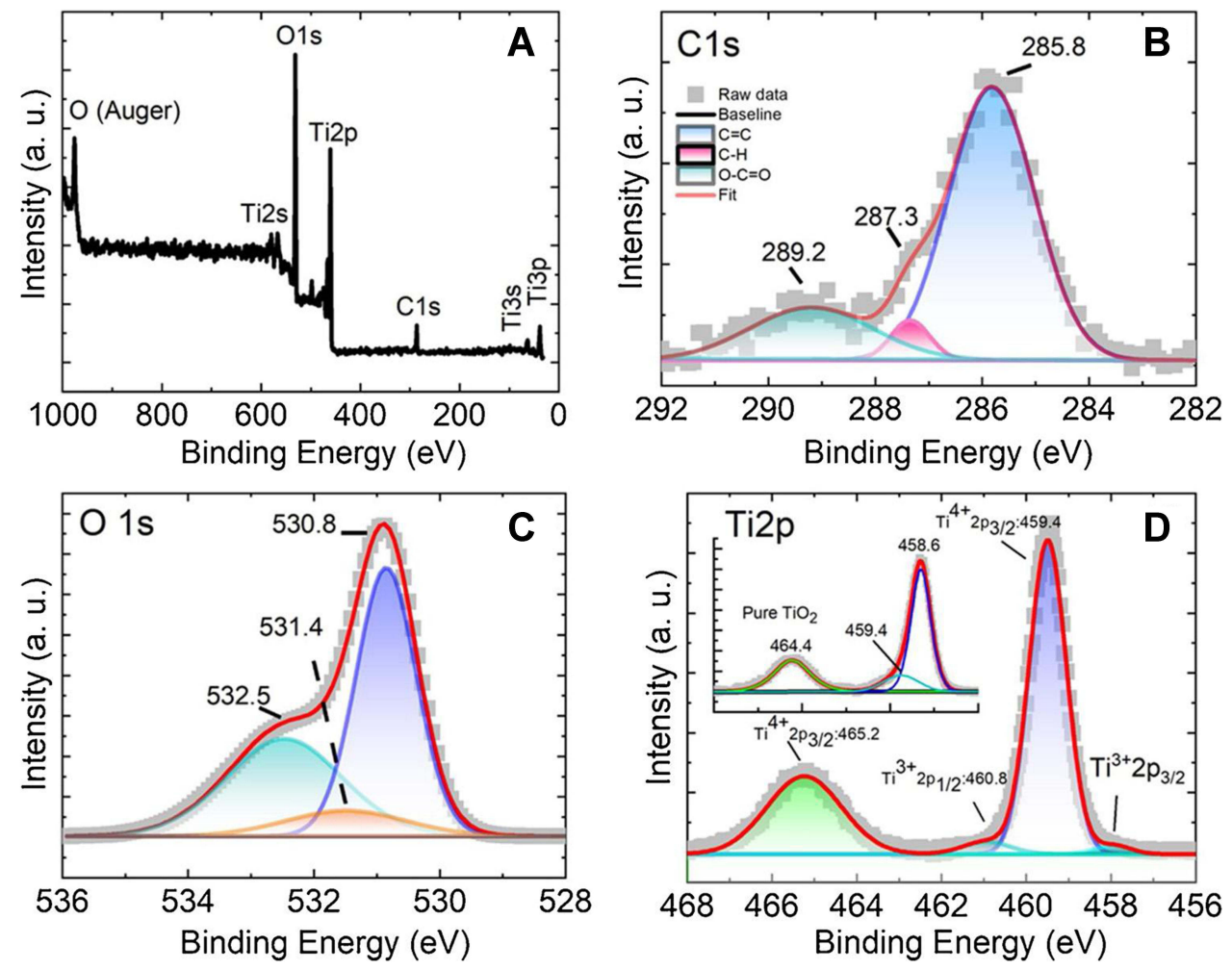

Figure 6 The XPS spectra of (A) survey, (B) $C_{1 s}$, (C) $\mathrm{O}_{1 \mathrm{~s}}$ and (D) $\mathrm{Ti}_{2 \mathrm{p}}$. Reprinted from Mahmood A, Shi G, Wang Z, et al. J Hazard Mater, $40 \mathrm{I}$, Carbon quantum dots-TiO2 nanocomposite as an efficient photocatalyst for the photodegradation of aromatic ring-containing mixed VOCs: an experimental and DFT studies of adsorption and electronic structure of the interface. 123402, Copyright 2021, with permission from Elsevier. ${ }^{113}$

are excited to emit and then measure the energy of photoelectrons. ${ }^{110}$ With the kinetic energy/binding energy of photoelectrons as the abscissa and the relative intensity as the ordinate, the photoelectron spectrum can be created to obtain relevant information on the CQDs. ${ }^{111}$ As a modern analytical method, XPS has the following characteristics: the ability to analyse all elements except $\mathrm{H}$ and He, strong identification, the ability to observe chemical shifts, quantitative analysis and high sensitivity. ${ }^{112}$ Figure $6 \mathrm{~A}-\mathrm{C}$ correspond to the survey, $\mathrm{C}_{1 \mathrm{~s}}$ and $\mathrm{O}_{1 \mathrm{~s}} \mathrm{XPS}$ spectra of the obtained CQDs, respectively. As shown in Figure 6D, two peaks at $459.4 \mathrm{eV}$ and $465.2 \mathrm{eV}$ corresponded to the $\mathrm{Ti}^{4+} 2 \mathrm{p}_{3 / 2}$ core level, while the peaks at $457.8 \mathrm{eV}$ and $460.9 \mathrm{eV}$ belonged to $\mathrm{Ti}^{3+} 2 \mathrm{p}_{1 / 2}$. XPS results demonstrated that CQDs were mainly composed of three elements, including carbon, oxygen and titanium. ${ }^{113}$

Interestingly, some researchers prepared green CQDs with food as raw material, which fully demonstrated the high biocompatibility of CQDs. ${ }^{114,115}$ Nevertheless, although the biocompatibility of CQDs has been reported in many studies, some researchers have found that there is a "threshold" for the low toxicity of CQDs. Liu et al reported the CQDs prepared at high temperature by mixing folic acid and $\mathrm{CuCl}_{2}$ with anhydrous ethanol. ${ }^{116}$ When the CQDs were mixed at different concentrations and added to cells, the cell viability was no less than $90 \%$ before 400 $\mu \mathrm{g} / \mathrm{mL}$ but gradually decreased from $600 \mu \mathrm{g} / \mathrm{mL}$. Therefore, it can be inferred that the toxicity and side effects of CQDs on cells are related to the type of cells coincubated, the concentration of CQDs and the coincubation time; these results are conducive to the subsequent exploration of the biocompatibility of CQDs and the design of their application in antitumour projects. It is expected that the toxicity assessment of therapeutic CQDs with potential biomedical applications will be carried out through animal models that conform to the norms of international organizations in the future.

\section{Applications of CQDs in Antitumour Diagnosis}

At present, clinical cancer is often found in the middle or even late stage, making later treatment much more difficult. When it is not discovered until the cancer develops to the late stage, the cancer is difficult to handle and shortens the life 
A
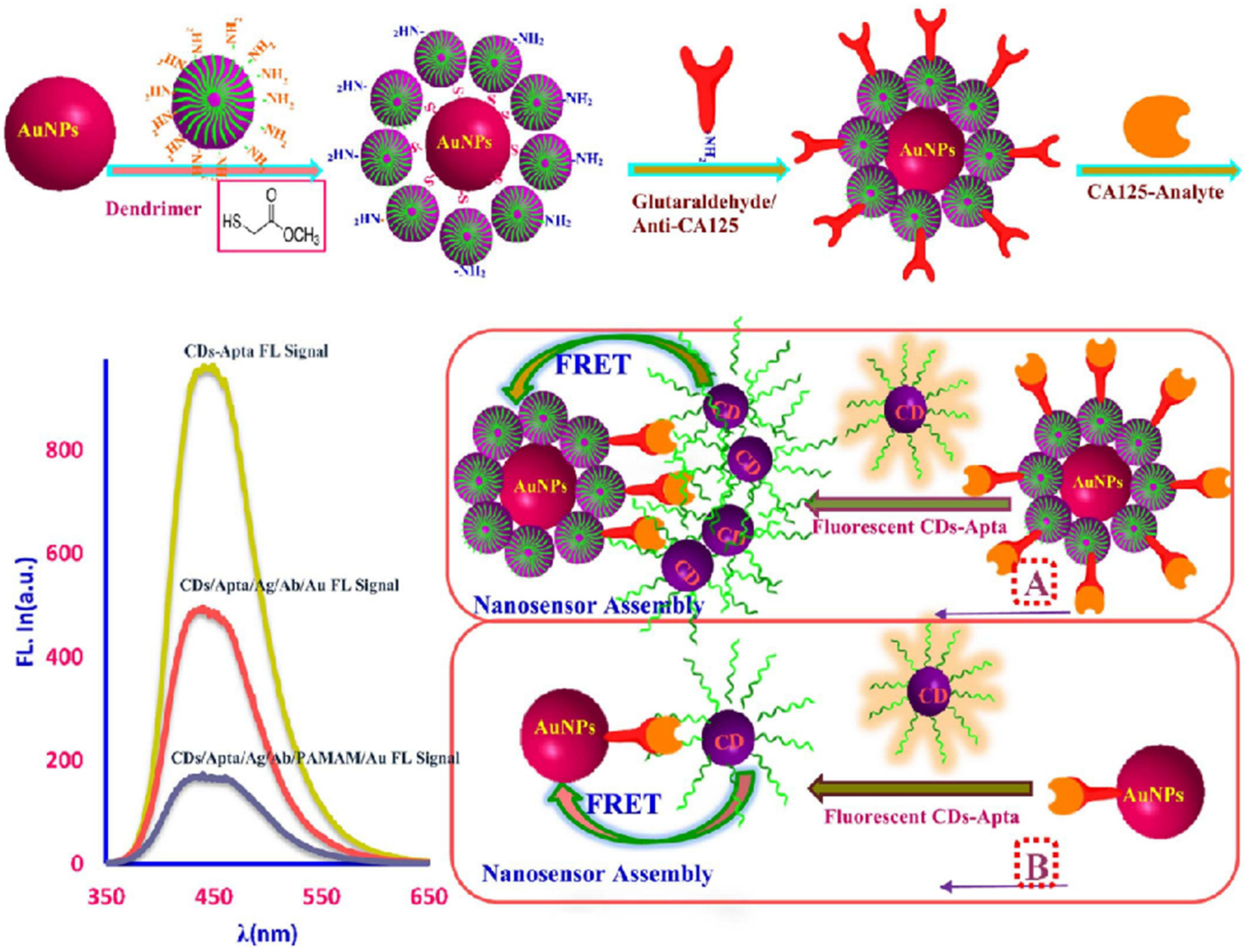

B

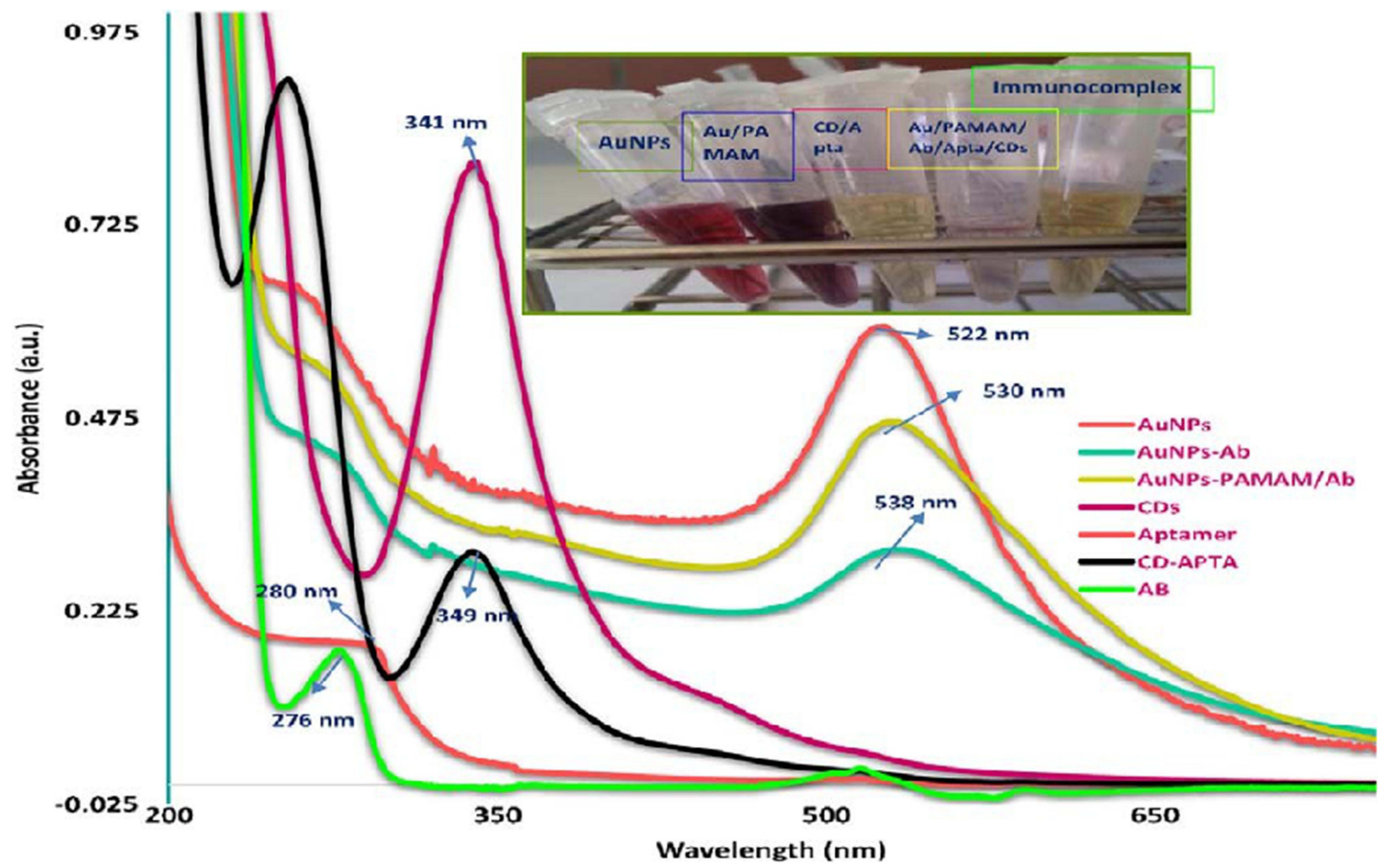

Figure 7 (A) The action mechanism diagram and (B) UV-vis absorption spectrum of AuNPs-PAMAM/Ab. Reprinted from Hamd-Ghadareh S, Salimi A, Fathi F, Bahrami S. Biosens Bioelectron, 96, An amplified comparative fluorescence resonance energy transfer immunosensing of CAI25 tumor marker and ovarian cancer cells using green and economic carbon dots for bio-applications in labeling, imaging and sensing. 308-316, Copyright 2017, with permission from Elsevier. ${ }^{135}$ Abbreviation: FRET, fluorescence resonance energy transfer. 
span. ${ }^{117}$ The treatment of advanced cancer can only rely on drugs, ${ }^{118}$ chemotherapy ${ }^{119}$ or radiotherapy ${ }^{120}$ to kill other free tumour cells, but these methods cannot completely kill all tumour cells in vivo. In addition, advanced cancer easily metastasizes and spreads, leading to the invasion of tumour cells in other normal parts of the body, which makes it impossible to control the tumours simply by removing the original area. ${ }^{121}$ Therefore, the development of tumour cell probes for early cancer screening is vital, ${ }^{122}$ and CQDs have become candidates for probes of tumour cells due to their excellent fluorescence properties and high sensitivity.

Because they are fluorescent, CQDs become excited after receiving electromagnetic radiation, thus emitting the same or different emission spectrum as the excitation spectrum and showing fluorescence. ${ }^{123}$ Due to this characteristic, CQDs have been widely used in fluorescence imaging and sensing. ${ }^{124-126}$ When two fluorescent groups meet, if the emission spectrum of one fluorescent group is consistent with the excitation spectrum of the other, the fluorescence signal of the former weakens or even disappears, which is called fluorescence resonance energy transfer (FRET). ${ }^{127}$ The conditions for effective FRET between the donor and the acceptor are specific. ${ }^{128}$ First, the emission spectrum of the donor and the absorption spectrum of the acceptor must overlap. $^{129}$ Second, FRET requires that the donor and the energy acceptor be close enough, generally 7-10 nm apart, and the FRET decreases significantly with distance. ${ }^{130}$ Finally, the fluorescent chromophores of the donor and the acceptor must be arranged correctly. ${ }^{131}$ Due to this principle, many researchers have combined FRET with CQDs for biological analysis. ${ }^{132-134}$ Using CQDs as donors and AuNPs as acceptors, Somayeh et al assembled a FRET-based sensor that could detect CA125 on the surface of ovarian cancer cells. Due to the $-\mathrm{NH}_{2}$ groups, anti-CA125 could be modified on the surface of AuNPs. ${ }^{135}$ The sandwich structure of the AuNPs-CA125-CDs could be formed when the CA125-trapped AuNPs met the DNA-coated CQDs, which promoted the occurrence of FRET and led to the fluorescence quenching of the CQDs. As shown in Figure 7A, by -S- wrapping PAMAM-Dendrimer with $\mathrm{NH}_{2}$ on the surface of AuNPs, the $-\mathrm{NH}_{2}$ on the surface of AuNPs could be amplified, which made the fluorescence quenching signal of CQDs more intense, thus greatly improving the sensitivity of the device to CA125. Moreover, the UVVis absorption spectrum showed that the absorbance of AuNPs-PAMAM/Ab was higher than that of AuNPs-Ab at any wavelength, which implied that the adjunction of PAMAM-Dendrimer could significantly enhance the fluorescence quenching signal (Figure 7B).

In recent years, as a combination of chemiluminescence and electrochemical methods, electrochemiluminescence (ECL) has attracted great interest due to its high sensitivity and selectivity. ${ }^{136}$ ECL is an electricity generation phenomenon in which certain substances are generated by electrochemical methods, and then these substances or biomass and other substances react further. ${ }^{137}$ It retains the advantages of chemiluminescence methods, such as high sensitivity, wide linear range and convenient observation, and has many incomparable advantages, including good reproducibility, easy control and partial repeatability. ${ }^{138}$ ECL not only greatly promotes biochemistry and molecular biology research but

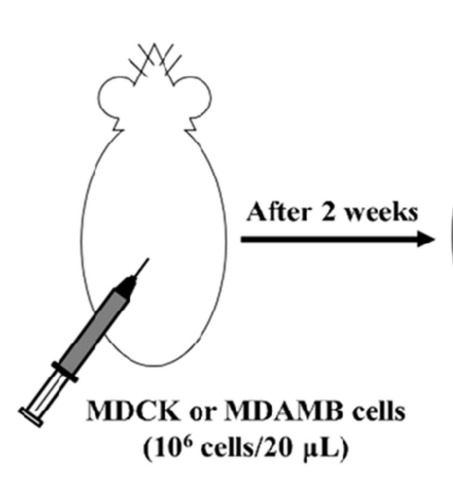

$\left(10^{6}\right.$ cells $\left./ 20 \mu \mathrm{L}\right)$
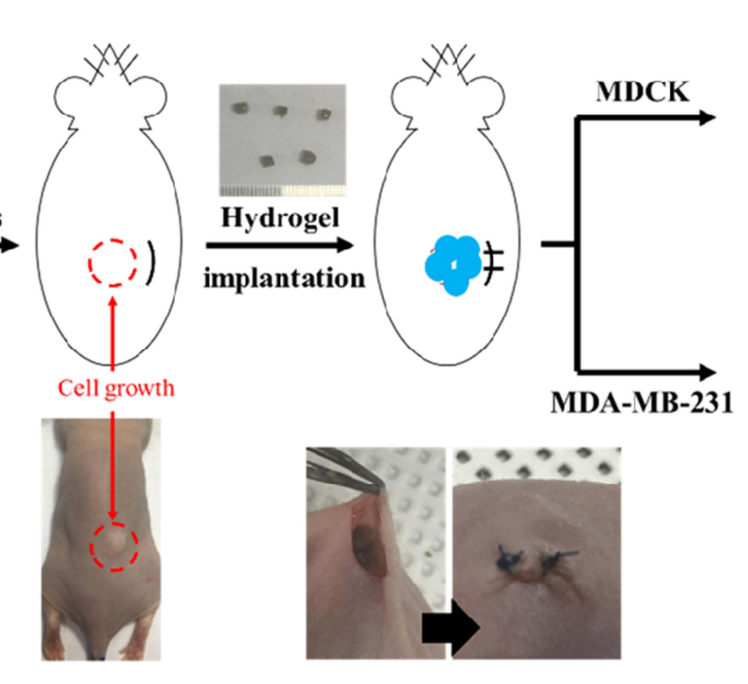

Figure 8 Photographic images of Gel-UPy/dsCQD hydrogel under normal and tumour environment. Reprinted with permission from Won HJ, Ryplida B, Kim SG, et al. Diselenide-bridged 1710 carbon-dot-mediated self-healing, conductive, and adhesive wirelesshydrogel sensors for label-free breast cancer detection. ACS Nano. 2020; 4 (7):8409-8420. Copyright (2020) American Chemical Society. ${ }^{145}$ 
also brings a technological revolution in clinical diagnosis, in which ECL probes play an important role. ${ }^{139}$ Although CQDs have been developed as ECL probes, ${ }^{140,141}$ they are not widely used because of their low ECL yield. Therefore, the modification of CQDs to amplify the ECL signal is conducive to the application of ECL technology in biological analysis. Qiu et al designed an ECL system by combining CQDs with magnetic beads. ${ }^{142}$ MCF-7 cells and MDA-MB -231 cells were captured on an ITO electrode by folic acid, and then HA-solid-state ZnCQDs could bind to CD44 on the surface of tumour cells through HA, resulting in an enhanced ECL effect. It can be utilized for monitoring tumour cells and evaluating the heterogeneity of CD44 expression, which is conducive to the early diagnosis and screening of breast cancer. Moreover, the greater amounts of $\mathrm{H}_{2} \mathrm{O}_{2}$ secreted by tumour cells can be used in active metabolism to induce stronger ECL emission from NHCDs combined with $\mathrm{Au}$ NPs, which provides another method of cancer monitoring. ${ }^{143}$ Nevertheless, without electrode plates, DNA or RNAs as aptamers that can identify HER2 on the surface of MCF-7 cells are applied to amplify the ECL signal through CQDs or synergistic metal-organic frameworks. ${ }^{144}$

In addition to FRET and ECL, CQDs can also be utilized to monitor the tumour environment by structural modification, spatial conformation or properties. Won et al combined gelatine and ureidopyriminone (Upy) into hydrogels (GelUPy) by performing isocyanate-amine group reactions, followed by mixing CQDs into the Gel-UPy to prepare a self-

Table 2 A Summary of Applications for Antitumour CQDs in Diagnosis

\begin{tabular}{|c|c|c|c|c|}
\hline Theory & Raw Materials & Model & Function & Reference \\
\hline FRET & $\begin{array}{l}\text { Citric acid, } \\
\text { ethylenediamine }\end{array}$ & MCF-7 cells & Diagnosis of breast cancer & {$[148]$} \\
\hline FRET & Carbon powders & OVCAR3 cells & Monitor the presence of tumour cells & {$[149]$} \\
\hline FRET & $\begin{array}{l}\text { Citric acid, } \\
\text { ethylenediamine }\end{array}$ & MCF-7 and HeLa cells & Diagnose as well as killing of tumour cells & {$[150]$} \\
\hline FRET & Glucose, PAAS & HeLa/HepG2 cells & $\begin{array}{l}\text { Determining prognosis of cancer and } \\
\text { investigation of cancer metastasis }\end{array}$ & {$[151]$} \\
\hline ECL & Zinc acetate, PEI & $\begin{array}{l}\text { MCF-7 and MDA-MB } \\
-231\end{array}$ & Monitor the presence of tumour cells & {$[142]$} \\
\hline $\mathrm{ECL}$ & Citric acid, DMF & Hela and MCF-7 cells & Monitor the presence of tumour cells & {$[143]$} \\
\hline $\mathrm{ECL}$ & - & MCF-7 cells & $\begin{array}{l}\text { Diagnosis of HER2 and HER2-overexpressed } \\
\text { living tumour cells }\end{array}$ & {$[144]$} \\
\hline $\mathrm{ECL}$ & $\begin{array}{l}\text { Candle soot, } \\
\text { nitric acid }\end{array}$ & Hela and MCF-7 cells & $\begin{array}{l}\text { Highly sensitive and selective tumor cells } \\
\text { detection, DNA and protein analysis }\end{array}$ & {$[152]$} \\
\hline $\begin{array}{l}\text { Coagulation and dissolution } \\
\text { of hydrogels }\end{array}$ & $\begin{array}{l}\text { DOPA-Br, } \\
\text { selenium ions }\end{array}$ & MDA-MB-23I cells & Breast cancer detection & {$[145]$} \\
\hline $\begin{array}{l}\text { Character dependent } \\
\text { fluorescence properties }\end{array}$ & $\begin{array}{l}\text { Citric acid, } \\
\text { ethylenediamine }\end{array}$ & - & Diagnosis of early lung cancer & {$[146]$} \\
\hline Detect GSH & $\begin{array}{l}\mathrm{GSH}, \mathrm{HAuCl}_{4} \text {, } \\
\text { glucose }\end{array}$ & HIBEpiC cells & Monitor the presence of tumour cells & {$[153]$} \\
\hline Targeting C6 glioma cells & $\begin{array}{l}\text { D-glucose, } \\
\text { L-aspartic acid }\end{array}$ & C6 glioma cells & $\begin{array}{l}\text { Diagnostic, targeting and therapeutic of brain } \\
\text { cancer cells }\end{array}$ & {$[154]$} \\
\hline $\begin{array}{l}\text { Change of emission } \\
\text { wavelength }\end{array}$ & Alizarin carmine & SMMC-772I cells & $\begin{array}{l}\text { Distinguish between tumour cells and normal } \\
\text { cells }\end{array}$ & {$[147]$} \\
\hline $\begin{array}{l}\text { Detect Carcinoembryonic } \\
\text { antigen }\end{array}$ & Citric acid, urea & $\begin{array}{l}\text { Liver cancer mice beared } \\
\text { HepG } 2 \text { cells }\end{array}$ & Detect tumour cells and drug delivery & {$[155]$} \\
\hline
\end{tabular}

Abbreviations: PAAS, poly(acrylate sodium); PEI, polyethylenimine; DMF, N, N-Dimethylformamidenot estimable; DOPA, dihydroxyphenylalanine; GSH, glutathione. 
healing Gel-UPy/dsCD hydrogel. ${ }^{145}$ The self-healing properties of the Gel-UPy/dsCD hydrogel depended on GSH and $\mathrm{H}_{2} \mathrm{O}_{2}$, which are produced by tumour cells rather than normal cells. As shown in Figure 8, after planting 5 pieces of GelUPy/dsCQD hydrogel into the cell inoculation site of mice, one hour later, the Gel-UPy/dsCQD hydrogel of the MDCK group was still a single slice, while the MDA-MB-231 group converged into a whole gel structure. This result indicates that the Gel-UPy/dsCQD hydrogel can self-heal at the tumour site but not in normal cells, so it can be used to monitor tumour cells through its self-healing function. In addition, Kalytchuk et al prepared CQDs with ICPA (a molecular fluorophore from the family of pyridines) on the surface, which caused fluorescence quenching when the CQDs were cooled to a solid and returned to the liquid state when heated, recovering their fluorescence. ${ }^{146}$ However, when the CQDs were in a cool solid-state, the addition of alcohol prevented fluorescence quenching. Therefore, they can be used to measure alcohol, which is conducive to the early diagnosis of lung cancer. In addition, CQDs can monitor tumours by using the fluorescence change of CQDs as the detection signal. Li et al fabricated CQDs that could produce $430 \mathrm{~nm}$ and $642 \mathrm{~nm}$ emission under $360 \mathrm{~nm}$ laser irradiation. ${ }^{147}$ When they encountered GSH, they only produced $430 \mathrm{~nm}$ excitation light, which made their fluorescence change from blue green to dark blue. The GSH content in tumour sites is much greater than that in normal tissues, so we can distinguish tumour cells from normal cells by the change in fluorescence colour of CQDs.

In contrast to normal cells, tumour cells have a unique acidic environment, tumour markers and related genes; these factors can be considered in the design of new treatments. Table 2 summarizes the application of CQDs for monitoring tumours or antitumour drugs in related research. At present, the optical properties of CQDs are mostly used in tumour monitoring research, in which FRET and ECL are the most widely used, while other properties are rarely involved. However, whether the other properties of CQDs, such as changes in surface functional groups, size and properties, could be utilized to monitor tumours remains to be explored in the future. In addition to the early diagnosis of tumours and the release of antitumour drugs, monitoring the heterogeneity, mutation, metastasis and recurrence of tumours is a possible application of CQD probes.

\section{Drug Delivery}

Traditional antitumour drugs have low bioavailability due to their nontargeting and metabolic dynamics, and they can damage normal cells. ${ }^{156}$ Therefore, it is urgent to improve the bioavailability of antitumour drugs. The natural, ultrasmall structure endows the CQDs with EPR, which actively causes them to gather in the tumour site. ${ }^{157}$ Using CQDs as carriers to deliver antitumour drugs to the body not only solves the drug targeting problem but also increases the time of drug aggregation in the tumour site. ${ }^{158}$

Doxorubicin (DOX), as a broad-spectrum antitumour drug, can inhibit the synthesis of RNA and DNA, inducing the death of tumour cells in various growth cycles. ${ }^{159-161}$ DOX can restrain DNA superhelix topoisomerase II by embedding and inhibiting the interaction between polymer biosynthesis and DNA, thus destroying the replication of the DNA strand. ${ }^{162,163}$ It can also act on chromatin with transcriptional activity, which leads to histone changes. In the clinic, DOX has been widely used in the treatment of various diseases, including breast cancer, ${ }^{164}$ lung cancer, ${ }^{165}$ ovarian cancer, ${ }^{166}$ leukaemia, ${ }^{167}$ and gastric cancer. ${ }^{168}$ Therefore, loading CQDs with DOX and incorporating them into the body for tumour treatment has become possible. Nitrogenand phosphorus-doped CQDs (PNHCDs) loaded with DOX were prepared by spontaneously heating glucose to boiling without additional heating operation. ${ }^{169}$ The tumour volume of tumour-bearing mice treated with PNHCDs-DOX was larger than that of tumour-bearing mice treated with free DOX. Moreover, the weight of tumour-bearing mice treated with free DOX gradually decreased, while that of the mice treated with PNHCDs-DOX showed an upward trend, which indicated that PNHCDs-DOX could not only inhibit tumour growth but also improve the tumour targeting of DOX, exhibiting the advantage of the EPR of CQDs. In addition, compared to free DOX, DOX-loaded and transferrin-modified C-Dot-Trans-Dox showed better therapeutic effects for brain cancer. ${ }^{170}$ Since both tumour cells and the blood brain barrier (BBB) have transferrin receptors, it is possible for C-DotTrans-Dox to cross the BBB and gather in brain tumour sites, which is promising for the treatment of brain tumourrelated diseases in the future. Moreover, due to the nitrogen functional groups on the surface of the CSCNP-R-CQDs, they could enter not only the tumour cell nucleus but also the cancer stem cell nucleus, which provides new possibilities for tumour eradication. ${ }^{171}$ As a pH-sensitive drug, DOX is more soluble under acidic conditions than under neutral conditions. Tumour tissues and cells can provide an appropriate $\mathrm{pH}$ environment for DOX release, which also leads to the tumour targeting of DOX. With the rapid development of CQDs technology, researchers are committed to combining it with other chemical compounds, biomaterials and even technology to play 


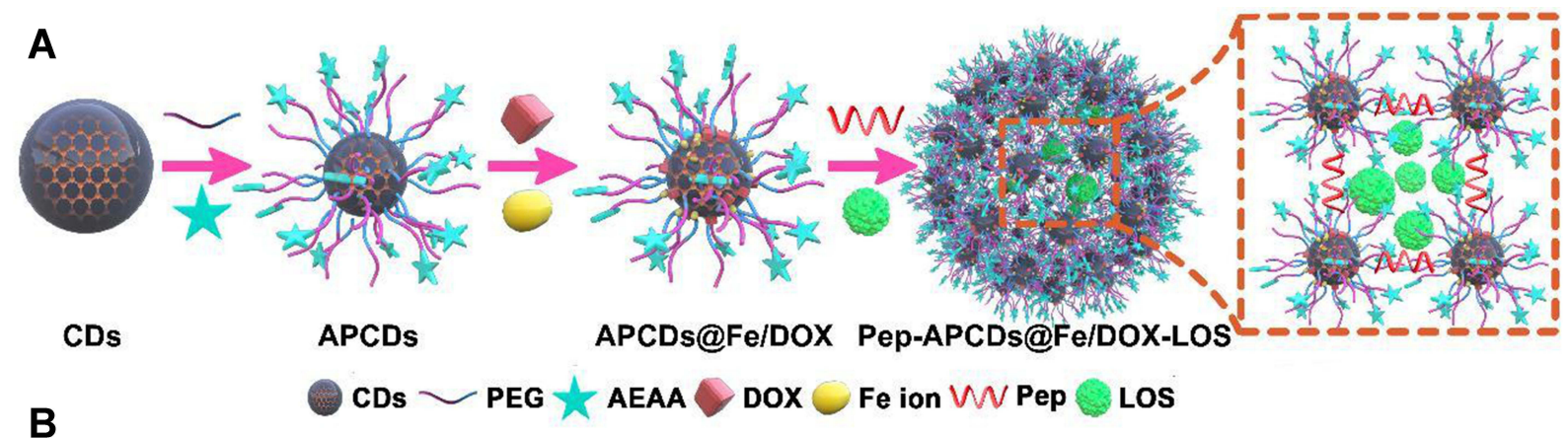

\section{Stroma-rich tumor}
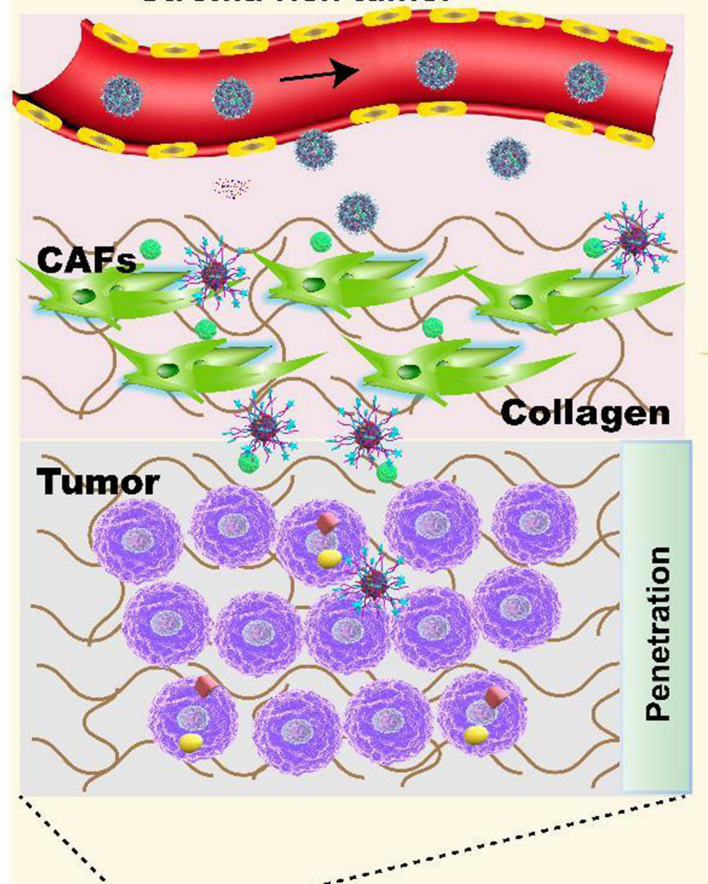
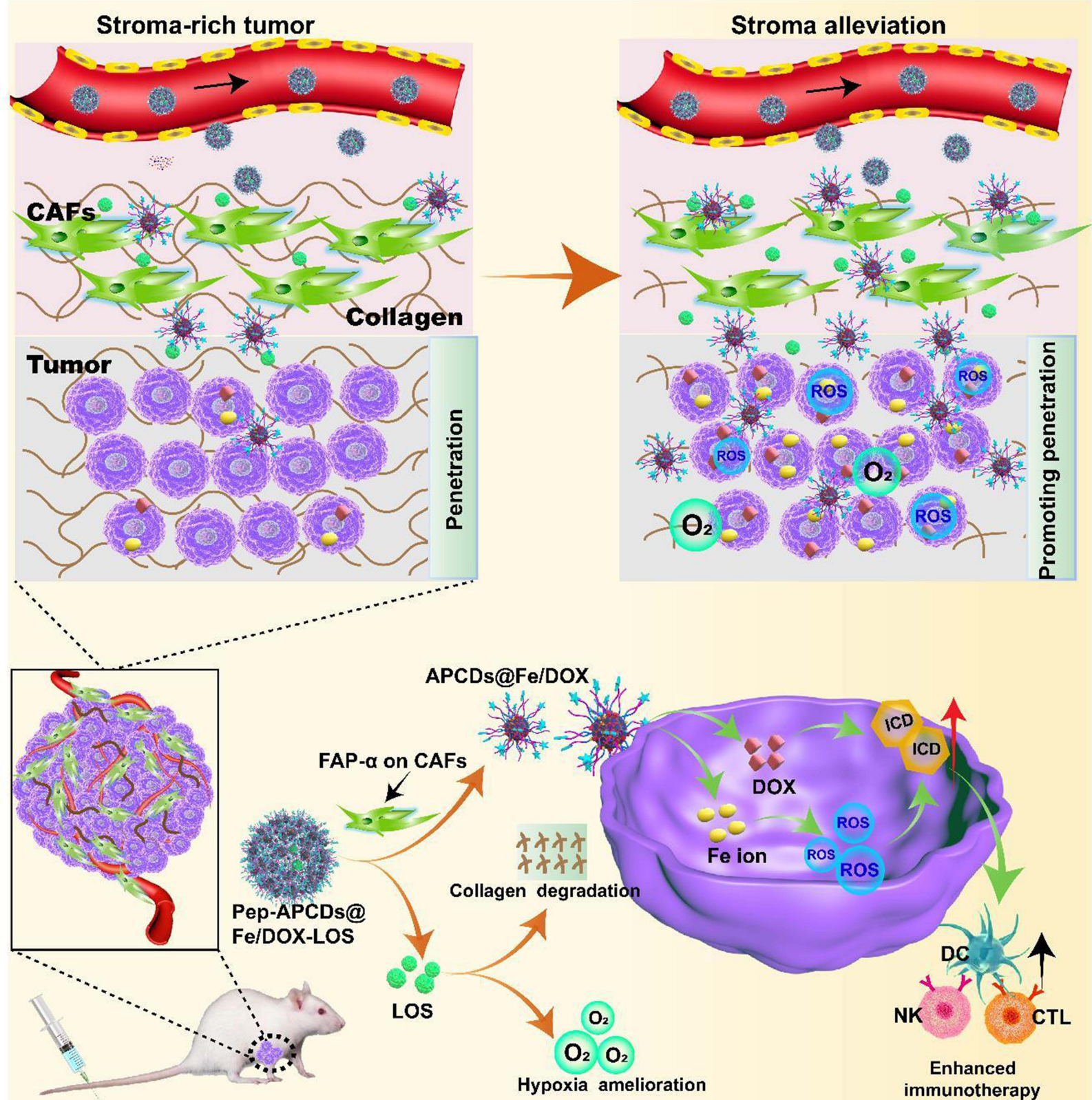

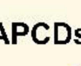

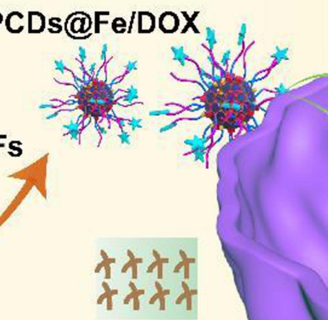

Collagen degradation
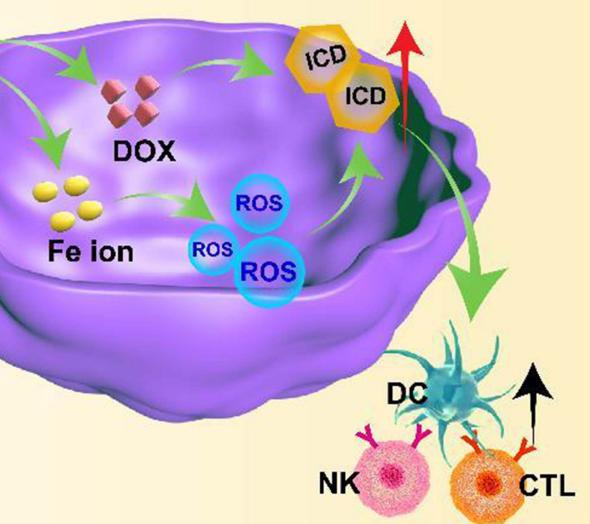

$\mathrm{O}_{2} \mathrm{O}_{2}$

Hypoxia amelioration

Enhanced immunotherapy

Figure 9 The $(\mathbf{A})$ formation process and (B) mechanism of Pep-APCDs@Fe/DOX-LOS. Reprinted from Hou L, Chen D, Wang R, et al. Transformable honeycomb-like nanoassemblies of carbon dots for regulated multisite delivery and enhanced antitumor chemoimmunotherapy. Angew Chem Int Ed Engl. 202I;60(I2):658I-6592. (C) 2020 Wiley-VCH GmbH. ${ }^{172}$

Abbreviations: PEG, polyethylene glycol; AEAA, aminoethyl anisamide; Pep, peptides; LOS, losartan; CAFs, cancer-associated fibroblasts. 
enhanced antitumour roles. Hou et al modified aminoethyl anisamide (AEAA) onto CQDs loaded with DOX and $\mathrm{Fe}$ ions to form APCDs@Fe/DOX. Then, APCDs@Fe/DOX were connected with each other by Asp-Ala-thl-gly-pro-Ala peptides (Pep) to form losartan (Los) wrapped in a mesoporous structure, thus finally forming Pep-APCDs @Fe/DOX-LOS. ${ }^{172}$ Pep was sensitive to the fibroblastactivating protein- $\alpha$ (FAP- $\alpha$ ), while FAP- $\alpha$ was overexpressed in cancer-associated fibroblasts (CAFs). When Pep-APCDs @Fe/DOX-LOS flowed through the CAFs, Pep was degraded, while APCDs@Fe/DOX and Los were released. Los, as a modifier of the tumour microenvironment, could deplete the tumour matrix. Along with Fe ions and DOX, Los had the ability to accelerate the infiltration of T cells and NK cells, promote the release of proinflammatory cytokines, and downregulate the recruitment of immunosuppressive cells (Figure 9). Kang et al coated silicon dioxide on the surface of a nanotube template and increased the temperature, forming CQDs on the surface of silicon dioxide. ${ }^{173}$ The template simultaneously dissolved to form a hollow structure (C-hMOS), and then the C-hMOS was filled with DOX by soaking. Moreover, after heat treatment, the DOX-delivering C-hMOS showed more significant fluorescence intensity, which endowed them with the ability to observe the distribution of DOX in vivo. In addition, Türk et al fabricated pH-sensitive hydrogels by self-crosslinking hydroxyapatite, NCQDs and DOX through Schiff bases, hydrogen bonds and ion interactions for the first time. ${ }^{174}$ After reaching the tumour site, the Schiff base broke away and DOX was released.

Similar to other platinum drugs, oxaliplatin (II) has an antitumour mechanism that targets DNA, and platinum atoms cross-bind with DNA to prevent its replication and transcription. ${ }^{175-177}$ Nevertheless, due to drug resistance and side effects, it is possible to use Pt(IV) complexes instead of oxaliplatin (II). ${ }^{178} \mathrm{Pt}(\mathrm{IV})$ complexes are prodrugs of oxaliplatin(II) that can be transformed into oxaliplatin(II) by a reduction reaction, and tumour cells can provide an inherent reducing environment. Based on this principle, CQDs were prepared by modified thermal pyrolysis with citric acid as the carbon source and polyene polyamine as the passivator, following which a $\mathrm{Pt}(\mathrm{IV})$ complex (oxa(IV)-COOH) was combined with CQDs to form CD-Oxa by dehydration condensation between the amino carboxyl groups. ${ }^{178}$ Under excitation light at 405 $\mathrm{nm}, 488 \mathrm{~nm}$ and $555 \mathrm{~nm}$, CD-Oxa could produce bright polychromatic fluorescence, which was conducive to its effective monitoring of tumour cells (Figure 10A-E). Moreover, with increasing drug concentration, the viability
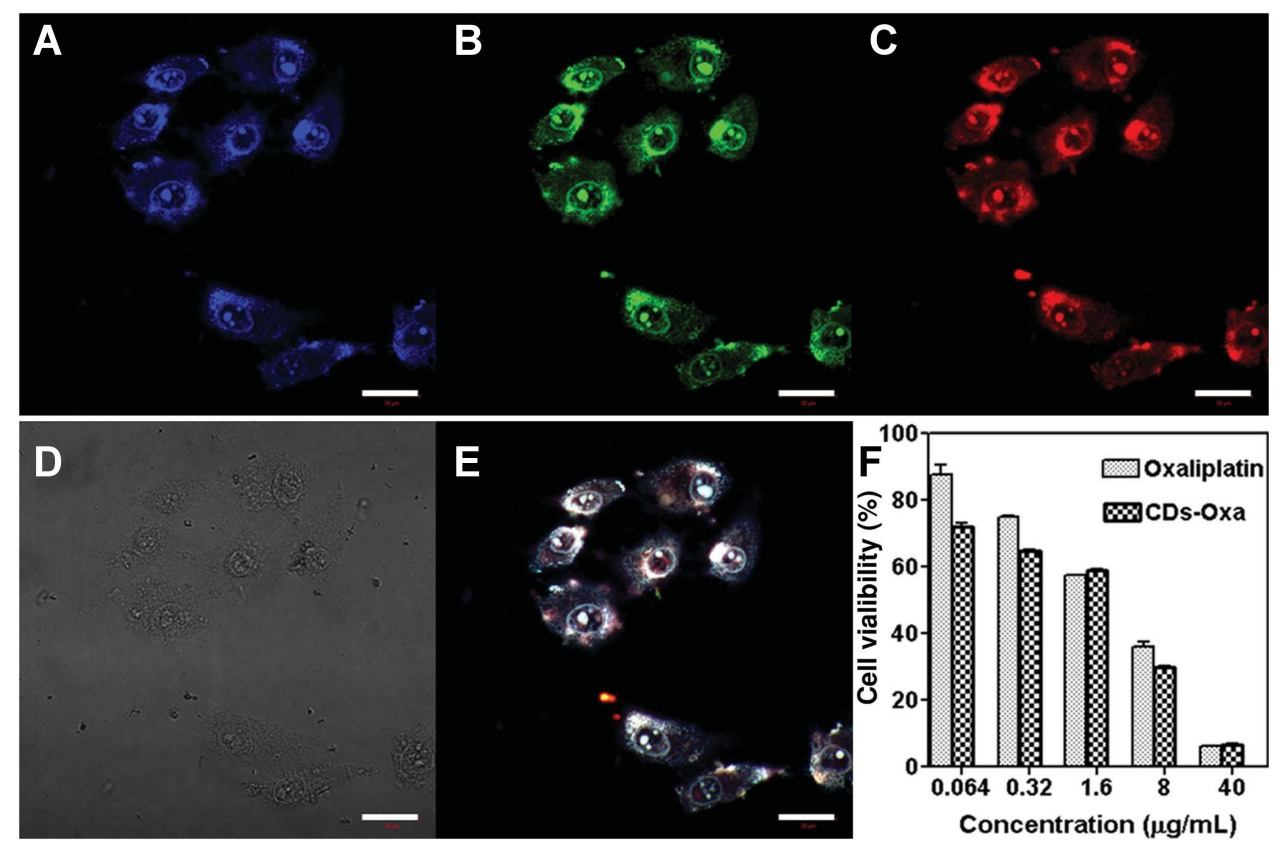

Figure 10 Confocal fluorescence images of HeLa cells treated with CD-Oxa under (A) $405 \mathrm{~nm},($ B) $488 \mathrm{~nm},(\mathbf{C}) 555 \mathrm{~nm}$, (D) bright field and (E) overlay. (F) Cell viability of HepG2 cells treated with oxaliplatin (II) or CD-Oxa. Reprinted from Zheng M, Liu S, Li J, et al. Integrating oxaliplatin with highly luminescent carbon dots: an unprecedented theranostic agent for personalized medicine. Adv Mater. 2014;26(2I):3554-3560. @ 2020 Wiley-VCH GmbH. ${ }^{178}$ Abbreviation: Oxa, oxaliplatin. 


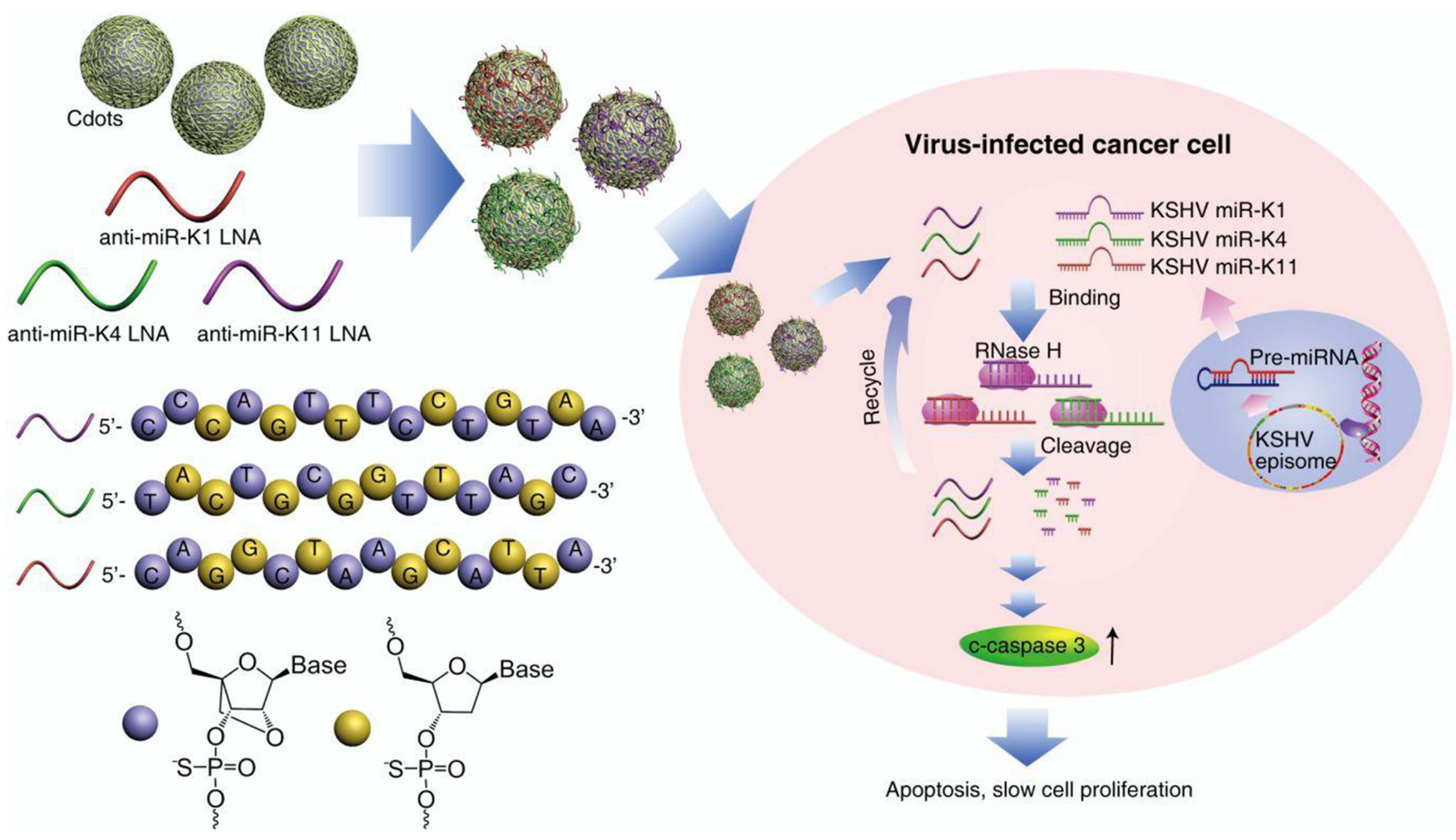

Figure I I The schematic diagram of Cdots/LNA inducing apoptosis and slowing down proliferation. Reprinted with permission from Ju E, Li T, Liu Z, et al. Specific inhibition of viral MicroRNAs bycarbon dots-mediated delivery of locked nucleic acids for therapyof virus-induced cancer. ACS Nano. 2020;14(I):476-487.Copyright (2020) American Chemical Society. ${ }^{187}$

Abbreviations: LNA, locked nucleic acid; KSHV, Kaposi's sarcoma-associated herpesvirus.

of HepG2 human tumour cells decreased gradually, and the decrease in the CD-Oxa group was greater than that of the free oxaliplatin group, which indicated that the curative effect of CD-Oxa was better than that of free oxaliplatin (Figure 10F). In addition, Feng et al mounted PEG(PAH/DMMA) on the surface of CQDs containing Pt(IV) (CDs-Pt(IV)). Among them, PEG-(PAH/DMMA) was equivalent to a "cap", which was not hydrolysed under normal conditions but hydrolyzed under the acidic conditions of tumour tissues, causing CDs-Pt(IV) to enter the cells. Finally, the $\mathrm{Pt}(\mathrm{IV})$ prodrug was reduced to oxaliplatin(II), which binds to the nucleic acid of tumour cells. ${ }^{179}$ Similarly, PEG-RGD was modified on CDs-Pt (IV), in which PEG and RGD were linked by benzoimide bonds. ${ }^{180}$ RGD could target the RGD receptor on the surface of tumour cells, but the RGD receptor was not specific to tumour cells. Therefore, PEG was designed to block RGD on the surface of CDs-Pt(IV). When CDsRGD-Pt(IV)-PEG reached the tumour cells, the benzoimide bond was hydrolysed under acidic conditions to expose RGD to achieve the targeting of tumour cells.
Gene therapy refers to the transfer of exogenous "repair genes" into target cells to treat related diseases at the gene level. ${ }^{181-183}$ The free gene is easily degraded by lysosomes after entering the cells, so it needs to be protected by the vector and then sent to the target cells to solve the problem. ${ }^{184}$ Although single CQDs do not have the ability to carry genes, if gene carrying substances are modified on their surface, they can carry genes into target cells for gene therapy. ${ }^{185,186}$ Three kinds of LNA-based oligonucleotides (anti-miR-K1, anti-miR-K4, and anti-miR-K11) were loaded onto CQDs by PEI modification. ${ }^{187}$ As shown in Figure 11, after entering lymphoma cells, Cdots/LNA could knock down miR-K1, miR-K4 and miR-K11 of Kaposi's sarcoma virus (KSHV), thus leading to apoptosis and growth inhibition of KSHV-positive primary active lymphoma cells through the caspase-3 pathway. Moreover, a novel DNA self-assembly nanostructure based on nitrogen-doped CQDs known as NPNCD was reported. ${ }^{188}$ The conjugation of NPNCD with KRAS siRNA showed a superior gene knockdown effect, which provided inspiration for the clinical treatment of nonsmall-cell lung cancer.

In addition to DOX, oxaliplatin and "therapeutic" genes, other forms of antitumour drugs have also been widely 
Table 3 A Summary of Applications for Antitumour CQDs in Drug Delivery

\begin{tabular}{|c|c|c|c|c|c|}
\hline Drug & Raw Materials & Model & Administration & Function & Reference \\
\hline DOX & Glucose, EDA, $\mathrm{H}_{3} \mathrm{PO}_{4}$ & $\begin{array}{l}\text { Hepatoma mice beared } \\
\text { HepG }_{2} \text { cells }\end{array}$ & I.V. & $\begin{array}{l}\text { Nuclear targeting of } \\
\text { tumor cells }\end{array}$ & [169] \\
\hline DOX & Carbon nanopowder & SJGBM2 cells & - & Cross the BBB & {$[170]$} \\
\hline DOX & $\begin{array}{l}\text { 4-amino-Phenol, potassium } \\
\text { periodate }\end{array}$ & $\begin{array}{l}\text { Cervical carcinoma mice } \\
\text { beared Hela cells }\end{array}$ & I.V. & $\begin{array}{l}\text { Enter the cancer stem } \\
\text { cell nucleus }\end{array}$ & {$[|7|]$} \\
\hline DOX & Tyrosine-derived melanin & $\begin{array}{l}\text { Breast cancer mice beared } \\
4 \mathrm{TI} \text { cells }\end{array}$ & I.V. & $\begin{array}{l}\text { Synergetic Fenton } \\
\text { reaction and } \\
\text { immunotherapy }\end{array}$ & {$[172]$} \\
\hline DOX & $\mathrm{SiO}_{2}$ & $\begin{array}{l}\text { Breast cancer mice beared } \\
\text { MCF-7 cells }\end{array}$ & I.T. & $\begin{array}{l}\mathrm{pH} \text { response of } \mathrm{DOX} \\
\text { release }\end{array}$ & {$[173]$} \\
\hline DOX & $\begin{array}{l}\text { I,4,5,8-tetraminoanthraquinone, } \\
\text { citric acid }\end{array}$ & $\begin{array}{l}\text { Brain glioma mice beared } \\
\text { U87 cells, cervical carcinoma } \\
\text { mice beared Hela cells }\end{array}$ & I.V. & $\begin{array}{l}\text { Mimicking large amino } \\
\text { acids, cross the BBB }\end{array}$ & [189] \\
\hline DOX & PEI, $\mathrm{H}_{2} \mathrm{O}_{2}$, anhydrous ethanol & A549 cells & - & $\begin{array}{l}\text { Deliver nucleic acid and } \\
\text { hydrophobic drug cargos }\end{array}$ & [193] \\
\hline DOX & Graphite, sugarcane waste & Hela cells & - & $\begin{array}{l}\text { Synergetic mesoporous } \\
\text { silica nanoparticles }\end{array}$ & [194] \\
\hline DOX & Glycerol, PEI & $\begin{array}{l}\text { Liver cancer mice beared } \\
\text { MHCC-97L cells }\end{array}$ & I.V. & $\begin{array}{l}\text { Treatment synergetic } \\
\text { monitoring }\end{array}$ & [195] \\
\hline DOX & Gelatin & MDA-MB-23I cells & - & $\begin{array}{l}\text { Through mitochondria } \\
\text { enhanced apoptosis and } \\
\text { autophagy pathway }\end{array}$ & [196] \\
\hline DOX & Citric acid & MCF-7 cells & - & $\begin{array}{l}\text { Overcoming drug } \\
\text { resistance }\end{array}$ & [197] \\
\hline DOX & Glucose, PEG & $\begin{array}{l}\text { Breast cancer mice beared } \\
4 \mathrm{TI} \text { cells }\end{array}$ & I.V. & $\begin{array}{l}\text { Encapsulated into } \\
\text { nanoparticles, } \\
\text { detachable at tumor site. }\end{array}$ & {$[198]$} \\
\hline $\operatorname{Pt}(\mathrm{IV})$ & Citric acid, polyene polyamine & $\begin{array}{l}\text { Hepatoma mice beared } \mathrm{H} 22 \\
\text { cells }\end{array}$ & I.T. & Multicolor imaging & [178] \\
\hline $\operatorname{Pt}(\mathrm{IV})$ & Citric acid, diethylenetriamine & $\begin{array}{l}\text { Cervical carcinoma mice } \\
\text { beared UI4 cells }\end{array}$ & I.V. & $\begin{array}{l}\text { PEG controlled drug } \\
\text { release }\end{array}$ & [179] \\
\hline $\begin{array}{l}\text { Epirubicin and } \\
\text { temozolomide }\end{array}$ & Carbon nano powders & U87 cells & - & $\begin{array}{l}\text { Epirubicin, temozolomi } \\
\text { and transferrin triple } \\
\text { conjugated }\end{array}$ & [199] \\
\hline LNA & PEl, citric acid & $\begin{array}{l}\text { Primary active lymphoma } \\
\text { mice beared BCBLI-Luc cells }\end{array}$ & I.P. & $\begin{array}{l}\text { Inhibiting irus-induced } \\
\text { cancer }\end{array}$ & [187] \\
\hline siRNA & EDTA, citric acid & KRAS-mutated NSCLC cells & - & $\begin{array}{l}\text { Induced DNA } \\
\text { polymerization }\end{array}$ & {$[188]$} \\
\hline TAAs & Mannose, EDTA, phosphoric acid & $\begin{array}{l}\text { Hepatoma mice beared } \\
\text { HepaI-6 cells }\end{array}$ & I.T. & $\begin{array}{l}\text { Synergetic } \\
\text { immunotherapy, } \\
\text { amplifying microwave } \\
\text { ablation }\end{array}$ & [190] \\
\hline
\end{tabular}

(Continued) 
Table 3 (Continued).

\begin{tabular}{|c|c|c|c|c|c|}
\hline Drug & Raw Materials & Model & Administration & Function & Reference \\
\hline $\mathrm{AgNPs}$ & Lemon slices & MCF 7 cells & - & $\begin{array}{l}\text { Producing ROS for } \\
\text { killing tumor cells }\end{array}$ & {$[191]$} \\
\hline Amygdalin & Golden acid & Hep3B cells & - & $\begin{array}{l}\text { Natural targeting tumor } \\
\text { cells }\end{array}$ & {$[192]$} \\
\hline Dextran & Acrylic acid and ethylenediamine & SKOV3 cells & - & $\begin{array}{l}\text { Synergistic nanogels } \\
\text { release drug in } \\
\text { controlled manner }\end{array}$ & [200] \\
\hline
\end{tabular}

Abbreviations: EDA, I,2-ethylenediamine; PEI, polyethylenimine; PEG, polyethylene glycol; EDTA, ethylenediamine tetraacetic acid; TAAs, tumor-associated antigens; ROS, reactive oxygen species.

researched. Large neutral amino acid transporter 1 (LAT1) is highly expressed in various tumour cells but is rarely expressed in normal cells. LAT1 transports amino acids into tumour cells by binding with amino and carboxyl groups on the surface of amino acids. Li et al utilized 1,4,5,8-tetraminoanthraquinone (TAAQ) and citric acid as raw materials to prepare CQDs based on simulated large amino acids (LAAM TC-CQDs). ${ }^{189}$ There were many paired amino and carboxyl groups on the surface of the LAAM TC-CQDs, which made the tumour cells mistakenly believe that they were amino acids; thus, the drug-loaded LAAM TC-CQDs could be transported into tumour cells through LAT1. It is exciting that LAT1 is expressed not only in tumour cells but also in the $\mathrm{BBB}$, which suggests that LAAM TC-CQDs can be utilized to treat brain cancer across the $\mathrm{BBB}$. In addition, microwave ablation (MWA) uses a special needle to puncture the lesion, transmits RF microwaves to the needle tip, generates a large quantity of heat at this position, and destroys the focus, thus treating the disease. Tumour cells killed by MWA can release tumour-associated antigens (TAAs). Some CQDs can capture TAAs, while some carbohydrate modifiers can target dendritic cells (DCs), and mannose-based CQDs (Man-CDs) combine the two. ${ }^{190}$ Man-CDSs can deliver captured TAAs to DCs, activate the immune system and amplify MWA, thus skillfully combining drug delivery with immunotherapy. Silver nanoparticles are natural nanodrugs that kill tumour cells. Ghosal et al utilized fresh lemon slices as raw materials to prepare green CQDs by a hydrothermal method and then added solid silver nitrate to CQDs aqueous solution to synthesize CQDs loaded with silver nanoparticles (CQD@AgNPs) in situ. ${ }^{191}$ CQD@AgNPs kill tumour cells by producing ROS without any other external roles. Amygdalin, a natural chemotherapeutic drug, is nontoxic, but when it is metabolized by $\beta$ glucosidase, it produces toxic hydrocyanic acid, which can be catalysed into nontoxic thiocyanate by thiocyanase. Kalaiyarasan et al used a gold acid as a raw material to prepare CQDs with many carboxylic acids on the surface and then functionalized them with almond protein by dehydration or esterification to form Amy@CQDs. ${ }^{192}$ Malignant cells contain more $\beta$-glucosidase than normal cells, while normal cells contain more thiocyanase than tumour cells, so Amy@CQDs can cleverly achieve selective killing of tumour cells after entering the body.

Table 3 summarizes the application of CQDs as drug carriers in antitumour research. To achieve good clinical antitumour effects, the selection of CQDs and drugs is very important. The choice of antitumour drugs can be made according to the different manifestations of drugs on normal tissues and tumour tissues. Tumour tissues have more acidic substances, $\mathrm{H}_{2} \mathrm{O}_{2}$, glutathione and tumour markers than normal tissues. If the antitumour drugs are nucleic acids, it is necessary to prepare CQDs with gene carrying materials such as PEI and chitosan or modify them on the surface of CQDs. Moreover, encapsulation of CQDs in macromolecules such as nanoparticles and hydrogels is also a possible strategy. In addition, CQDs can be reformed by doping, grafting and modification so that they can combine with antitumour drugs to target tumour sites to expand the therapeutic effect against cancer. In summary, the primary purpose of these methods is to improve the targeting of drug delivery and prolong the residence time of drugs in tumour sites, thus achieving better antitumour efficacy than that of free drugs.

\section{Monitoring the Release of Antitumour Drugs}

Antitumour drugs need to be released in time after reaching the tumour sites to exert antitumour effects, and CQDs can monitor their release in real time. P-CQDs were CQDs 
covered with PEI on the surface, which could emit blue fluorescence under the activation of the excitation signal under normal circumstances. ${ }^{201}$ When hyaluronic acidconjugated doxorubicin (HA-Dox) was coated on the surface of P-CQDs, the fluorescence of P-CQDs was quenched by FRET, in which P-CQDs and HA-Dox were the donor and the acceptor, respectively. When P-CQDs/HA-Dox reached and entered tumour cells, the HA on the surface of P-CQDs/ HA-Dox was degraded into small fragments by intracellular hyaluronidase; thus, DOX was released, and the P-CQDs were exposed. Additionally, the fluorescence recovery of P-CQDs could be used to monitor drug release. Similarly, under the effect of FRET, CQDs-Pt(IV) emitted blue, green and red fluorescence, but the blue fluorescence was limited

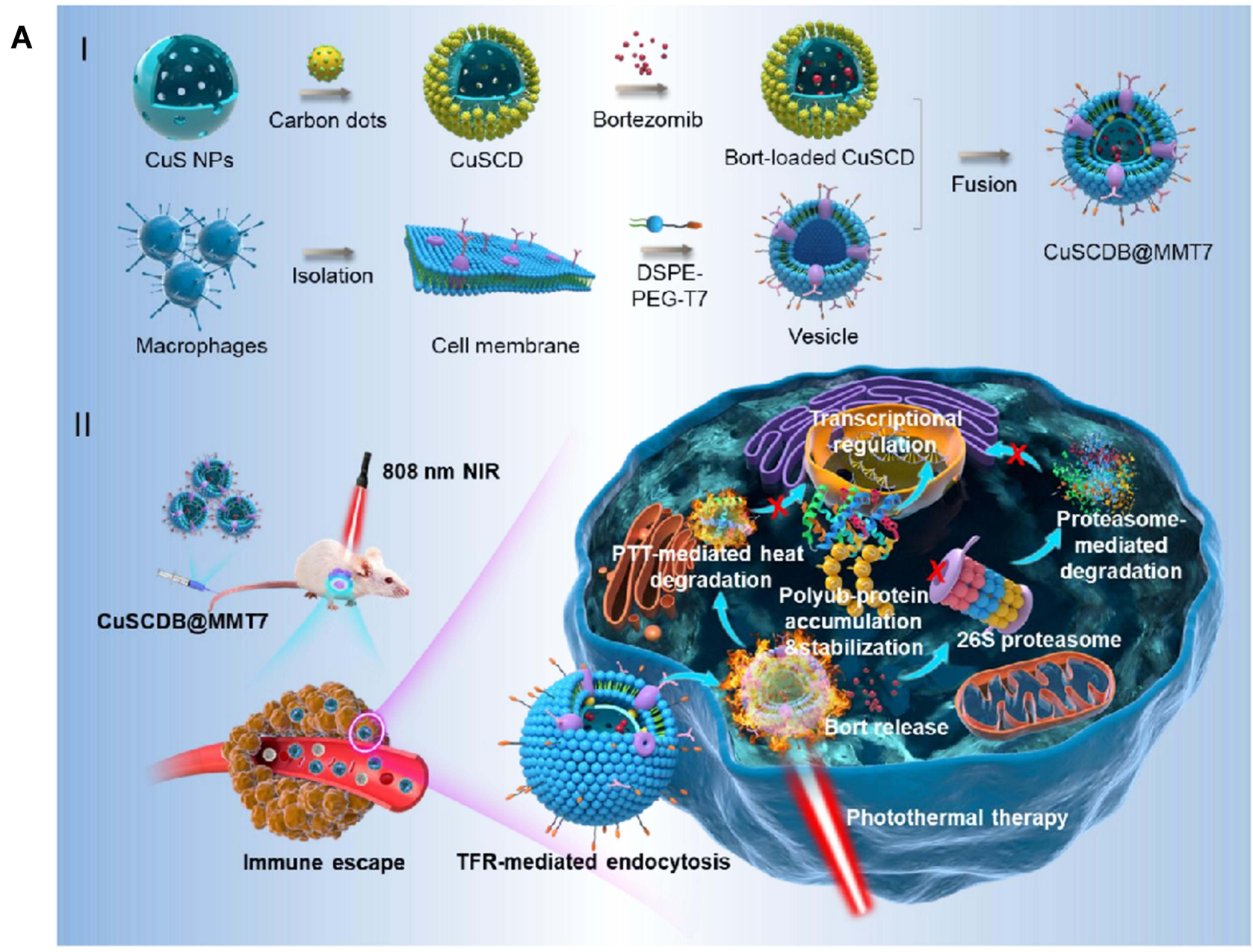

B

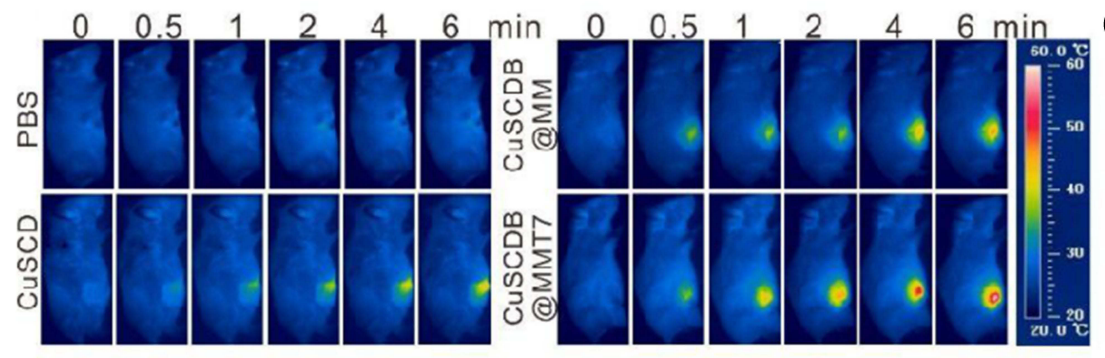

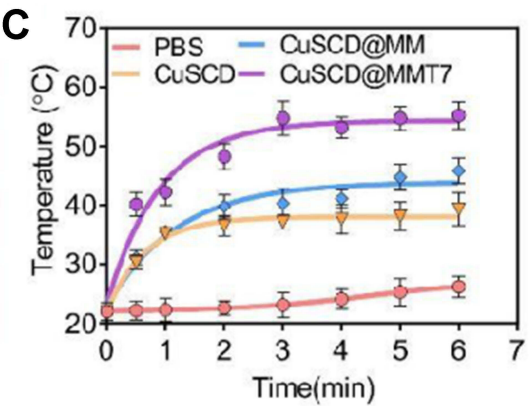

Figure 12 (A) Preparation and mechanism of CuSCD@MMT7, (B) thermography images and (C) temperature curves of breast cancer mice beared 4TI cells treated with PBS, CuSCD, CuSCDB and CuSCD@MMT7. Reprinted with permission from Yu Y, Song M, Chen C, et al. Bortezomib-encapsulated CuS/carbon dot nanocomposites for enhanced photothermal therapy via stabilization of polyubiquitinated substrates in the proteasomal degradation pathway. ACS Nano. 2020;14(8): I0688-I0703. Copyright (2020) American Chemical Society. ${ }^{215}$

Abbreviations: DSPE, distearoyl phosphoethanolamine; PEG, polyethylene glycol. 
by the quenching agent dabsyl. ${ }^{202}$ Under the condition of an intracellular reduction reaction, the three substances disintegrated and released $\mathrm{Pt}(\mathrm{IV})$, and the blue fluorescence of the CQDs was restored, which was used to monitor the activation of antitumour prodrugs in a complex biological microenvironment. Li et al encapsulated the CQDs and DOX into mesoporous silica nanoparticles to form DOX-CQDs /PNVCL@MSNs. ${ }^{203}$ PNVCL was folded on the surface of the DOX-CQD/PNVCL@MSNs by hydrophobic phase transition, which blocked the orifices and hindered DOX release and concealed the fluorescence of the CQDs. Due to the acidic conditions of the tumour, the Schiff base linkage between MSNs and CQDs/PNVCL was broken, and then DOX and CQDs were released, so the release of antitumour drugs can be monitored by the fluorescence of CQDs.

\section{Photothermal Therapy}

In recent years, photothermal therapy (PTT) has attracted extensive research, which aims to use a photothermal conversion agent to absorb near-infrared light $(650 \sim 900 \mathrm{~nm})$ and convert the absorbed light energy into heat energy to further achieve the deep penetration of tissues and the minimum heating of nontarget tissues. ${ }^{204-206}$ Therefore, the choice of photothermal agent is the key factor in determining the success of photothermal therapy. First, to obtain effective treatment results, near-infrared photothermal agent-mediated tumour treatment usually requires a near-infrared laser irradiation power density significantly less than the maximum allowable skin exposure. ${ }^{207}$ Second, photothermal agents are applied for photothermal treatment of the tumour, and they should have good biocompatibility with surrounding tissues. ${ }^{208}$ Third, only when the size of the photothermal agent is small enough can it enter the tissue cells for photothermal therapy, so it must have superior tissue targeting. ${ }^{209}$ At present, widely used photothermal materials include noble metal nanoparticles such as $\mathrm{Au}$, $\mathrm{Ag}$ and $\mathrm{Pt},{ }^{210,211}$ carbon materials such as graphene and carbon nanorods, ${ }^{212}$ metal and nonmetal compounds such as $\mathrm{CuS}$ and $\mathrm{ZnS},{ }^{213}$ and organic dyes such as indocyanine green and Prussian blue, ${ }^{214}$ while few studies have mentioned CQDs.

$\mathrm{CuS}$ nanoparticles carrying CQDs and bortezomib were synthetized, coated with macrophage membranes and modified with the $\mathrm{T} 7$ peptide to form CuSCDB@MMT7. ${ }^{215}$ After CuSCDB@MMT7 enters the body, the immune system does not attack them because they are protected by the macrophage membrane, but instead, it transports them to tumour cells through the T7 peptide. CQDs are used for photothermal ablation under $808 \mathrm{~nm}$ NIR, while bortezomib is a proteasome inhibitor that can protect tumour suppressor proteins from degradation, thus uniting in opposition to tumours (Figure 12A). As shown in Figures $12 \mathrm{~B}$ and $\mathrm{C}$, the photothermal conversion efficiency of the composites increased with increasing irradiation time. Compared to the PBS, CuSCD and CuSCD@MM groups, the CuSCD@MMT7 group could reach $50{ }^{\circ} \mathrm{C}$ in 3 minutes, indicating its superior photothermal conversion rate, thus demonstrating the feasibility of thermal ablation therapy for tumour cells. Wang et al prepared a self-crosslinked chitosan hydrogel (CCHN) coated with DOX and CQDs with an average particle size of $65 \mathrm{~nm}$ to endow injectability. ${ }^{216}$ When CCHNs reached the tumour site, chitosan hydrolysed and released CQDs and DOX. CQDs kill tumour cells through PTT; however, DOX is an antitumour drug, so this system achieves a dual antitumour effect of PTT synergistic drug delivery. In addition, Qian et al developed a CQDs-based mesoporous silica scaffold (CQD@MSN) for photothermal synergistic immunotherapy. ${ }^{217}$ CQD@MSNs targeted tumour sites and participated in photothermal ablation, while biodegradable CQD@MSN fragments could obtain TAAs from photothermally lethal tumour cells and then carry them away from necrotic tissue, initiating the immune response by stimulating the proliferation and activation of NK cells and macrophages.

\section{Photodynamic Therapy}

Photodynamic therapy (PDT) is a new method for treating tumour diseases with photosensitive drugs and laser activation, whose mechanism of action is to produce ROS by the interaction between a photosensitizer and oxygen to kill tumour cells. ${ }^{218-220}$ The photosensitizer absorbed by the tissue is stimulated by laser irradiation of a specific wavelength, and the excited photosensitizer transfers energy to the surrounding oxygen to generate highly active singlet oxygen. ${ }^{221}$ Singlet oxygen reacts with adjacent biological macromolecules to induce cytotoxicity, which leads to cell damage and even death. ${ }^{222}$ In the treatment of oesophageal cancer, ${ }^{223}$ lung cancer, 224 skin cancer, 225 breast cancer ${ }^{226}$ and other diseases, PDT is a new tumour treatment technology that has risen and developed in recent years. As a cold photochemical reaction, the basic elements of PDT are oxygen, photosensitizer and visible light (commonly applied with a laser). Only by choosing an appropriate photosensitizer can PDT achieve the purpose of killing tumours. First, photosensitizers have a certain selectivity and affinity for tumour tissues and remain in tumour sites for a long time so that the 


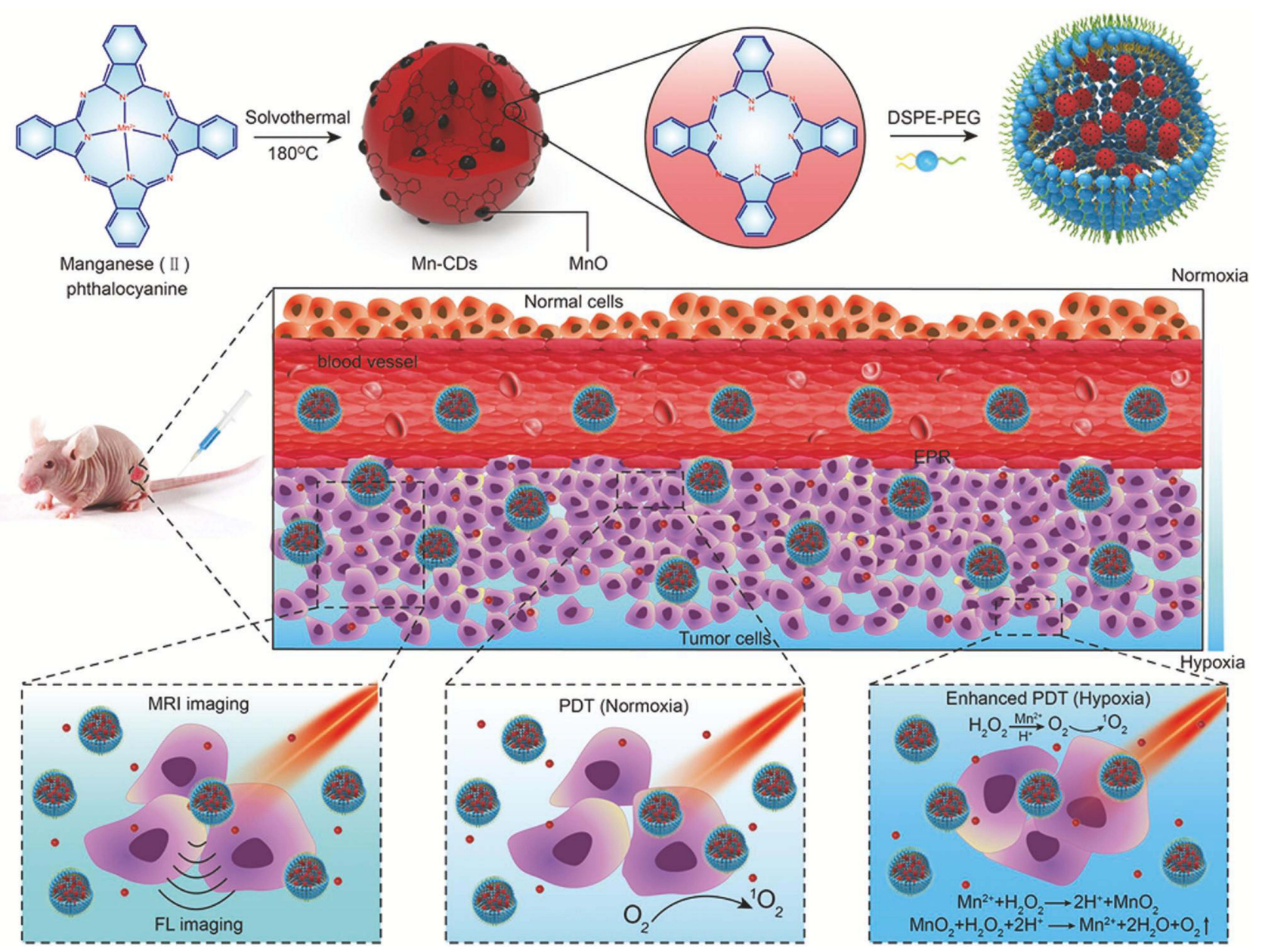

Figure 13 Preparation and mechanism of Mn-CDs. Reprinted from Jia Q, Ge J, Liu W, et al. A magneto fluorescent carbon dot assembly as an acidic H2O2 -driven oxygenerator to regulate tumor hypoxia for simultaneous bimodal imaging and enhanced photodynamic therapy. Adv Mater. 20I8;30(I3):eI706090. (C) 20I8 WILEY-VCH Verlag GmbH \& Co. KGaA, Weinheim. ${ }^{230}$

Abbreviations: DSPE, distearoyl phosphoethanolamine; PEG, polyethylene glycol.

concentration difference between tumour sites and normal tissues is maximized. ${ }^{227}$ Second, a photosensitizer can produce singlet oxygen in tumour tissue by illumination. ${ }^{228}$ Last, the photosensitizer is excited by light of an appropriate wavelength. ${ }^{229}$

Jia et al utilized manganese phthalocyanine (Mn-PC) as a raw material to prepare hydrophobic magnetic fluorescent CQDs (Mn-CDs) by a high-temperature method, followed by inserting PEG on the surface to improve their hydrophilicity. ${ }^{230} \mathrm{Mn}^{2+}$ in Mn-CDs could be used as a catalyst to decompose a large amount of $\mathrm{H}_{2} \mathrm{O}_{2}$ at the tumour sites into oxygen, and ${ }^{1} \mathrm{O}_{2}$ could be converted into ROS under irradiation with NIR light (635 nm), killing tumour cells (Figure 13). The lack of $\mathrm{O}_{2}$ in tumour tissues limits the efficacy of PDT in antitumour therapy. Therefore, increasing $\mathrm{O}_{2}$ content in tumour sites becomes the primary premise of PDT phototherapy. In addition, although $\mathrm{C}_{3} \mathrm{~N}_{4}$, a water splitting material, can decompose water into $\mathrm{O}_{2}$ by PDT, the decomposition efficiency is not high. To solve this problem, Zheng et al embedded CQDs and protoporphyrin IV (PpIV) on $\mathrm{C}_{3} \mathrm{~N}_{4}$ to form PCCN. ${ }^{231}$ Among them, CQDs were used to enhance the water decomposition of $\mathrm{C}_{3} \mathrm{~N}_{4}$, thereby increasing the production of $\mathrm{O}_{2}$, followed by transforming $\mathrm{O}_{2}$ into ROS by PpIV under light and killing the tumour cells. Nevertheless, traditional PDT applies ultraviolet and visible light as the excitation light source, which cannot penetrate the tissues sufficiently, so PDT can only be used for shallow tumours. It is not effective for deep tumours, which greatly limits the scope of PDT in clinical applications. At present, there are studies that combine upconversion nanophosphors (UCNPs) with PDT; such methods use low-energy nearinfrared light as the excitation light source and upconvert 

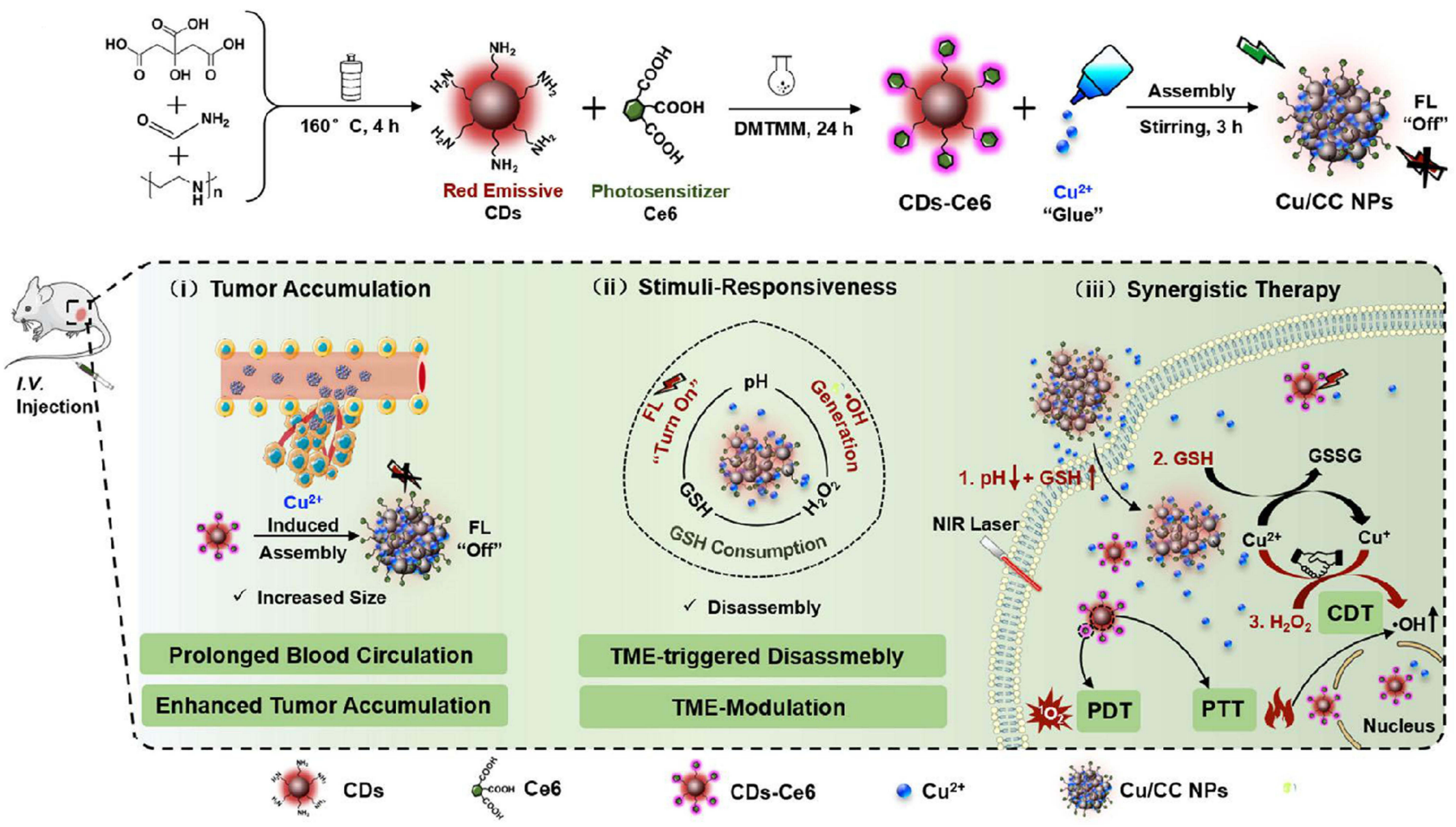

Figure 14 Preparation and mechanism of Cu/CC NPs. Reprinted from Sun S, Chen Q, Tang Z, et al.Tumor microenvironment stimuli-responsive fluorescence imaging and synergistic cancer therapy by Carbon-Dot-Cu2+ nanoassemblies. Angew Chem Int Ed Engl. 2020;59(47):21041-21048. (C) 2020 Wiley-VCH GmbH. 239

Abbreviations: Ce6, Chlorin e6; CDs-Ce6, Carbon quantum dots modified with Ce6; Cu/CC NPs, Nanoparticles loaded with Cu ${ }^{2+}$ and CDs-Ce6; DMTMM, 4-(4,6-Dimethoxy[1.3.5]triazin-2-yl)-4-methylmorpholinium chloride hydrate.

it into high-energy light to achieve the required spectrum of PDT photosensitizers. ${ }^{232,233}$ Near-infrared light has a deeper light transmission depth, which allows PDT to be utilized for deeper tissue treatment. Chan et al combined UCNPs with CQDs for the treatment of tumours through PDT. ${ }^{234}$ Among them, UCNPs were used as light converters to transform $808 \mathrm{~nm}$ near-infrared light into ultraviolet light for CQDs to produce ROS and then kill tumour cells.

\section{Photothermal Therapy and Synergetic Photodynamic Therapy}

PTT or PDT alone cannot completely eliminate tumours, so the combination of these two methods improves the curative effects. ${ }^{235-237}$ Based on the upconversion luminescence (UCL) principle described above, the combination of PDT and PTT for tumour phototherapy provides a new opportunity to apply CQDs in tumour treatment. Using $\mathrm{ZnPc}$ as a photosensitizer and CQDs as thermal sensitizers, Lv et al prepared a nanomaterial with CQDs and UCNPs, in which the CQDs could gradually heat and ablate tumour cells while the UCNPs could transfer energy to $\mathrm{ZnPc}$ to generate ROS to kill the tumour cells under $980 \mathrm{~nm}$ near-infrared light irradiation; this method was expected to yield twice the result with half the effort. ${ }^{238}$ The CQDs grafted with the photosensitizer Ce6 were mixed with $\mathrm{Cu}^{2+}$ to form nanoparticles $(\mathrm{Cu} / \mathrm{CC}$ NPs). ${ }^{239}$ A shown in Figure 14, Under the low pH, glutathione (GSH) overexpression and $\mathrm{H}_{2} \mathrm{O}_{2}$ surplus of the tumour environment, the $\mathrm{Cu} / \mathrm{CC}$ NPs disintegrated and released $\mathrm{CDs}-\mathrm{Ce} 6$ and $\mathrm{Cu}^{2+}$. GSH can eliminate ROS, which seriously hinders the PDT pathway of killing tumour cells. Therefore, the addition of $\mathrm{Cu}^{2+}$ can initiate Fenton-like reactions to eliminate $\mathrm{H}_{2} \mathrm{O}_{2}$ and produce $\mathrm{O}_{2}$ for PDT while also removing GSH and strengthening PDT. Moreover, due to FRET, the assembled $\mathrm{Cu} / \mathrm{CC}$ NPs hide the fluorescence of the CQDs, but they disintegrate and release CQDs when entering tumour cells, thus exposing the fluorescence of the CQDs and providing the possibility for monitoring their entrance into tumour cells. Hua et al grafted HPPH into CQDs doped with $\mathrm{Cu}^{2+}$ and $\mathrm{Gd}^{3+}$ to form BCCGH. ${ }^{240}$ CQDs, as thermal sensitizers, enabled PTT under $808 \mathrm{~nm}$ laser irradiation, while HPPH was a photosensitizer that produced ROS to kill tumour cells under $671 \mathrm{~nm}$ laser irradiation. In addition, Zhang et al combined PTT, PDT, 


\begin{tabular}{|c|c|c|c|c|c|c|c|c|c|c|}
\hline 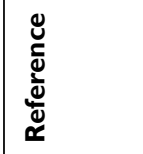 & $\frac{\sqrt{n}}{\Omega}$ & $\frac{\square}{2}$ & $\frac{\Sigma}{d}$ & $\stackrel{\widetilde{I}}{d}$ & $\stackrel{\overline{\mathfrak{d}}}{\underline{d}}$ & $\underset{\mathrm{I}}{\mathrm{g}}$ & $\stackrel{\sqrt[p]{d}}{d}$ & $\stackrel{⿱ 乛 J}{d}$ & 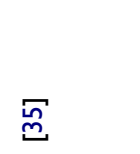 & 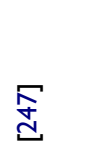 \\
\hline 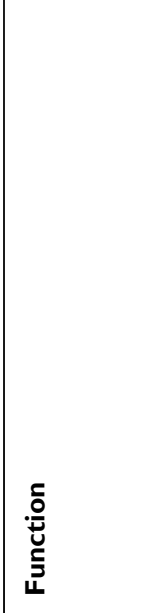 & 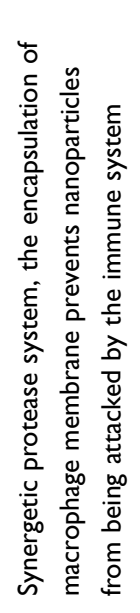 & 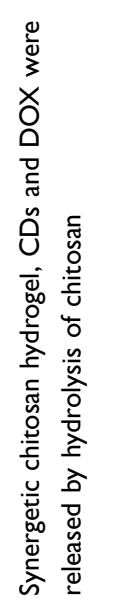 & 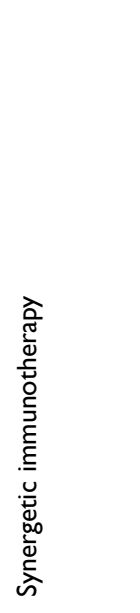 & 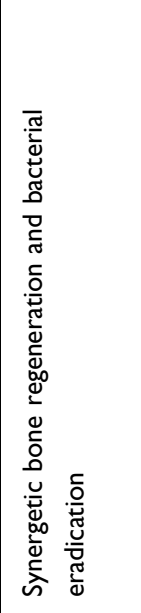 & 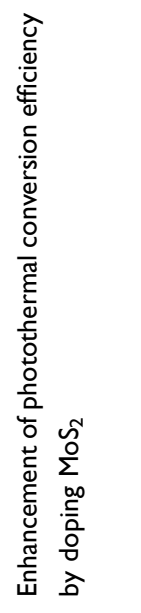 & 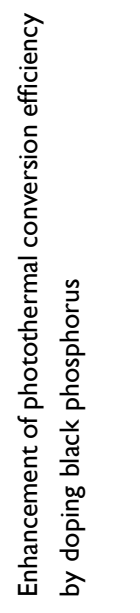 & 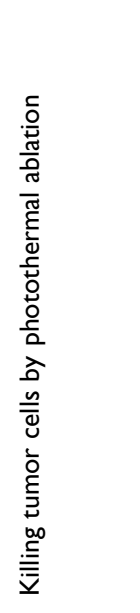 & 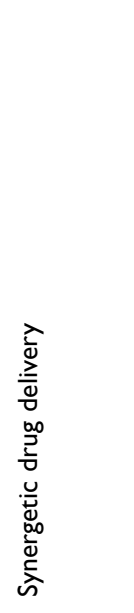 & 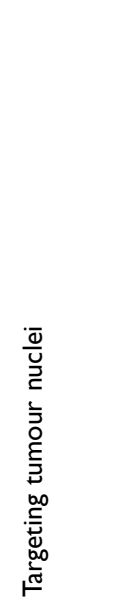 & 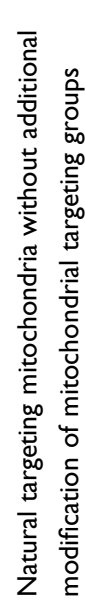 \\
\hline 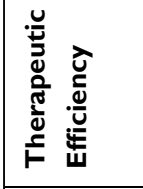 & $\begin{array}{l}\stackrel{\circ}{\hat{े}} \\
\text { 今. }\end{array}$ & $\begin{array}{l}\stackrel{+}{+} \\
\text { in }\end{array}$ & 1 & 1 & 1 & $\begin{array}{l}\stackrel{\circ}{+} \\
\stackrel{\infty}{\sim}\end{array}$ & I & 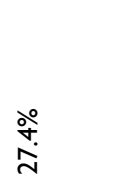 & 1 & 1 \\
\hline 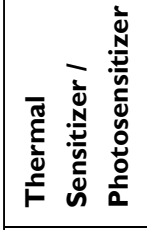 & O̊̊ & O̊ & O̊̊ & O̊̊ & O̊̊ & O̊̊ & O̊̊ & O̊̊ & 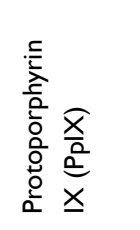 & 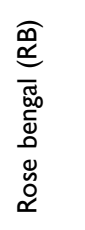 \\
\hline 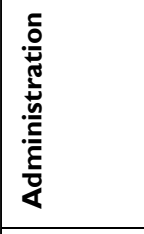 & $\geqq$ & $\geqq$ & $\geqq$ & $\stackrel{ }{=}$ & $\geqq$ & $\geqq$ & $\geqq$ & $\geqq$ & $\geqq$ & 1 \\
\hline $\begin{array}{l}\bar{\delta} \\
\bar{\delta} \\
\frac{\Sigma}{\Sigma}\end{array}$ & 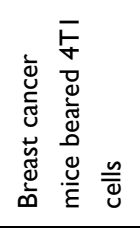 & 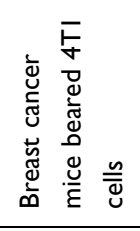 & 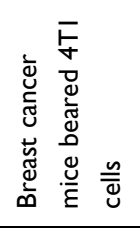 & 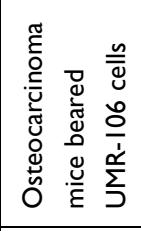 & 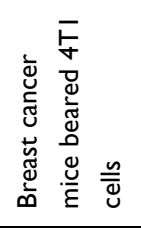 & 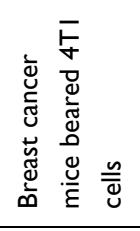 & 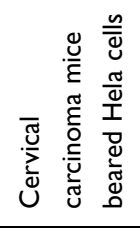 & 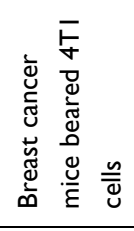 & 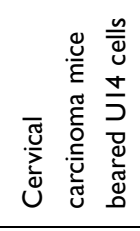 & 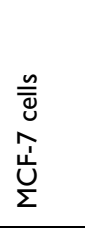 \\
\hline 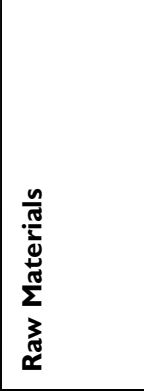 & 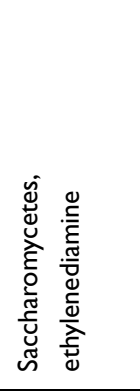 & 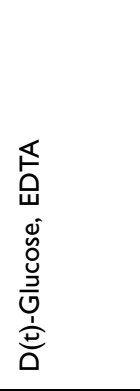 & 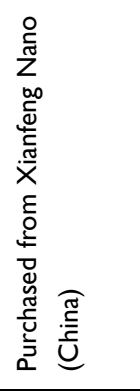 & 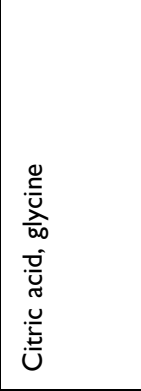 & 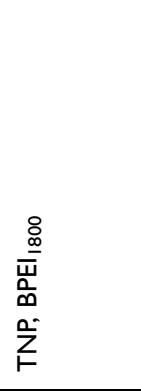 & 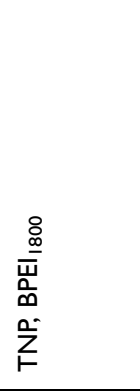 & 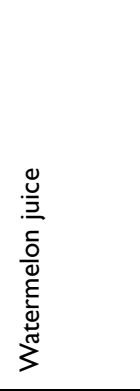 & 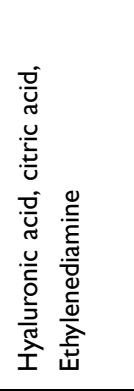 & 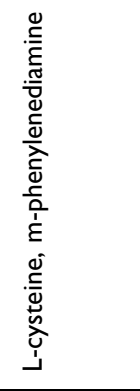 & 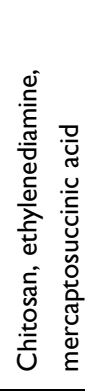 \\
\hline 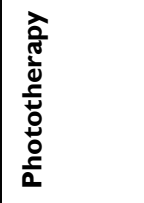 & $E$ & E & $E$ & $E$ & $E$ & $E$ & $E$ & E & $\stackrel{\circ}{a}$ & $\stackrel{\circ}{a}$ \\
\hline
\end{tabular}




\begin{tabular}{|c|c|c|c|c|c|c|c|c|c|c|}
\hline ס्ల్ర & $\overline{\bar{\Xi}}$ & $\underset{\text { 守 }}{\text { S }}$ & 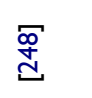 & 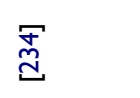 & 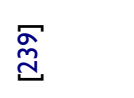 & 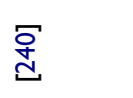 & 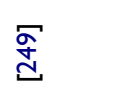 & 吕 & $\stackrel{\overline{\bar{d}}}{\stackrel{\bar{d}}{ }}$ & $\stackrel{\infty}{\underset{d}{d}}$ \\
\hline 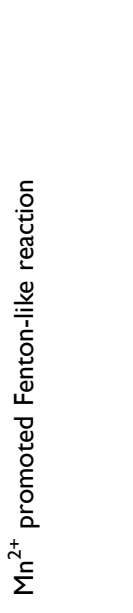 & 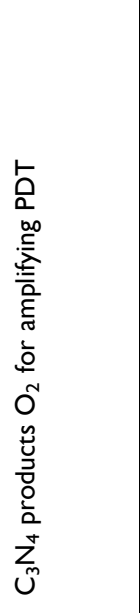 & 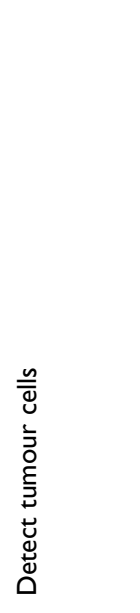 & 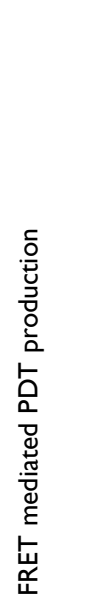 & 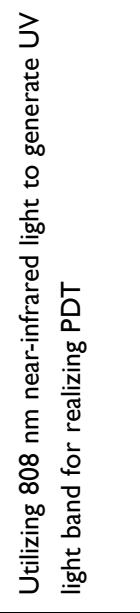 & 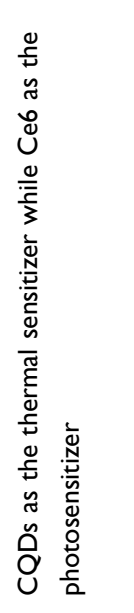 & 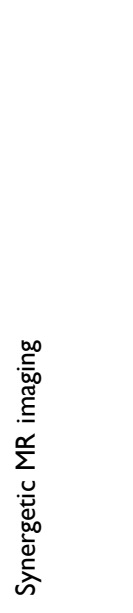 & 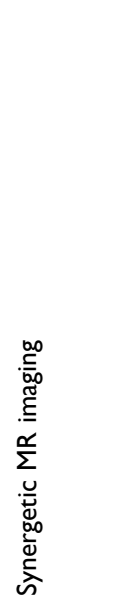 & 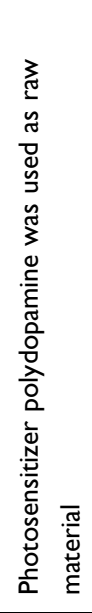 & 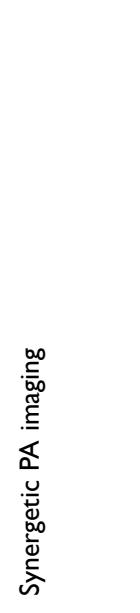 & 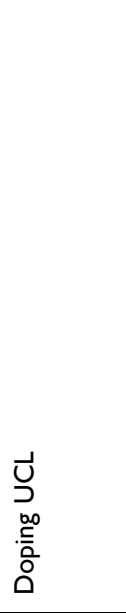 \\
\hline 1 & 1 & 1 & 1 & ㅇํㅇ & $\stackrel{\circ}{\stackrel{\circ}{m}}$ & $\begin{array}{l}\stackrel{\circ}{+} \\
\stackrel{\circ}{0}\end{array}$ & $\begin{array}{l}\stackrel{\text { సे }}{\text { లे }}\end{array}$ & 1 & । & 1 \\
\hline $\begin{array}{l}\text { Oొ } \\
\stackrel{1}{\Sigma}\end{array}$ & 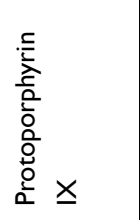 & Ü & $\begin{array}{l}\frac{0}{\lambda} \\
\sum_{k}^{0}\end{array}$ & $\begin{array}{l}\text { Õ } \\
\text { Zu }\end{array}$ & 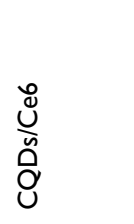 & 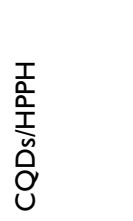 & 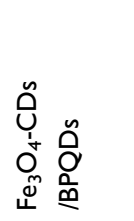 & 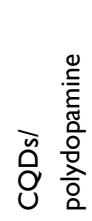 & 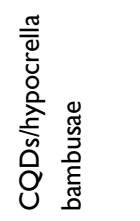 & 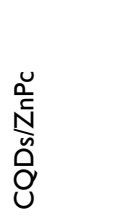 \\
\hline$\geqq$ & $\geqq$ & $\geqq$ & 1 & 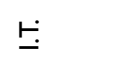 & $\geqq$ & $\geqq$ & $\geqq$ & 1 & $\geqq$ & 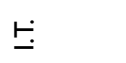 \\
\hline 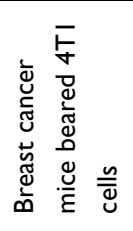 & 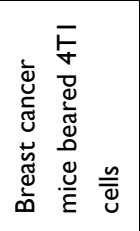 & 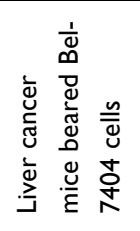 & $\begin{array}{l}\frac{n}{\bar{J}} \\
\frac{\tilde{O}}{\mathbb{O}} \\
\frac{1}{I}\end{array}$ & 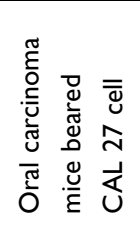 & 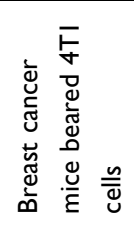 & 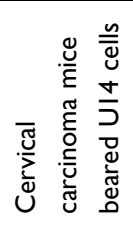 & 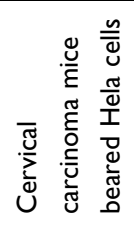 & 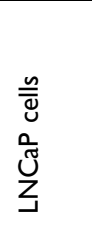 & 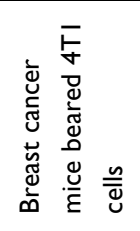 & 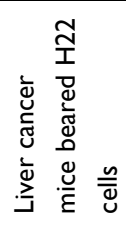 \\
\hline 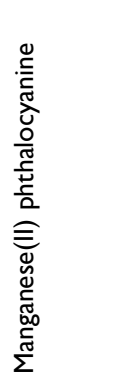 & 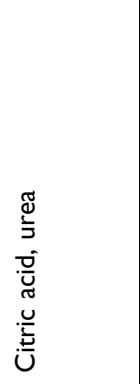 & 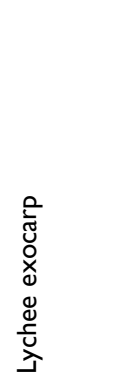 & 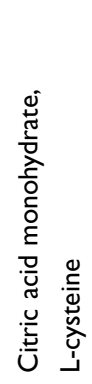 & 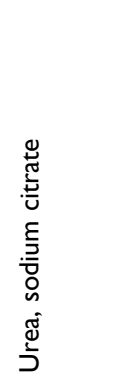 & 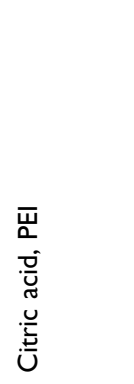 & 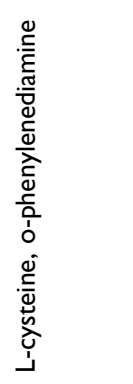 & 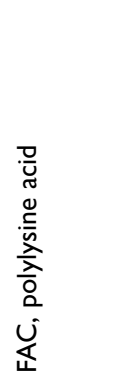 & 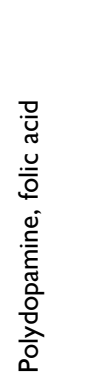 & 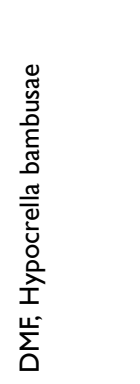 & 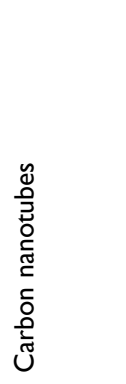 \\
\hline$\stackrel{5}{a}$ & $\stackrel{5}{a}$ & 号 & $\stackrel{5}{a}$ & 占 & 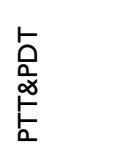 & 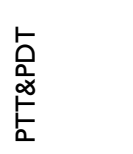 & $\begin{array}{l}\frac{5}{0} \\
\text { Q } \\
F^{\circ}\end{array}$ & $\begin{array}{l}\frac{5}{0} \\
\text { o } \\
\frac{1}{2}\end{array}$ & $\begin{array}{l}\frac{5}{a} \\
\frac{a}{\alpha} \\
\frac{5}{2}\end{array}$ & $\begin{array}{l}\frac{5}{0} \\
\frac{a}{\otimes} \\
\stackrel{5}{a}\end{array}$ \\
\hline
\end{tabular}




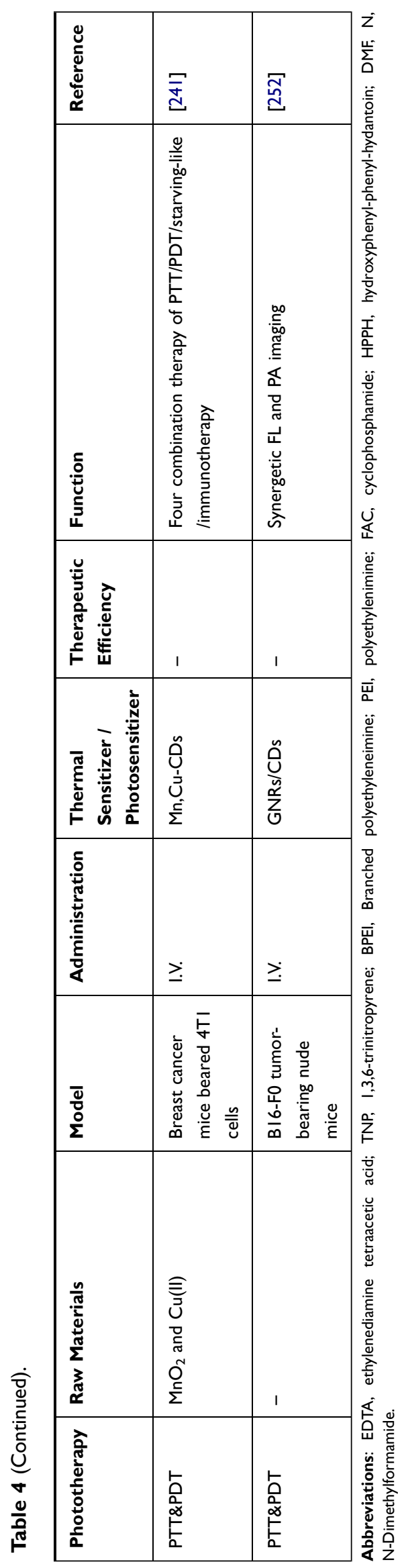

starvation-like therapy and immunotherapy to fight tumours, in which $\mathrm{Mn}, \mathrm{Cu}-\mathrm{CDs}$ were utilized as both photosensitizers and thermal sensitizers, while the glucose-metabolic reaction agent glucose oxidase (GOx) snatched glucose from the tumour cells, causing them to starve. ${ }^{241}$ Moreover, the tumour-associated antigens released by the above three ways of killing tumour cells stimulated cytotoxic $\mathrm{T}$ lymphocytes to penetrate distant tumours through the PD-1/PD-L1 pathway, which not only killed the primary tumours but also blocked the growth of distant tumours.

Compared with that of other nanoparticles, research on the application of CQDs in phototherapy is very limited. Table 4 summarizes the application of CQDs as thermal sensitizers/photosensitizers in antitumour research. Moreover, most CQD-mediated PTT systems are designed to encapsulate CQDs into nanoparticles. PTT requires that the thermal sensitizer has a superior photothermal conversion rate, and CQDs are candidates for thermal sensitizers owing to their naturally dark colour. The efficiency of photothermal conversion can be enhanced by screening raw materials and reforming synthetic CQDs. To design materials for CQD-mediated PDT, we need to bind a photosensitizer to the CQDs, and because tumour sites lack enough oxygen to produce ROS, so we also need to add specific materials to produce $\mathrm{O}_{2}$. Among them, some transition metals, such as $\mathrm{Co}^{2+}, \mathrm{Cd}^{2+}, \mathrm{Cu}^{2+}, \mathrm{Ag}^{+}, \mathrm{Mn}^{2+}$ and $\mathrm{Ni}^{2+}$, can accelerate or replace $\mathrm{Fe}^{2+}$ to promote a Fenton-like reaction, thus becoming oxygen suppliers. Moreover, due to the low tumour eradication rates of PTT and PDT alone, the combination of PTT and PDT or with other therapies, including immunotherapy, radiotherapy, chemotherapy, hormone therapy and precision medicine, to achieve a higher tumour eradication rate needs further research.

\section{Tumour-Targeting Lethal CQDs}

Tumour-targeting lethal CQDs have antitumour effects without any other synergism and depend on the production of ROS after they are absorbed by tumour cells. Such CQDs only kill tumours, while normal cells can escape them. Using polyethylene glycol (PEG) as a carbon source, imidazole as a nitrogen source and phosphoric acid as a phosphorus source, Bajpai et al prepared N- and P-doped CQDs (NPCDs) by a heating method that could induce cell cycle arrest, autophagy and apoptosis in B16F10 melanoma cells. ${ }^{253}$ Yao et al utilized ginsenoside as a raw material, adding appropriate amounts of citric acid and EDA to improve the fluorescence performance to prepare 
antitumour Re-CQDs, ${ }^{254}$ while Emam and Ahmed used $\mathrm{NaOH}$ to dissolve carrageenan and pullulan and then fabricated two kinds of CQDs by a hydrothermal method, which were used for antitumour and antiviral activities. ${ }^{255}$

\section{Summary and Outlook}

In this review, the preparation methods, features and characterizations of CQDs were briefly introduced, and the application prospects of CQDs in the antitumour field were also summarized. The preparation methods of CQDs include "top-down" methods and "bottom-up" methods. The difference is that the former separates the CQDs from matter with a large molecular weight, while the latter produces CQDs by carbonization of small molecules. CQDs have excellent biocompatibility due to their small structure and hydrophilic groups on the surface. Moreover, although there is no consensus on the luminescence mechanism of CQDs, it is known to be related to the vacancies of surface groups and epitopes.

The applications of CQDs in antitumour therapy mainly include the detection and diagnosis of early tumours, delivery of antitumour drugs as carriers, monitoring the release of antitumour drugs, phototherapy as photosensitizers or thermosensitizers, and targeted killing of tumour cells by autonomic production of ROS. Early-stage tumours have no obvious clinical manifestations, and the changes in tumour markers are very small, which makes them difficult to detect, diagnose and treat early. CQDs have excellent specificity and sensitivity, and they can be used to effectively monitor early-stage tumours by means of FRET, ECL, and structural modifications to enable the detection of tumour markers or the tumour microenvironment and to release antitumour drugs. CQDs are most widely utilized in antitumour therapy for drug delivery, including traditional drugs and gene therapy drugs. The small size of CQDs increases their specific surface area, which is conducive to the improvement of the encapsulation and loading efficiency of a series of antitumour drug molecules. In addition, the high biocompatibility, low relative cytotoxicity and good cell uptake ability of CQDs also make them excellent materials for drug delivery. CQDs can combine with drugs by covalent bonds, noncovalent bonds, or both, so they can create different types of connections to exhibit high performance while maintaining their original properties. Moreover, because tumour cells are more sensitive to the thermal environment than normal cells, CQDs can be utilized as thermal sensitizers to achieve the targeted killing of tumour cells. Moreover, a photosensitizer can be doped into CQDs or encapsulated in nanoparticles with CQDs to achieve the antitumour effect of synergistic PTT and PDT. The mechanism of
PDT is to produce ROS to damage tumour cells, which is consistent with the mechanism of killing tumour cells by tumour-targeting lethal CQDs.

Although CQDs have made significant contributions to the discovery, diagnosis and treatment of tumours, some challenges remain to be further explored. First, the combination of CQDs with other therapies, such as immunotherapy, gene therapy, endocrine therapy, cryotherapy and radiotherapy, needs to be further studied and promoted. Second, the biocompatibility of CQDs is concentration-dependent. Once the concentration threshold is exceeded, CQDs become toxic. The ameliorative concentration threshold for improving the biocompatibility without affecting the properties of CQDs remains to be further studied. Finally, PTT therapy with CQDs is only suitable for photothermal ablation of superficial tumours, so its treatment of deep tumours is a direction of future research.

\section{Acknowledgments}

We greatly acknowledge the financial support from the National Nature Science Foundation of China (82074473), the Natural Science Foundation of Jiangsu province (BK20191201, BE2020666), the Suzhou Health Personnel Training Project (GSWS2019074 and GSWS2020103), the Zhangjiagang Health Personnel Training Project (ZJGWSRC2020002), the Zhangjiagang Health System Youth Science and Technology Project (ZYYQ2005).

\section{Disclosure}

The authors report no conflicts of interest in this work.

\section{References}

1. Chaput F, Amer R, Baglivo E, et al. Intraocular T-cell lymphoma: clinical presentation, diagnosis, treatment, and outcome. Ocul Immunol Inflamm. 2017;25(5):639-648. doi:10.3109/09273948.2016.1139733

2. Wang SY, Chen XX, Li Y, Zhang YY. Application of multimodality imaging fusion technology in diagnosis and treatment of malignant tumors under the precision medicine plan. Chin Med J (Engl). 2016;129 (24):2991-2997. doi:10.4103/0366-6999.195467

3. Fisher B. Biological research in the evolution of cancer surgery: a personal perspective. Cancer Res. 2008;68(24):10007-10020. doi:10.1158/0008-5472.CAN-08-0186

4. Epstein RJ. Drug-induced DNA damage and tumor chemosensitivity. $J$ Clin Oncol. 1990;8(12):2062-2084. doi:10.1200/JCO.1990. 8.12.2062

5. Wang J, Wang $\mathrm{H}$, Wang $\mathrm{H}$, et al. Nonviolent self-catabolic DNAzyme nanosponges for smart anticancer drug delivery. ACS Nano. 2019;13(5):5852-5863. doi:10.1021/acsnano.9b01589

6. Laperriere NJ, Bernstein M. Radiotherapy for brain tumors. $C A$ Cancer J Clin. 1994;44(2):96-108. doi:10.3322/canjclin.44.2.96

7. Wang X, Hu C, Eisbruch A. Organ-sparing radiation therapy for head and neck cancer. Nat Rev Clin Oncol. 2011;8(11):639-648. doi:10.1038/nrclinonc.2011.106 
8. de Dios NR, Murcia-Mejía M. Current and future strategies in radiotherapy for small-cell lung cancer. J Clin Transl Res. 2020;6 (4):97-108.

9. Ianzini F, Kosmacek EA, Nelson ES, et al. Activation of meiosis-specific genes is associated with depolyploidization of human tumor cells following radiation-induced mitotic catastrophe. Cancer Res. 2009;69(6):2296-2304. doi:10.1158/ 0008-5472.CAN-08-3364

10. Mendonca MS, Howard KL, Farrington DL, et al. Delayed apoptotic responses associated with radiation-induced neoplastic transformation of human hybrid cells. Cancer Res. 1999;59 (16):3972-3979.

11. Negi H, Merugu SB, Mangukiya HB, et al. Anterior gradient-2 monoclonal antibody inhibits lung cancer growth and metastasis by upregulating p53 pathway and without exerting any toxicological effects: a Preclinical Study. Cancer Lett. 2019;449:125-134. doi:10.1016/j.canlet.2019.01.025

12. Vahdat V, Ryan KE, Keating PL, et al. Atomic-scale wear of amorphous hydrogenated carbon during intermittent contact: a combined study using experiment, simulation, and theory. ACS Nano. 2014;8(7):7027-7040. doi:10.1021/nn501896e

13. Clancy AJ, Bayazit MK, Hodge SA, et al. Charged carbon nanomaterials: redox chemistries of fullerenes, carbon nanotubes, and graphenes. Chem Rev. 2018;118(16):7363-7408. doi:10.1021/acs. chemrev.8b00128

14. Deline AR, Frank BP, Smith CL, et al. Influence of oxygen-containing functional groups on the environmental properties, transformations, and toxicity of carbon nanotubes. Chem Rev. 2020;120(20):11651-11697. doi:10.1021/acs. chemrev.0c00351

15. Zou M, Zhao W, Wu H, et al. Single carbon fibers with a macroscopic-thickness, 3D highly porous carbon nanotube coating. Adv Mater. 2018;30(13):e1704419. doi:10.1002/ adma.201704419

16. Nekoueian K, Amiri M, Sillanpää M, et al. Carbon-based quantum particles: an electroanalytical and biomedical perspective. Chem Soc Rev. 2019;48(15):4281-4316. doi:10.1039/ C8CS00445E

17. Tunuguntla RH, Henley RY, Yao YC, et al. Enhanced water permeability and tunable ion selectivity in subnanometer carbon nanotube porins. Science. 2017;357(6353):792-796. doi:10.1126/ science.aan 2438

18. Zhang S, Kang L, Wang X, et al. Arrays of horizontal carbon nanotubes of controlled chirality grown using designed catalysts. Nature. 2017;543(7644):234-238. doi:10.1038/nature21051

19. Chen S, Qiu L, Cheng HM. Carbon-based fibers for advanced electrochemical energy storage devices. Chem Rev. 2020;120 (5):2811-2878. doi:10.1021/acs.chemrev.9b00466

20. Stergiou A, Tagmatarchis N. Interfacing carbon dots for charge-transfer processes. Small. 2021;e2006005. doi:10.1002/ smll.202006005

21. Wang B, Yu J, Sui L, et al. Rational design of multi-coloremissive carbon dots in a single reaction system by hydrothermal. Adv Sci (Weinh). 2020;8(1):2001453. doi:10.1002/ advs. 202001453

22. $\mathrm{Xu} \mathrm{X,} \mathrm{Ray} \mathrm{R,} \mathrm{Gu} \mathrm{Y,} \mathrm{et} \mathrm{al.} \mathrm{Electrophoretic} \mathrm{analysis} \mathrm{and} \mathrm{purifica-}$ tion of fluorescent single-walled carbon nanotube fragments. J Am Chem Soc. 2004;126(40):12736-12737. doi:10.1021/ ja040082h

23. Cao L, Wang X, Meziani MJ, et al. Carbon dots for multiphoton bioimaging. J Am Chem Soc. 2007;129(37):11318-11319. doi:10.1021/ja0735271

24. Lin Z, Xue W, Chen H, Lin JM. Classical oxidant induced chemiluminescence of fluorescent carbon dots. Chem Commun (Camb). 2012;48(7):1051-1053. doi:10.1039/C1CC15290D
25. Yuan F, Wang Z, Li X, et al. Bright multicolor bandgap fluorescent carbon quantum dots for electroluminescent light-emitting diodes. Adv Mater. 2017;29(3):1604436.

26. Guo Z, Li Q, Li Z, et al. Fabrication of efficient alginate composite beads embedded with N-doped carbon dots and their application for enhanced rare earth elements adsorption from aqueous solutions. J Colloid Interface Sci. 2020;562:224-234. doi:10.1016/j.jcis.2019.12.030

27. Tao Y, Lin J, Wang D, Wang $\mathrm{Y}$. $\mathrm{Na}^{+}$-functionalized carbon dots with aggregation-induced and enhanced cyan emission. J Colloid Interface Sci. 2021;588:469-475. doi:10.1016/j.jcis.2020.12.104

28. Li H, He X, Kang Z, et al. Water-soluble fluorescent carbon quantum dots and photocatalyst design. Angew Chem Int Ed Engl. 2010;49(26):4430-4434. doi:10.1002/anie.200906154

29. Liu Y, Tian Y, Tian Y, et al. Carbon-dot-based nanosensors for the detection of intracellular redox state. Adv Mater. 2015;27 (44):7156-7160. doi:10.1002/adma.201503662

30. Xue X, Fang T, Yin L. Multistage delivery of CDs-DOX/ICGloaded liposome for highly penetration and effective chemo-photothermal combination therapy. Drug Deliv. 2018;25 (1):1826-1839. doi:10.1080/10717544.2018.1482975

31. Xu B, Zhao C, Wei W, et al. Aptamer carbon nanodot sandwich used for fluorescent detection of protein. Analyst. 2012;137 (23):5483-5486. doi:10.1039/c2an36174d

32. Wei JS, Ding C, Zhang P, et al. Robust negative electrode materials derived from carbon dots and porous hydrogels for high-performance hybrid supercapacitors. Adv Mater. 2019;31 (5):e1806197.

33. Lim SY, Shen W, Gao Z. Carbon quantum dots and their applications. Chem Soc Rev. 2015;44(1):362-381. doi:10.1039/ C4CS00269E

34. Yan C, Wang C, Hou $\mathrm{T}$, et al. Lasting tracking and rapid discrimination of live gram-positive bacteria by peptidoglycan-targeting carbon quantum dots. ACS Appl Mater Interfaces. 2021;13(1):1277-1287. doi:10.1021/acsami.0c19651

35. Hua XW, Bao YW, Wu FG. Fluorescent carbon quantum dots with intrinsic nucleolus-targeting capability for nucleolus imaging and enhanced cytosolic and nuclear drug delivery. ACS Appl Mater Interfaces. 2018;10(13):10664-10677. doi:10.1021/acsami.7b19549

36. Mosquera J, García I, Henriksen-Lacey M, et al. Reversible control of protein corona formation on gold nanoparticles using host-guest interactions. ACS Nano. 2020;14(8):10745-10746. doi:10.1021/acsnano.0c06355

37. Song Y, Wang H, Zhang L, et al. Protein Corona formation of human serum albumin with carbon quantum dots from roast salmon. Food Funct. 2020;11(3):2358-2367. doi:10.1039/ C9FO02967B

38. Yan C, Guo L, Shao X, et al. Amino acid-functionalized carbon quantum dots for selective detection of $\mathrm{Al}^{3+}$ ions and fluorescence imaging in living cells. Anal Bioanal Chem. 2021;413 (15):3965-3974. doi:10.1007/s00216-021-03348-x

39. He X, Luo Q, Zhang J, et al. Gadolinium-doped carbon dots as nano-theranostic agents for MR/FL diagnosis and gene delivery. Nanoscale. 2019;11(27):12973-12982. doi:10.1039/ C9NR03988K

40. Zhang J, Zhang H, Jiang J, et al. Doxorubicin-loaded carbon dots lipid-coated calcium phosphate nanoparticles for visual targeted delivery and therapy of tumor. Int $J$ Nanomedicine. 2020;15:433-444. doi:10.2147/IJN.S229154

41. Wu J. The enhanced permeability and retention (EPR) effect: the significance of the concept and methods to enhance its application. J Pers Med. 2021;11(8):771. doi:10.3390/jpm11080771

42. Nakamura Y, Mochida A, Choyke PL, Kobayashi H. Nanodrug delivery: is the enhanced permeability and retention effect sufficient for curing cancer? Bioconjug Chem. 2016;27 (10):2225-2238. doi:10.1021/acs.bioconjchem.6b00437 
43. Arcudi F, Đorđević L, Prato M. Design, synthesis, and functionalization strategies of tailored carbon nanodots. Acc Chem Res. 2019;52(8):2070-2079. doi:10.1021/acs.accounts.9b00249

44. Papaioannou N, Titirici MM, Sapelkin A. Investigating the effect of reaction time on carbon dot formation, structure, and optical properties. ACS Omega. 2019;4(26):21658-21665. doi:10.1021/ acsomega.9b01798

45. Wu ZL, Liu ZX, Yuan YH. Carbon dots: materials, synthesis, properties and approaches to long-wavelength and multicolor emission. J Mater Chem B. 2017;5(21):3794-3809. doi:10.1039/ C7TB00363C

46. Zhang M, Wang H, Wang B, et al. Maltase decorated by chiral carbon dots with inhibited enzyme activity for glucose level control. Small. 2019;15(48):e1901512. doi:10.1002/smll.2019 01512

47. Qiao ZA, Wang Y, Gao Y, et al. Commercially activated carbon as the source for producing multicolor photoluminescent carbon dots by chemical oxidation. Chem Commun (Camb). 2010;46 (46):8812-8814. doi:10.1039/c0cc02724c

48. Yu H, Li X, Zeng X, Lu Y. Preparation of carbon dots by non-focusing pulsed laser irradiation in toluene. Chem Commun (Camb). 2016;52(4):819-822. doi:10.1039/C5CC08384B

49. Zahiri M, Shafiee Afarani M, Arabi AM. Combustion synthesis of $\mathrm{ZnO} / \mathrm{ZnS}$ nanocomposite phosphors. J Fluoresc. 2019;29 (5):1227-1239. doi:10.1007/s10895-019-02434-9

50. Ye X, Xiang Y, Wang Q, et al. A red emissive two-photon fluorescence probe based on carbon dots for intracellular $\mathrm{pH}$ detection. Small. 2019;15(48):e1901673. doi:10.1002/ smll.201901673

51. Atchudan R, Edison TNJI, Aseer KR, et al. Highly fluorescent nitrogen-doped carbon dots derived from Phyllanthus acidus utilized as a fluorescent probe for label-free selective detection of $\mathrm{Fe}^{3+}$ ions, live cell imaging and fluorescent ink. Biosens Bioelectron. 2018;99:303-311. doi:10.1016/j. bios.2017.07.076

52. Jiang K, Gao X, Feng X, et al. Carbon dots with dual-emissive, robust, and aggregation-induced room-temperature phosphorescence characteristics. Angew Chem Int Ed Engl. 2020;59 (3):1263-1269. doi:10.1002/anie.201911342

53. Zheng XT, Tan YN. Development of blood-cell-selective fluorescent biodots for lysis-free leukocyte imaging and differential counting in whole blood. Small. 2020;16(12):e1903328. doi:10.1002/smll.201903328

54. Zhang M, Ju H, Zhang L, et al. Engineering iodine-doped carbon dots as dual-modal probes for fluorescence and X-ray CT imaging. Int J Nanomedicine. 2015;10:6943-6953.

55. Liu C, Zhang P, Zhai X, et al. Nano-carrier for gene delivery and bioimaging based on carbon dots with PEI-passivation enhanced fluorescence. Biomaterials. 2012;33(13):3604-3613. doi:10.1016/ j.biomaterials.2012.01.052

56. Singh R, Kashayap S, Singh V, et al. QPRTase modified $\mathrm{N}$-doped carbon quantum dots: a fluorescent bioprobe for selective detection of neurotoxin quinolinic acid in human serum. Biosens Bioelectron. 2018;101:103-109. doi:10.1016/j. bios.2017.10.017

57. Yang $\mathrm{P}$, Zhu Z, Zhang T, et al. Orange-emissive carbon quantum dots: toward application in wound $\mathrm{pH}$ monitoring based on colorimetric and fluorescent changing. Small. 2019;15(44): e1902823. doi:10.1002/smll.201902823

58. Pierrat P, Wang R, Kereselidze D, et al. Efficient in vitro and in vivo pulmonary delivery of nucleic acid by carbon dot-based nanocarriers. Biomaterials. 2015;51:290-302. doi:10.1016/j. biomaterials.2015.02.017

59. Du FY, Jin X, Chen JH, et al. Nitrogen-doped carbon dots as multifunctional fluorescent probes. J Nanoparticle Res. 2014;16 (11):2720. doi:10.1007/s11051-014-2720-8
60. Yang $\mathrm{P}$, Zhang ZW, Zou GD, et al. Template thermolysis to create a carbon dots-embedded mesoporous titanium-oxo sulfate framework for visible-light photocatalytic applications. Inorg Chem. 2020;59(3):2062-2069. doi:10.1021/acs. inorgchem.9b03493

61. Yen YC, Lin CC, Chen PY, et al. Green synthesis of carbon quantum dots embedded onto titanium dioxide nanowires for enhancing photocurrent. Royal Soc Open Sci. 2017;4(5):161051-161060. doi:10.1098/rsos.161051

62. Hu C, Zhu Y, Zhao X. On-off-on nanosensors of carbon quantum dots derived from coal tar pitch for the detection of $\mathrm{Cu}^{2+}, \mathrm{Fe}^{3+}$, and L-ascorbic acid. Spectrochim Acta A Mol Biomol Spectrosc. 2021;250:119325. doi:10.1016/j.saa.2020.119325

63. Kang S, Kim KM, Jung K, et al. Graphene oxide quantum dots derived from coal for bioimaging: facile and green approach. $\mathrm{Sci}$ Rep. 2019;9(1):4101. doi:10.1038/s41598-018-37479-6

64. Han Y, Tang D, Yang Y, et al. Non-metal single/dual doped carbon quantum dots: a general flame synthetic method and electro-catalytic properties. Nanoscale. 2015;7(14):5955-5962. doi:10.1039/C4NR07116F

65. Zhang KY, Yu Q, Wei H, et al. Long-lived emissive probes for time-resolved photoluminescence bioimaging and biosensing. Chem Rev. 2018;118(4):1770-1839. doi:10.1021/acs. chemrev.7b00425

66. Chouksey S, Sankaranarayanan S, Pendem V, et al. Strong size dependency on the carrier and photon dynamics in InGaN/GaN single nanowalls determined using photoluminescence and ultrafast transient absorption spectroscopy. Nano Lett. 2017;17 (8):4596-4603. doi:10.1021/acs.nanolett.7b00970

67. Yakunin S, Benin BM, Shynkarenko Y, et al. High-resolution remote thermometry and thermography using luminescent low-dimensional tin-halide perovskites. Nat Mater. 2019;18 (8):846-852. doi:10.1038/s41563-019-0416-2

68. Nguyen HA, Srivastava I, Pan D, Gruebele M. Unraveling the fluorescence mechanism of carbon dots with sub-single-particle resolution. ACS Nano. 2020;14(5):6127-6137. doi:10.1021/ acsnano.0c01924

69. Ehrat F, Bhattacharyya S, Schneider J, et al. Tracking the source of carbon dot photoluminescence: aromatic domains versus molecular fluorophores. Nano Lett. 2017;17(12):7710-7716. doi:10.1021/acs.nanolett.7b03863

70. Feng T, Zhu S, Zeng Q, et al. Supramolecular cross-link-regulated emission and related applications in polymer carbon dots. ACS Appl Mater Interfaces. 2018;10(15):12262-12277. doi:10.1021/ acsami.7b14857

71. Wang BB, Jin JC, Xu ZQ, et al. Single-step synthesis of highly photoluminescent carbon dots for rapid detection of $\mathrm{Hg} 2+$ with excellent sensitivity. $J$ Colloid Interface Sci. 2019;551:101-110. doi:10.1016/j.jcis.2019.04.088

72. Bai J, Sun C, Jiang X. Carbon dots-decorated multiwalled carbon nanotubes nanocomposites as a high-performance electrochemical sensor for detection of $\mathrm{H} 2 \mathrm{O} 2$ in living cells. Anal Bioanal Chem. 2016;408(17):4705-4714. doi:10.1007/s00216-016-9554-4

73. Tian XT, Yin XB. Carbon dots, unconventional preparation strategies, and applications beyond photoluminescence. Small. 2019;15(48):e1901803. doi:10.1002/smll.201901803

74. Wang B, Tan H, Zhang $\mathrm{T}$, et al. Hydrothermal synthesis of $\mathrm{N}$-doped carbon dots from an ethanolamine-ionic liquid gel to construct label-free multifunctional fluorescent probes for $\mathrm{Hg} 2+$, $\mathrm{Cu} 2+$ and S2O32-. Analyst. 2019;144(9):3013-3022. doi:10.1039/C9AN00116F

75. Nasrin A, Hassan M, Gomes VG. Two-photon active nucleus-targeting carbon dots: enhanced ROS generation and photodynamic therapy for oral cancer. Nanoscale. 2020;12 (40):20598-20603. doi:10.1039/D0NR05210H 
76. Wu W, Zheng T, Tian Y. An enzyme-free amplification strategy based on two-photon fluorescent carbon dots for monitoring miR9 in live neurons and brain tissues of Alzheimer's disease mice. Chem Commun (Camb). 2020;56(58):8083-8086. doi:10.1039/ D0CC01971B

77. Liu C, Xiao G, Yang M, et al. Mechanofluorochromic carbon nanodots: controllable pressure-triggered blue- and red-shifted photoluminescence. Angew Chem Int Ed Engl. 2018;57 (7):1893-1897. doi:10.1002/anie.201711409

78. Ding H, Yu SB, Wei JS, Xiong HM. Full-color light-emitting carbon dots with a surface-state-controlled luminescence mechanism. ACS Nano. 2016;10(1):484-491. doi:10.1021/ acsnano. $5 \mathrm{~b} 05406$

79. Zhang M, Zhao L, Du F, et al. Facile synthesis of cerium-doped carbon quantum dots as a highly efficient antioxidant for free radical scavenging. Nanotechnology. 2019;30(32):325101. doi:10.1088/1361-6528/ab12ef

80. Li L, Jin J, Liu J, et al. Accurate SERS monitoring of the plasmon mediated UV/visible/NIR photocatalytic and photothermal catalytic process involving Ag@carbon dots. Nanoscale. 2021;13 (2):1006-1015. doi:10.1039/D0NR06293F

81. Tsurugaya T, Yoshida K, Yajima F, et al. Terahertz spectroscopy of individual carbon nanotube quantum dots. Nano Lett. 2019;19 (1):242-246. doi:10.1021/acs.nanolett.8b03801

82. Jangra H, Chen Q, Fuks E, et al. Nucleophilicity and electrophilicity parameters for predicting absolute rate constants of highly asynchronous 1,3-dipolar cycloadditions of aryldiazomethanes. J Am Chem Soc. 2018;140(48):16758-16772. doi:10.1021/jacs.8b09995

83. Atchudan R, Edison TNJI, Lee YR. Nitrogen-doped carbon dots originating from unripe peach for fluorescent bioimaging and electrocatalytic oxygen reduction reaction. J Colloid Interface Sci. 2016;482:8-18. doi:10.1016/j.jcis.2016.07.058

84. Ansari F, Kahrizi D. Hydrothermal synthesis of highly fluorescent and non-toxic carbon dots using Stevia rebaudiana Bertoni. Cell Mol Biol (Noisy-Le-Grand). 2018;64(12):32-36. doi:10.14715/ $\mathrm{cmb} / 2018.64 .12 .7$

85. Li T, Wang ES, Wang J, Chen X. Regulating the properties of carbon dots via a solvent-involved molecule fusion strategy for improved sensing selectivity. Anal Chim Acta. 2019;1088:107-115. doi:10.1016/j.aca.2019.08.027

86. Qi H, Teng M, Liu M, et al. Biomass-derived nitrogen-doped carbon quantum dots: highly selective fluorescent probe for detecting $\mathrm{Fe} 3+$ ions and tetracyclines. J Colloid Interface Sci. 2019;539:332-341. doi:10.1016/j.jcis.2018.12.047

87. Liu H, He Z, Jiang LP, Zhu JJ. Microwave-assisted synthesis of wavelength-tunable photoluminescent carbon nanodots and their potential applications. ACS Appl Mater Interfaces. 2015;7 (8):4913-4920. doi:10.1021/am508994w

88. Zhao DL, Chung TS. Applications of carbon quantum dots (CQDs) in membrane technologies: a review. Water Res. 2018;147:43-49. doi:10.1016/j.watres.2018.09.040

89. Biswas MC, Islam MT, Nandy PK, Hossain MM. Graphene Quantum Dots (GQDs) for bioimaging and drug delivery applications: a review. ACS Mater Lett. 2021;3(6):899-911. doi:10.1021/ acsmaterialslett.0c00550

90. Chen WF, Li DJ, Tian L, et al. Synthesis of graphene quantum dots from natural polymer starch for cell imaging. Green Chem. 2018;20(19):4438-4442. doi:10.1039/C8GC02106F

91. Yan CR, Hu XL, Guan P, et al. Highly biocompatible graphene quantum dots: green synthesis, toxicity comparison and fluorescence imaging. J Mater Sci. 2020;55(3):1198-1215. doi:10.1007/ s10853-019-04079-2

92. Hage FS, Radtke G, Kepaptsoglou DM, et al. Single-atom vibrational spectroscopy in the scanning transmission electron microscope. Science. 2020;367(6482):1124-1127. doi:10.1126/ science.aba1136
93. Zhang L, Yang T, Du C, et al. Lithium whisker growth and stress generation in an in situ atomic force microscope-environmental transmission electron microscope set-up. Nat Nanotechnol. 2020;15(2):94-98. doi:10.1038/s41565-019-0604-x

94. Schorb M, Haberbosch I, Hagen WJH, et al. Software tools for automated transmission electron microscopy. Nat Methods. 2019;16(6):471-477. doi:10.1038/s41592-019-0396-9

95. Lim K, Bae Y, Jeon S, et al. A large-scale array of ordered graphene-sandwiched chambers for quantitative liquid-phase transmission electron microscopy. Adv Mater. 2020;32(39): e2002889. doi:10.1002/adma.202002889

96. Parent LR, Bakalis E, Proetto M, et al. Tackling the challenges of dynamic experiments using liquid-cell transmission electron microscopy. Acc Chem Res. 2018;51(1):3-11. doi:10.1021/acs.accounts.7b00331

97. Nakamura E. Atomic-resolution transmission electron microscopic movies for study of organic molecules, assemblies, and reactions: the first 10 years of development. Acc Chem Res. 2017;50(6):1281-1292. doi:10.1021/acs.accounts.7b00076

98. Hernandez-Cerdan P, Mansel BW, Leis A, et al. Structural analysis of polysaccharide networks by transmission electron microscopy: comparison with small-angle X-ray scattering. Biomacromolecules. 2018;19(3):989-995. doi:10.1021/acs.biomac.7b01773

99. Zhang J, Yuan Y, Liang G, Yu SH. Scale-up synthesis of fragrant nitrogen-doped carbon dots from bee pollens for bioimaging and catalysis. Adv Sci (Weinh). 2015;2(4):1500002. doi:10.1002/ advs.201500002

100. Li J, Li P, Wang D, Dong C. One-pot synthesis of aqueous soluble and organic soluble carbon dots and their multi-functional applications. Talanta. 2019;202:375-383. doi:10.1016/j.talanta.2019.05.019

101. Sun X, Brückner C, Lei Y. One-pot and ultrafast synthesis of nitrogen and phosphorus co-doped carbon dots possessing bright dual wavelength fluorescence emission. Nanoscale. 2015;7 (41):17278-17282. doi:10.1039/C5NR05549K

102. Liu X, Li J, Huang Y, et al. Adsorption, Aggregation, and Deposition Behaviors of Carbon Dots on Minerals. Environ Sci Technol. 2017;51(11):6156-6164. doi:10.1021/acs.est.6b06558

103. Amarie S, Ganz T, Keilmann F. Mid-infrared near-field spectroscopy. Opt Express. 2009;17(24):21794-21801. doi:10.1364/OE.17.021794

104. Griffiths PR. The early days of commercial FT-IR spectrometry: a personal perspective. Appl Spectrosc. 2017;71(3):329-340. doi:10.1177/0003702816683529

105. Erfan M, Sabry YM, Sakr M, et al. On-chip micro-electromechanical system fourier transform infrared (MEMS FT-IR) spectrometer-based gas sensing. Appl Spectrosc. 2016;70 (5):897-904. doi:10.1177/0003702816638295

106. Andreeva AB, Le KN, Chen L, et al. Soft mode metal-linker dynamics in carboxylate MOFs evidenced by variable-temperature infrared spectroscopy. $J$ Am Chem Soc. 2020;142(45):19291-19299. doi:10.1021/jacs.0c09499

107. Wu Y, Xu L, Qian J, et al. Methotrexate-Mn2+ based nanoscale coordination polymers as a theranostic nanoplatform for MRI guided chemotherapy. Biomater Sci. 2020;8(2):712-719. doi:10.1039/C9BM01584A

108. Zhang M, Yao Q, Lu C, et al. Layered double hydroxide-carbon dot composite: high-performance adsorbent for removal of anionic organic dye. ACS Appl Mater Interfaces. 2014;6 (22):20225-20233. doi:10.1021/am505765e

109. Nguyen L, Tao FF, Tang Y, et al. Understanding catalyst surfaces during catalysis through near ambient pressure X-ray photoelectron spectroscopy. Chem Rev. 2019;119(12):6822-6905. doi:10.1021/acs.chemrev.8b00114

110. Borgwardt M, Mahl J, Roth F, et al. Photoinduced charge carrier dynamics and electron injection efficiencies in au nanoparticle-sensitized $\mathrm{TiO}_{2}$ determined with picosecond time-resolved X-ray photoelectron spectroscopy. J Phys Chem Lett. 2020;11(14):5476-5481. doi:10.1021/acs.jpclett.0c00825 
111. Zhang Y, Tamijani AA, Taylor ME, et al. Molecular surface functionalization of carbon materials via radical-induced grafting of terminal alkenes. J Am Chem Soc. 2019;141(20):8277-8288. doi:10.1021/jacs.9b02369

112. Takagi Y, Uruga T, Tada M, et al. Ambient pressure hard X-ray photoelectron spectroscopy for functional material systems as fuel cells under working conditions. Acc Chem Res. 2018;51 (3):719-727. doi:10.1021/acs.accounts.7b00563

113. Mahmood A, Shi G, Wang Z, et al. Carbon quantum dots-TiO2 nanocomposite as an efficient photocatalyst for the photodegradation of aromatic ring-containing mixed VOCs: an experimental and DFT studies of adsorption and electronic structure of the interface. J Hazard Mater. 2021;401:123402. doi:10.1016/j. jhazmat.2020.123402

114. Ghereghlou M, Esmaeili AA, Darroudi M. Green synthesis of fluorescent carbon dots from elaeagnus angustifolia and its application as tartrazine sensor. J Fluoresc. 2021;31(1):185-193. doi:10.1007/s10895-020-02645-5

115. Wu Y, Song X, Wang N, et al. Carbon dots from roasted chicken accumulate in lysosomes and induce lysosome-dependent cell death. Food Funct. 2020;11(11):10105-10113. doi:10.1039/D0FO02144J

116. Liu Y, Wu P, Wu X, et al. Nitrogen and copper (II) co-doped carbon dots for applications in ascorbic acid determination by non-oxidation reduction strategy and cellular imaging. Talanta. 2020;210:120649. doi:10.1016/j.talanta.2019.120649

117. Drake JM, Paull EO, Graham NA, et al. Phosphoproteome integration reveals patient-specific networks in prostate cancer. Cell. 2016;166(4):1041-1054. doi:10.1016/j.cell.2016.07.007

118. Klaeger S, Heinzlmeir S, Wilhelm M, et al. The target landscape of clinical kinase drugs. Science. 2017;358(6367):eaan4368. doi: $10.1126 /$ science.aan 4368

119. Coleman RL, Fleming GF, Brady MF, et al. Veliparib with first-line chemotherapy and as maintenance therapy in ovarian cancer. $N$ Engl J Med. 2019;381(25):2403-2415. doi:10.1056/ NEJMoa1909707

120. Barton MK. Encouraging long-term outcomes reported in patients with stage I non-small cell lung cancer treated with stereotactic ablative radiotherapy. CA Cancer J Clin. 2017;67(5):349-350. doi:10.3322/caac. 21375

121. Hu Z, Li Z, Ma Z, Curtis C. Multi-cancer analysis of clonality and the timing of systemic spread in paired primary tumors and metastases. Nat Genet. 2020;52(7):701-708. doi:10.1038/s41588-020-0628-Z

122. Liu HW, Chen $\mathrm{L}, \mathrm{Xu} \mathrm{C}$, et al. Recent progresses in small-molecule enzymatic fluorescent probes for cancer imaging. Chem Soc Rev. 2018;47(18):7140-7180.

123. Li D, Jing P, Sun L, et al. Near-infrared excitation/emission and multiphoton-induced fluorescence of carbon dots. Adv Mater. 2018;30(13):e1705913. doi:10.1002/adma.201705913

124. Du J, Xu N, Fan J, et al. Carbon dots for in vivo bioimaging and theranostics. Small. 2019;15(32):e1805087. doi:10.1002/ smll.201805087

125. Lesani P, Singh G, Viray CM, et al. Two-photon dual-emissive carbon dot-based probe: deep-tissue imaging and ultrasensitive sensing of intracellular ferric ions. ACS Appl Mater Interfaces. 2020;12(16):18395-18406. doi:10.1021/acsami.0c05217

126. Lu W, Jiao Y, Gao Y, et al. Bright yellow fluorescent carbon dots as a multifunctional sensing platform for the label-free detection of fluoroquinolones and histidine. ACS Appl Mater Interfaces. 2018;10(49):42915-42924. doi:10.1021/acsami.8b16710

127. Wu L, Huang C, Emery BP, et al. Förster resonance energy transfer (FRET)-based small-molecule sensors and imaging agents. Chem Soc Rev. 2020;49(15):5110-5139. doi:10.1039/ C9CS00318E

128. Hou S, Chen Y, Lu D, et al. A self-assembled plasmonic substrate for enhanced fluorescence resonance energy transfer. Adv Mater. 2020;32(8):e1906475. doi:10.1002/adma.201906475
129. Wypijewska Del Nogal A, Füchtbauer AF, Bood M, et al. Getting DNA and RNA out of the dark with $2 \mathrm{CNqA}$ : a bright adenine analogue and interbase FRET donor. Nucleic Acids Res. 2020;48 (14):7640-7652. doi:10.1093/nar/gkaa525

130. Baibakov M, Patra S, Claude JB, et al. Extending single-molecule förster resonance energy transfer (FRET) range beyond 10 nanometers in zero-mode waveguides. ACS Nano. 2019;13 (7):8469-8480. doi:10.1021/acsnano.9b04378

131. Zheng W, Borgia A, Buholzer K, et al. Probing the action of chemical denaturant on an intrinsically disordered protein by simulation and experiment. $J$ Am Chem Soc. 2016;138 (36):11702-11713. doi:10.1021/jacs.6b05443

132. Kudr J, Richtera L, Xhaxhiu K, et al. Carbon dots based FRET for the detection of DNA damage. Biosens Bioelectron. 2017;92:133-139. doi:10.1016/j.bios.2017.01.067

133. Kim YJ, Guo P, Schaller RD. Aqueous carbon quantum dot-embedded PC60-PC61BM nanospheres for ecological fluorescent printing: contrasting fluorescence resonance energy-transfer signals between watermelon-like and random morphologies. J Phys Chem Lett. 2019;10(21):6525-6535. doi:10.1021/acs.jpclett.9b02426

134. Wang $Y$, Meng $H$, Jia $M$, et al. Intraparticle FRET of $\mathrm{Mn}$ (ii)-doped carbon dots and its application in discrimination of volatile organic compounds. Nanoscale. 2016;8 (39):17190-17195. doi:10.1039/C6NR05927A

135. Hamd-Ghadareh S, Salimi A, Fathi F, Bahrami S. An amplified comparative fluorescence resonance energy transfer immunosensing of CA125 tumor marker and ovarian cancer cells using green and economic carbon dots for bio-applications in labeling, imaging and sensing. Biosens Bioelectron. 2017;96:308-316. doi:10.1016/j.bios.2017.05.003

136. Lee S, Lee HJ, Ji Y, et al. Electrochemiluminescent transistors: a new strategy toward light-emitting switching devices. Adv Mater. 2021;33(5):e2005456. doi:10.1002/adma.202005456

137. Zhao Y, Yu J, Xu G, et al. Photoinduced electrochemiluminescence at silicon electrodes in water. J Am Chem Soc. 2019;141 (33):13013-13016. doi:10.1021/jacs.9b06743

138. Zanut A, Palomba F, Rossi Scota M, et al. Dye-doped silica nanoparticles for enhanced ECL-based immunoassay analytical performance. Angew Chem Int Ed Engl. 2020;59 (49):21858-21863. doi:10.1002/anie.202009544

139. Liu G, Chen Z, Jin BK, Jiang LP. A ratiometric electrochemiluminescent cytosensor based on polyaniline hydrogel electrodes in spatially separated electrochemiluminescent systems. Analyst. 2021;146(6):1835-1838. doi:10.1039/D0AN02408B

140. Liu Q, Ma C, Liu XP, et al. A novel electrochemiluminescence biosensor for the detection of microRNAs based on a DNA functionalized nitrogen doped carbon quantum dots as signal enhancers. Biosens Bioelectron. 2017;92:273-279. doi:10.1016/j.bios.2017.02.027

141. Qin D, Jiang X, Mo G, et al. Electrochemiluminescence immunoassay of human chorionic gonadotropin using silver carbon quantum dots and functionalized polymer nanospheres. Mikrochim Acta. 2020;187 (8):482. doi:10.1007/s00604-020-04450-0

142. Qiu Y, Zhou B, Yang X, et al. Novel single-cell analysis platform based on a solid-state zinc-coadsorbed carbon quantum dots electrochemiluminescence probe for the evaluation of CD44 expression on breast cancer cells. ACS Appl Mater Interfaces. 2017;9 (20):16848-16856. doi:10.1021/acsami.7b02793

143. Chen A, Liang W, Wang H, et al. Anodic electrochemiluminescence of carbon dots promoted by nitrogen doping and application to rapid cancer cell detection. Anal Chem. 2020;92 (1):1379-1385. doi:10.1021/acs.analchem.9b04537

144. Gu C, Guo C, Li Z, et al. Bimetallic ZrHf-based metal-organic framework embedded with carbon dots: ultra-sensitive platform for early diagnosis of HER2 and HER2-overexpressed living cancer cells. Biosens Bioelectron. 2019;134:8-15. doi:10.1016/j. bios.2019.03.043 
145. Won HJ, Ryplida B, Kim SG, et al. Diselenide-bridged carbon-dot-mediated self-healing, conductive, and adhesive wireless hydrogel sensors for label-free breast cancer detection. ACS Nano. 2020;14(7):8409-8420. doi:10.1021/ acsnano.0c02517

146. Kalytchuk S, Zdražil L, Bad'ura Z, et al. Carbon dots detect water-to-ice phase transition and act as alcohol sensors via fluorescence turn-off/on mechanism. ACS Nano. 2021;15(4):6582-6593. doi:10.1021/acsnano.0c09781

147. Li L, Shi L, Jia J, et al. Dual photoluminescence emission carbon dots for ratiometric fluorescent GSH sensing and cancer cell recognition. ACS Appl Mater Interfaces. 2020;12(16):18250-18257. doi:10.1021/ acsami.0c00283

148. Mohammadi S, Salimi A. Fluorometric determination of microRNA-155 in cancer cells based on carbon dots and $\mathrm{MnO}_{2}$ nanosheets as a donor-acceptor pair. Mikrochim Acta. 2018;185 (8):372. doi:10.1007/s00604-018-2868-5

149. Tang C, Zhou J, Qian Z, et al. A universal fluorometric assay strategy for glycosidases based on functional carbon quantum dots: $\beta$-galactosidase activity detection in vitro and in living cells. J Mater Chem B. 2017;5(10):1971-1979. doi:10.1039/ C6TB03361J

150. Sidhu JS, Singh A, Garg N, Singh N. Carbon dot based, naphthalimide coupled FRET pair for highly selective ratiometric detection of thioredoxin reductase and cancer screening. ACS Appl Mater Interfaces. 2017;9(31):25847-25856. doi:10.1021/ acsami.7b07046

151. Liu Q, Xu S, Niu C, et al. Distinguish cancer cells based on targeting turn-on fluorescence imaging by folate functionalized green emitting carbon dots. Biosens Bioelectron. 2015;64:119-125. doi:10.1016/j.bios.2014.08.052

152. Wu L, Wang J, Ren J, et al. Highly sensitive electrochemiluminescent cytosensing using carbon nanodot@Ag hybrid material and graphene for dual signal amplification. Chem Commun (Camb). 2013;49(50):5675-5677. doi:10.1039/c3cc42637h

153. Xie X, Peng Z, Wang Z, et al. Monitoring biothiols dynamics in living cells by ratiometric fluorescent gold carbon dots. Talanta. 2020;218:121214. doi:10.1016/j.talanta.2020.121214

154. Zheng M, Ruan S, Liu S, et al. Self-targeting fluorescent carbon dots for diagnosis of brain cancer cells. ACS Nano. 2015;9 (11):11455-11461. doi:10.1021/acsnano.5b05575

155. Ji X, Lv H, Sun X, Ding C. Green-emitting carbon dot loaded silica nanoparticles coated with DNA-cross-linked hydrogels for sensitive carcinoembryonic antigen detection and effective targeted cancer therapy. Chem Commun (Camb). 2019;55 (100):15101-15104. doi:10.1039/C9CC07831B

156. Chramiec A, Teles D, Yeager $\mathrm{K}$, et al. Integrated human organ-on-a-chip model for predictive studies of anti-tumor drug efficacy and cardiac safety. Lab Chip. 2020;20(23):4357-4372. doi:10.1039/D0LC00424C

157. Wu S, Zhou R, Chen H, et al. Highly efficient oxygen photosensitization of carbon dots: the role of nitrogen doping. Nanoscale. 2020;12(9):5543-5553. doi:10.1039/C9NR10986B

158. Li RS, Gao PF, Zhang HZ, et al. Chiral nanoprobes for targeting and long-term imaging of the Golgi apparatus. Chem Sci. 2017;8 (10):6829-6835. doi:10.1039/C7SC01316G

159. Broxterman HJ, Gotink KJ, Verheul HM. Understanding the causes of multidrug resistance in cancer: a comparison of doxorubicin and sunitinib. Drug Resist Updat. 2009;12(4-5):114-126. doi:10.1016/j.drup.2009.07.001

160. Han D, Wang Y, Wang Y, et al. The tumor-suppressive human circular RNA CircITCH sponges miR-330-5p to ameliorate doxorubicin-induced cardiotoxicity through upregulating SIRT6, survivin, and SERCA2a. Circ Res. 2020;127(4):e108-e125. doi:10.1161/CIRCRESAHA.119.316061
161. Gyöngyösi M, Lukovic D, Zlabinger K, et al. Liposomal doxorubicin attenuates cardiotoxicity via induction of interferon-related DNA damage resistance. Cardiovasc Res. 2020;116(5):970-982.

162. Harris LN, Broadwater G, Abu-Khalaf M, et al. Topoisomerase II \{alpha\} amplification does not predict benefit from dose-intense cyclophosphamide, doxorubicin, and fluorouracil therapy in HER2-amplified early breast cancer: results of CALGB 8541/150013. J Clin Oncol. 2009;27(21):3430-3436. doi:10.1200/JCO.2008.18.4085

163. Fornari FA, Randolph JK, Yalowich JC, et al. Interference by doxorubicin with DNA unwinding in MCF-7 breast tumor cells. Mol Pharmacol. 1994;45(4):649-656.

164. Xiang S, Dauchy RT, Hauch A, et al. Doxorubicin resistance in breast cancer is driven by light at night-induced disruption of the circadian melatonin signal. J Pineal Res. 2015;59(1):60-69. doi:10.1111/jpi.12239

165. Koukourakis MI, Koukouraki S, Giatromanolaki A, et al. Liposomal doxorubicin and conventionally fractionated radiotherapy in the treatment of locally advanced non-small-cell lung cancer and head and neck cancer. J Clin Oncol. 1999;17 (11):3512-3521. doi:10.1200/JCO.1999.17.11.3512

166. Wallin JJ, Guan J, Prior WW, et al. Nuclear phospho-Akt increase predicts synergy of PI3K inhibition and doxorubicin in breast and ovarian cancer. Sci Transl Med. 2010;2(48):48ra66. doi:10.1126/ scitranslmed.3000630

167. Pan XQ, Zheng X, Shi G, et al. Strategy for the treatment of acute myelogenous leukemia based on folate receptor beta-targeted liposomal doxorubicin combined with receptor induction using all-trans retinoic acid. Blood. 2002;100(2):594-602. doi:10.1182/ blood.V100.2.594

168. Di Lauro L, Belli F, Arena MG, et al. Epirubicin, cisplatin and docetaxel combination therapy for metastatic gastric cancer. Ann Oncol. 2005;16(9):1498-1502. doi:10.1093/annonc/mdi281

169. Gong X, Zhang Q, Gao Y, et al. Phosphorus and nitrogen dual-doped hollow carbon dot as a nanocarrier for doxorubicin delivery and biological imaging. ACS Appl Mater Interfaces. 2016;8(18):11288-11297. doi:10.1021/acsami.6b01577

170. Li S, Amat D, Peng Z, et al. Transferrin conjugated nontoxic carbon dots for doxorubicin delivery to target pediatric brain tumor cells. Nanoscale. 2016;8(37):16662-16669. doi:10.1039/C6NR05055G

171. Su W, Guo R, Yuan F, et al. Red-emissive carbon quantum dots for nuclear drug delivery in cancer stem cells. J Phys Chem Lett. 2020;11(4):1357-1363. doi:10.1021/acs.jpclett.9b03891

172. Hou L, Chen D, Wang R, et al. Transformable honeycomb-like nanoassemblies of carbon dots for regulated multisite delivery and enhanced antitumor chemoimmunotherapy. Angew Chem Int Ed Engl. 2021;60 (12):6581-6592. doi:10.1002/anie.202014397

173. Kang MS, Singh RK, Kim TH, et al. Optical imaging and anticancer chemotherapy through carbon dot created hollow mesoporous silica nanoparticles. Acta Biomater. 2017;55:466-480. doi:10.1016/j.actbio.2017.03.054

174. Türk S, Altınsoy I, Gç E, et al. A novel multifunctional NCQDs-based injectable self-crosslinking and in situ forming hydrogel as an innovative stimuli responsive smart drug delivery system for cancer therapy. Mater Sci Eng C Mater Biol Appl. 2021;121:111829. doi:10.1016/j. msec.2020.111829

175. Sutton EC, McDevitt CE, Prochnau JY, et al. Nucleolar stress induction by oxaliplatin and derivatives. J Am Chem Soc. 2019;141(46):18411-18415. doi:10.1021/jacs.9b10319

176. Hamfjord J, Guren TK, Dajani O, et al. Total circulating cell-free DNA as a prognostic biomarker in metastatic colorectal cancer before first-line oxaliplatin-based chemotherapy. Ann Oncol. 2019;30(7):1088-1095. doi:10.1093/annonc/mdz139

177. Singhal C, Pundir CS, Narang J. A genosensor for detection of consensus DNA sequence of dengue virus using $\mathrm{ZnO} / \mathrm{Pt}-\mathrm{Pd}$ nanocomposites. Biosens Bioelectron. 2017;97:75-82. doi:10.1016/j.bios.2017.05.047 
178. Zheng M, Liu S, Li J, et al. Integrating oxaliplatin with highly luminescent carbon dots: an unprecedented theranostic agent for personalized medicine. Adv Mater. 2014;26(21):3554-3560. doi:10.1002/adma.201306192

179. Feng T, Ai X, An G, et al. Charge-convertible carbon dots for imaging-guided drug delivery with enhanced in vivo cancer therapeutic efficiency. ACS Nano. 2016;10(4):4410-4420. doi:10.1021/acsnano.6b00043

180. Feng T, Ai X, Ong H, Zhao Y. Dual-responsive carbon dots for tumor extracellular microenvironment triggered targeting and enhanced anticancer drug delivery. ACS Appl Mater Interfaces. 2016;8(29):18732-18740. doi:10.1021/acsami.6b06695

181. High KA, Roncarolo MG. Gene therapy. N Engl J Med. 2019;381 (5):455-464. doi:10.1056/NEJMra1706910

182. Kuzmin DA, Shutova MV, Johnston NR, et al. The clinical landscape for AAV gene therapies. Nat Rev Drug Discov. 2021;20 (3):173-174. doi:10.1038/d41573-021-00017-7

183. Sun J, Roy S. Gene-based therapies for neurodegenerative diseases. Nat Neurosci. 2021;24(3):297-311. doi:10.1038/ s41593-020-00778-1

184. Liu X, Bao X, Hu M, et al. Inhibition of PCSK9 potentiates immune checkpoint therapy for cancer. Nature. 2020;588 (7839):693-698. doi:10.1038/s41586-020-2911-7

185. Yang X, Wang Y, Shen X, et al. One-step synthesis of photoluminescent carbon dots with excitation-independent emission for selective bioimaging and gene delivery. $J$ Colloid Interface Sci. 2017;492:1-7. doi:10.1016/j.jcis.2016.12.057

186. Devi P, Saini S, Kim KH. The advanced role of carbon quantum dots in nanomedical applications. Biosens Bioelectron. 2019;141:111158. doi:10.1016/j.bios.2019.02.059

187. Ju E, Li T, Liu Z, et al. Specific inhibition of viral MicroRNAs by carbon dots-mediated delivery of locked nucleic acids for therapy of virus-induced cancer. ACS Nano. 2020;14(1):476-487. doi:10.1021/acsnano.9b06333

188. Wu D, Li BL, Zhao Q, et al. Assembling defined DNA nanostructure with nitrogen-enriched carbon dots for theranostic cancer applications. Small. 2020;16(19):e1906975. doi:10.1002/ smll.201906975

189. Li S, Su W, Wu H, et al. Targeted tumour theranostics in mice via carbon quantum dots structurally mimicking large amino acids. Nat Biomed Eng. 2020;4(7):704-716. doi:10.1038/s41551-020 0540-y

190. Zhou Q, Gong N, Zhang D, et al. Mannose-derived carbon dots amplify microwave ablation-induced antitumor immune responses by capturing and transferring "danger signals" to dendritic cells. ACS Nano. 2021;15 (2):2920-2932. doi:10.1021/acsnano.0c09120

191. Ghosal K, Ghosh S, Ghosh D, Sarkar K. Natural polysaccharide derived carbon dot based in situ facile green synthesis of silver nanoparticles: synergistic effect on breast cancer. Int $J$ Biol Macromol. 2020;162:1605-1615.

192. Kalaiyarasan G, Veerapandian M, JebaMercy G, et al. Amygdalin-functionalized carbon quantum dots for probing $\beta$ glucosidase activity for cancer diagnosis and therapeutics. ACS Biomater Sci Eng. 2019;5(6):3089-3099. doi:10.1021/ acsbiomaterials.9b00394

193. Wang HJ, He X, Luo TY, et al. Amphiphilic carbon dots as versatile vectors for nucleic acid and drug delivery. Nanoscale. 2017;9(18):5935-5947. doi:10.1039/C7NR01029J

194. Prasad R, Aiyer S, Chauhan DS, et al. Bioresponsive carbon nano-gated multifunctional mesoporous silica for cancer theranostics. Nanoscale. 2016;8(8):4537-4546. doi:10.1039/ C5NR06756A

195. Hailing Y, Xiufang L, Lili W, et al. Doxorubicin-loaded fluorescent carbon dots with PEI passivation as a drug delivery system for cancer therapy. Nanoscale. 2020;12(33):17222-17237. doi:10.1039/D0NR01236J
196. Li WQ, Wang Z, Hao S, et al. Mitochondria-based aircraft carrier enhances in vivo imaging of carbon quantum dots and delivery of anticancer drug. Nanoscale. 2018;10(8):3744-3752. doi:10.1039/ C7NR08816G

197. Zhang Y, Zhang C, Chen J, et al. Trackable mitochondria-targeting nanomicellar loaded with doxorubicin for overcoming drug resistance. ACS Appl Mater Interfaces. 2017;9 (30):25152-25163. doi:10.1021/acsami.7b07219

198. Ma J, Kang K, Zhang Y, et al. Detachable polyzwitterion-coated ternary nanoparticles based on peptide dendritic carbon dots for efficient drug delivery in cancer therapy. ACS Appl Mater Interfaces. 2018;10(50):43923-43935. doi:10.1021/acsami.8b17041

199. Hettiarachchi SD, Graham RM, Mintz KJ, et al. Triple conjugated carbon dots as a nano-drug delivery model for glioblastoma brain tumors. Nanoscale. 2019;11(13):6192-6205. doi:10.1039/C8NR08970A

200. Li W, Liu Q, Zhang P, Liu L. Zwitterionic nanogels crosslinked by fluorescent carbon dots for targeted drug delivery and simultaneous bioimaging. Acta Biomater. 2016;40:254-262. doi:10.1016/j.actbio.2016.04.006

201. Gao N, Yang W, Nie H, et al. Turn-on theranostic fluorescent nanoprobe by electrostatic self-assembly of carbon dots with doxorubicin for targeted cancer cell imaging, in vivo hyaluronidase analysis, and targeted drug delivery. Biosens Bioelectron. 2017;96:300-307. doi:10.1016/j.bios.2017.05.019

202. Feng T, Chua HJ, Zhao Y. Reduction-responsive carbon dots for real-time ratiometric monitoring of anticancer prodrug activation in living cells. ACS Biomater Sci Eng. 2017;3(8):1535-1541. doi:10.1021/acsbiomaterials.7b00264

203. Li X, Hu S, Lin Z, et al. Dual-responsive mesoporous silica nanoparticles coated with carbon dots and polymers for drug encapsulation and delivery. Nanomedicine (Lond). 2020;15 (25):2447-2458. doi:10.2217/nnm-2019-0440

204. Li X, Lovell JF, Yoon J, Chen X. Clinical development and potential of photothermal and photodynamic therapies for cancer. Nat Rev Clin Oncol. 2020;17(11):657-674. doi:10.1038/ s41571-020-0410-2

205. Zhou C, Zhang L, Sun T, et al. Activatable NIR-II plasmonic nanotheranostics for efficient photoacoustic imaging and photothermal cancer therapy. Adv Mater. 2021;33(3):e2006532. doi:10.1002/adma.202006532

206. Li L, Lu Y, Jiang C, et al. Actively targeted deep tissue imaging and photothermal-chemo therapy of breast cancer by antibody-functionalized drug-loaded x-ray-responsive bismuth sulfide@mesoporous silica core-shell nanoparticles. Adv Funct Mater. 2018;28(5):1704623. doi:10.1002/adfm.201704623

207. $\mathrm{Xu} \mathrm{C}, \mathrm{Pu} \mathrm{K}$. Second near-infrared photothermal materials for combinational nanotheranostics. Chem Soc Rev. 2021;50 (2):1111-1137. doi:10.1039/D0CS00664E

208. Zhang J, Yang C, Zhang R, et al. Biocompatible D-A semiconducting polymer nanoparticle with light-harvesting unit for highly effective photoacoustic imaging guided photothermal therapy. Adv Funct Mater. 2017;27(13):1605094. doi:10.1002/adfm.201605094

209. Liu X, Wang C, Wang X, et al. A dual-targeting Fe3O4@C/ $\mathrm{ZnO}-\mathrm{DOX}-\mathrm{FA}$ nanoplatform with $\mathrm{pH}$-responsive drug release and synergetic chemo-photothermal antitumor in vitro and in vivo. Mater Sci Eng C Mater Biol Appl. 2021;118:111455. doi:10.1016/j.msec.2020.111455

210. Diroll BT, Brumberg A, Leonard AA, et al. Photothermal behaviour of titanium nitride nanoparticles evaluated by transient X-ray diffraction. Nanoscale. 2021;13(4):2658-2664. doi:10.1039/D0NR08202C

211. Espinosa A, Curcio A, Cabana S, et al. Intracellular biodegradation of Ag nanoparticles, storage in ferritin, and protection by a $\mathrm{Au}$ shell for enhanced photothermal therapy. ACS Nano. 2018;12(7):6523-6535. doi:10.1021/acsnano.8b00482 
212. Zhou S, Shang L, Zhao Y, et al. Pd single-atom catalysts on nitrogen-doped graphene for the highly selective photothermal hydrogenation of acetylene to ethylene. Adv Mater. 2019;31(18): e1900509. doi:10.1002/adma.201900509

213. Neelgund GM, Oki A, Bandara S, Carson L. Photothermal effect and cytotoxicity of $\mathrm{CuS}$ nanoflowers deposited over folic acid conjugated nanographene oxide. J Mater Chem B. 2021;9 (7):1792-1803. doi:10.1039/D0TB02366C

214. Xue K, Wei F, Lin J, et al. Tumor acidity-responsive carrier-free nanodrugs based on targeting activation via ICG-templated assembly for NIR-II imaging-guided photothermal-chemotherapy. Biomater Sci. 2021;9(3):1008-1019. doi:10.1039/D0BM01864C

215. Yu Y, Song M, Chen C, et al. Bortezomib-encapsulated CuS/ carbon dot nanocomposites for enhanced photothermal therapy via stabilization of polyubiquitinated substrates in the proteasomal degradation pathway. ACS Nano. 2020;14(8):10688-10703. doi:10.1021/acsnano.0c05332

216. Wang H, Mukherjee S, Yi J, et al. Biocompatible chitosan-carbon dot hybrid nanogels for NIR-imaging-guided synergistic photothermal-chemo therapy. ACS Appl Mater Interfaces. 2017;9(22):18639-18649. doi:10.1021/acsami.7b06062

217. Qian M, Chen L, Du Y, et al. Biodegradable mesoporous silica achieved via carbon nanodots-incorporated framework swelling for debris-mediated photothermal synergistic immunotherapy. Nano Lett. 2019;19(12):8409-8417. doi:10.1021/acs. nanolett.9b02448

218. Lo PC, Rodríguez-Morgade MS, Pandey RK, et al. The unique features and promises of phthalocyanines as advanced photosensitisers for photodynamic therapy of cancer. Chem Soc Rev. 2020;49(4):1041-1056. doi:10.1039/C9CS00129H

219. Li M, Sun W, Tian R, et al. Smart J-aggregate of cyanine photosensitizer with the ability to target tumor and enhance photodynamic therapy efficacy. Biomaterials. 2021;269:120532. doi:10.1016/j.biomaterials.2020.120532

220. Wu Y, Li F, Zhang X, et al. Tumor microenvironment-responsive PEGylated heparin-pyropheophorbide-a nanoconjugates for photodynamic therapy. Carbohydr Polym. 2021;255:117490. doi:10.1016/j.carbpol.2020.117490

221. Zhao X, Liu J, Fan J, et al. Recent progress in photosensitizers for overcoming the challenges of photodynamic therapy: from molecular design to application. Chem Soc Rev. 2021;50 (6):4185-4219. doi:10.1039/D0CS00173B

222. Zhu T, Shi L, Ma C, et al. Fluorinated chitosan-mediated intracellular catalase delivery for enhanced photodynamic therapy of oral cancer. Biomater Sci. 2021;9(3):658-662. doi:10.1039/ D0BM01898H

223. Li Y, Sui H, Jiang C, et al. Dihydroartemisinin increases the sensitivity of photodynamic therapy Via NF- $\mathrm{BB} / \mathrm{HIF}-1 \alpha / \mathrm{VEGF}$ pathway in esophageal cancer cell in vitro and in vivo. Cell Physiol Biochem. 2018;48(5):2035-2045. doi:10.1159/000492541

224. Liu B, Qiao G, Han Y, et al. Targeted theranostics of lung cancer: PD-L1-guided delivery of gold nanoprisms with chlorin e6 for enhanced imaging and photothermal/photodynamic therapy. Acta Biomater. 2020;117:361-373. doi:10.1016/j.actbio.2020.09.040

225. Tham HP, Xu K, Lim WQ, et al. Microneedle-assisted topical delivery of photodynamically active mesoporous formulation for combination therapy of deep-seated melanoma. ACS Nano. 2018;12(12):11936-11948. doi:10.1021/acsnano.8b03007

226. Dos Santos AF, Inague A, Arini GS, et al. Distinct photo-oxidation-induced cell death pathways lead to selective killing of human breast cancer cells. Cell Death Dis. 2020;11 (12):1070. doi:10.1038/s41419-020-03275-2

227. Cho HJ, Park SJ, Jung WH, et al. Injectable single-component peptide depot: autonomously rechargeable tumor photosensitization for repeated photodynamic therapy. ACS Nano. 2020;14 (11):15793-15805. doi:10.1021/acsnano.0c06881
228. Nash GT, Luo T, Lan G, et al. Nanoscale metal-organic layer isolates phthalocyanines for efficient mitochondria-targeted photodynamic therapy. $J$ Am Chem Soc. 2021;143 (5):2194-2199. doi:10.1021/jacs.0c12330

229. Huang Z, Xu Z, Mahboub M, et al. Enhanced near-infrared-tovisible upconversion by synthetic control of $\mathrm{PbS}$ nanocrystal triplet photosensitizers. $J$ Am Chem Soc. 2019;141 (25):9769-9772. doi:10.1021/jacs.9b03385

230. Jia Q, Ge J, Liu W, et al. A magnetofluorescent carbon dot assembly as an acidic $\mathrm{H}_{2} \mathrm{O}_{2}$-driven oxygenerator to regulate tumor hypoxia for simultaneous bimodal imaging and enhanced photodynamic therapy. Adv Mater. 2018;30(13):e1706090. doi:10.1002/adma.201706090

231. Zheng DW, Li B, Li CX, et al. Carbon-dot-decorated carbon nitride nanoparticles for enhanced photodynamic therapy against hypoxic tumor via water splitting. ACS Nano. 2016;10 (9):8715-8722. doi:10.1021/acsnano.6b04156

232. Teh DBL, Bansal A, Chai C, et al. A flexi-PEGDA upconversion implant for wireless brain photodynamic therapy. Adv Mater. 2020;32(29):e2001459. doi:10.1002/adma.202001459

233. Chen G, Jaskula-Sztul R, Esquibel CR, et al. Neuroendocrine tumor-targeted upconversion nanoparticle-based micelles for simultaneous NIR-controlled combination chemotherapy and photodynamic therapy, and fluorescence imaging. Adv Funct Mater. 2017;27(8):1604671. doi:10.1002/adfm.201604671

234. Chan MH, Pan YT, Lee IJ, et al. Minimizing the heat effect of photodynamic therapy based on inorganic nanocomposites mediated by 808 nm near-infrared light. Small. 2017;13(21):1700038.

235. Wang Y, Luo S, Wu Y, et al. Highly penetrable and on-demand oxygen release with tumor activity composite nanosystem for photothermal/photodynamic synergetic therapy. ACS Nano. 2020;14(12):17046-17062. doi:10.1021/acsnano.0c06415

236. Chen J, Wen K, Chen $\mathrm{H}$, et al. Achieving high-performance photothermal and photodynamic effects upon combining D-A structure and nonplanar conformation. Small. 2020;16(17): e2000909. doi:10.1002/smll.202000909

237. Huang J, He B, Zhang Z, et al. Aggregation-induced emission luminogens married to $2 \mathrm{D}$ black phosphorus nanosheets for highly efficient multimodal theranostics. Adv Mater. 2020;32 (37):e2003382. doi:10.1002/adma.202003382

238. Lv R, Yang P, He F, et al. A yolk-like multifunctional platform for multimodal imaging and synergistic therapy triggered by a single near-infrared light. ACS Nano. 2015;9(2):1630-1647. doi:10.1021/ nn5063613

239. Sun S, Chen Q, Tang Z, et al. Tumor microenvironment stimuli-responsive fluorescence imaging and synergistic cancer therapy by Carbon-Dot-Cu ${ }^{2+}$ nanoassemblies. Angew Chem Int Ed Engl. 2020;59(47):21041-21048. doi:10.1002/anie.202007786

240. Hua XW, Bao YW, Zeng J, Wu FG. Ultrasmall all-in-one nanodots formed via carbon dot-mediated and albumin-based synthesis: multimodal imaging-guided and mild laser-enhanced cancer therapy. ACS Appl Mater Interfaces. 2018;10(49):42077-42087. doi:10.1021/acsami.8b16065

241. Zhang M, Wang W, Wu F, et al. Biodegradable Poly $(\gamma$-glutamic acid) @glucose oxidase@carbon dot nanoparticles for simultaneous multimodal imaging and synergetic cancer therapy. Biomaterials. 2020;252:120106. doi:10.1016/j.biomaterials.2020.120106

242. Lu Y, Li L, Li M, et al. Zero-dimensional carbon dots enhance bone regeneration, osteosarcoma ablation, and clinical bacterial eradication. Bioconjug Chem. 2018;29(9):2982-2993. doi:10.1021/acs.bioconjchem. 8 b00400

243. Geng B, Qin H, Zheng F, et al. Carbon dot-sensitized MoS2 nanosheet heterojunctions as highly efficient NIR photothermal agents for complete tumor ablation at an ultralow laser exposure. Nanoscale. 2019;11(15):7209-7220. doi:10.1039/ C8NR10445J 
244. Geng B, Shen W, Li P, et al. Carbon dot-passivated black phosphorus nanosheet hybrids for synergistic cancer therapy in the NIR-II window. ACS Appl Mater Interfaces. 2019;11 (48):44949-44960. doi:10.1021/acsami.9b15569

245. Li Y, Bai G, Zeng S, Hao J. Theranostic carbon dots with innovative NIR-II emission for in vivo renal-excreted optical imaging and photothermal therapy. ACS Appl Mater Interfaces. 2019;11(5):4737-4744. doi:10.1021/acsami.8b14877

246. Wang X, Li X, Mao Y, et al. Multi-stimuli responsive nanosystem modified by tumor-targeted carbon dots for chemophototherapy synergistic therapy. J Colloid Interface Sci. 2019;552:639-650. doi:10.1016/j.jcis.2019.05.085

247. Xue M, Zhao J, Zhan Z, et al. Dual functionalized natural biomass carbon dots from lychee exocarp for cancer cell targetable near-infrared fluorescence imaging and photodynamic therapy. Nanoscale. 2018;10(38):18124-18130. doi:10.1039/ C8NR05017A

248. Wang J, Zhang Z, Zha S, et al. Carbon nanodots featuring efficient FRET for two-photon photodynamic cancer therapy with a low fs laser power density. Biomaterials. 2014;35 (34):9372-9381. doi:10.1016/j.biomaterials.2014.07.063

249. Zhang M, Wang W, Cui Y, et al. Near-infrared light-mediated photodynamic/photothermal therapy nanoplatform by the assembly of $\mathrm{Fe} 3 \mathrm{O} 4$ carbon dots with graphitic black phosphorus quantum dots. Int J Nanomedicine. 2018;13:2803-2819. doi:10.2147/ IJN.S 156434
250. Phan LMT, Gul AR, Le TN, et al. One-pot synthesis of carbon dots with intrinsic folic acid for synergistic imaging-guided photothermal therapy of prostate cancer cells. Biomater Sci. 2019;7(12):5187-5196. doi:10.1039/C9BM01228A

251. Jia Q, Zheng X, Ge J, et al. Synthesis of carbon dots from Hypocrella bambusae for bimodel fluorescence/photoacoustic imaging-guided synergistic photodynamic/photothermal therapy of cancer. $J$ Colloid Interface Sci. 2018;526:302-311. doi:10.1016/j.jcis.2018.05.005

252. Jia Q, Ge J, Liu W, et al. Gold nanorod@silica-carbon dots as multifunctional phototheranostics for fluorescence and photoacoustic imaging-guided synergistic photodynamic/photothermal therapy. Nanoscale. 2016;8(26):13067-13077. doi:10.1039/ C6NR03459D

253. Bajpai VK, Khan I, Shukla S, et al. Multifunctional N-P-doped carbon dots for regulation of apoptosis and autophagy in B16F10 melanoma cancer cells and in vitro imaging applications. Theranostics. 2020;10(17):7841-7856. doi:10.7150/thno.42291

254. Yao H, Li J, Song Y, et al. Synthesis of ginsenoside re-based carbon dots applied for bioimaging and effective inhibition of cancer cells. Int J Nanomedicine. 2018;13:6249-6264. doi:10.2147/IJN.S176176

255. Emam HE, Ahmed HB. Antitumor/antiviral carbon quantum dots based on carrageenan and pullulan. Int J Biol Macromol. 2021;170:688-700. doi:10.1016/j.ijbiomac.2020.12.151
International Journal of Nanomedicine

\section{Publish your work in this journal}

The International Journal of Nanomedicine is an international, peerreviewed journal focusing on the application of nanotechnology in diagnostics, therapeutics, and drug delivery systems throughout the biomedical field. This journal is indexed on PubMed Central, MedLine, CAS, SciSearch ${ }^{\circledR}$, Current Contents ${ }^{\circledR} /$ Clinical Medicine,

\section{Dovepress}

Journal Citation Reports/Science Edition, EMBase, Scopus and the Elsevier Bibliographic databases. The manuscript management system is completely online and includes a very quick and fair peer-review system, which is all easy to use. Visit http://www.dovepress.com/ testimonials.php to read real quotes from published authors. 